THE

\title{
ANNUAL REPORT TO NATIONAL INSTITUTE FOR HEALTH RESEARCH 2017-2018
}

Nathaniel Mills, Gemma Wheeler and Joe Langley https://doi.org/10.7190/starworks-NIHR-1718 


\section{CONTENTS}

Overview of activities and progress made through the work packages

Phase One: Establishing the network (Work Package 1)

Phase Two: Multi-stakeholder needs assessment (Work Package 2)

Findings from Phase Two

Key lessons learned from Phase Two

Phase Three: Starworks Sandpit Events (Work Package 3)

Findings from Phase Three

Key lessons learned from Phase Two

Phase Four: Proof of Concept funding

Approach to commissioning

Phase Five: Maintaining and growing the network (Work Package 6)

Future growth of the NIHR Child Prosthetics Research Collaboration

Patient and Public Involvement, Engagement and Participation

Top Three achievements during the 2017/2018 financial year

Discussion

\section{List of Appendices}

1 - Summary and signposting of original Work Packages

2 - Child and Family Phase Two Needs Assessment

3 - Clinician Phase Two Needs Assessment

4 - Academic Phase Two Needs Assessment

5 - Industry Phase Two Needs Assessment

6 - Snapshots of Phase Three Sandpit Events

7 - Detailed breakdowns of the funded 'Proof of Concept' projects

8 - Illustration of the Starworks Project

9 - Illustration of 'a day in the life' of a child who uses a lower limb prosthetic 


\section{OVERVIEW OF ACTIVITIES \& PROGRESS MADE THROUGH THE WORK PACKAGES}

This section will describe the activities of the NIHR Child Prosthetics Research Collaboration (branded as The Starworks Network), and the progress made towards each of the original objectives and work packages as a cohesive narrative. This is to better reflect how the work packages built upon each other in response to the input from children, families, clinicians, academics and industry partners.

Original objectives of the NIHR Child Prosthetics Research Collaboration

- Within the 18 months of initiating the collaboration, establish a shared and comprehensive understanding of child prosthetic needs

- Initiate 4-8 example programmes to set the pace of invention

- Create the ongoing platform to stimulate and support innovation

- $\quad$ Spread vision of what is possible to all stakeholders

- Obtain a coherent set of commitments from relevant organisations in place by mid programme to ensure that the Collaborative continues beyond the first phase of funding

Leadership, governance and management arrangements

In order to ensure all stakeholders are represented a Project Reference Group (PRG) was established to ensure transparency, focus and guidance. The PRG are a multidisciplinary team of key opinion leaders in the field and include families and charities. The Starworks project is managed by the NIHR Devices for Dignity MedTech Co-operative (D4D) team and reports to the D4D Steering Committee three times a year.

As host for D4D, Sheffield Teaching Hospital NHS Foundation Trust provide governance support and have been invaluable in providing guidance for the proof of funding project allocations and specific

\section{OVERVIEW OF ACHIEVEMENTS MADE THROUGH THE WORK PACKAGES}

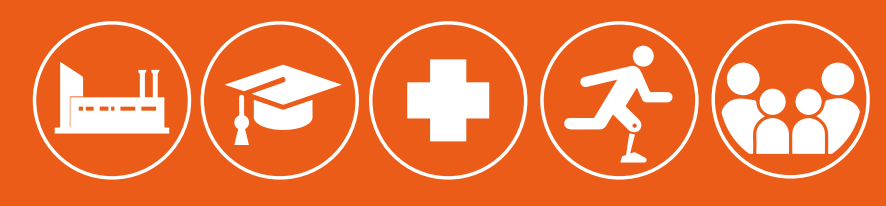

All stakeholders

involved in the identification
of system-wide needs in child prosthetics

4 Sandpit 88.88

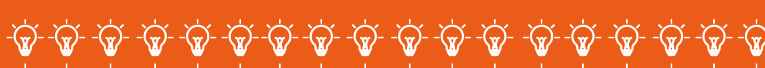

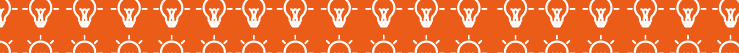

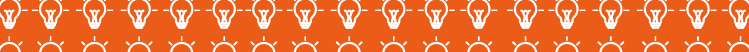

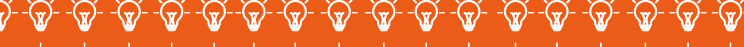

60

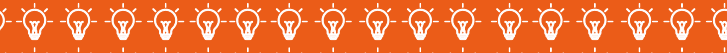

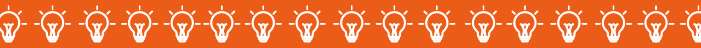

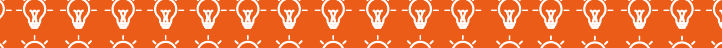

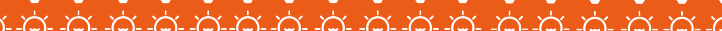

-

60

$\square$ (ه)

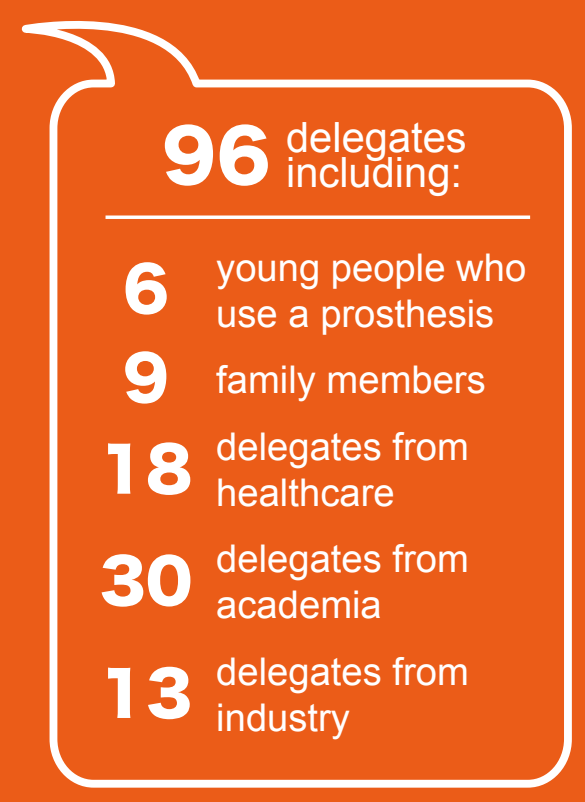

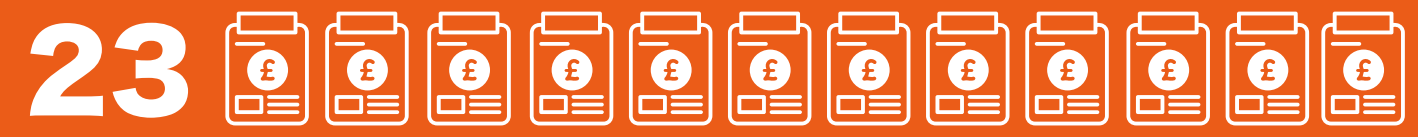

funding

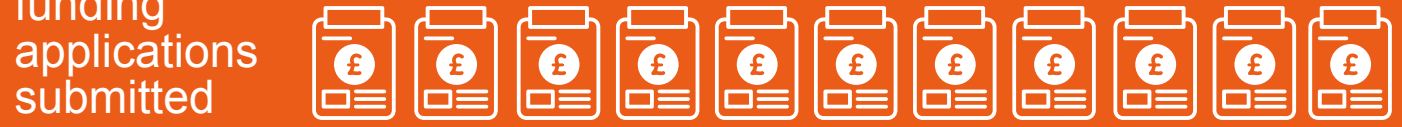
ogeoge
10
$£ £ £ £ £$
high quality projects
were funded, involving
all stakeholders 
PHASE ONE: ESTABLISHING THE NETWORK

Work Package 1

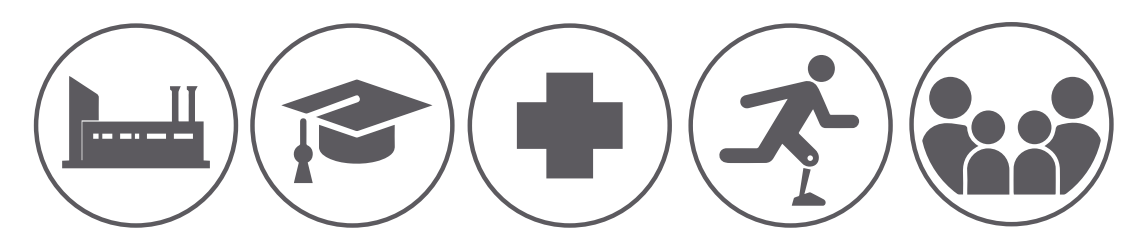

Four key stakeholder groups have been central to the Starworks project throughout; clinicians, academics, industry experts, and (most importantly) children and families. The Starworks team set out to engage with the relevant clinical, academic and industry networks to attract the best talent, ideas and collaborations that have expertise in child prosthetics. To achieve this, the Starworks team undertook a great deal of intelligence gathering on the key personnel, groups, academic units and opinion leaders with industry. This included face to face industry. This included face to face meetings and detalled interviews to gain a thorough understanding of the issues around child prosthetics from the multiple stakeholders' perspectives. Alongside this, we worked with the key charities and created open social media channels to engage with children and families. This was seen as a key aspect of our early engagement work and was extremely successful in gaining trust and understanding from the children and families.

In order to support the fou stakeholder groups in working together to share unmet needs consideration was given to the possible input of the eight NIHR HTCs. Both NIHR Brain Ijury HTC and NIHR Trauma Management HTC subsequently became actively involved in the Starworks project (alongside D4D). The collaboration utilised the methodology of Technology Innovation Transforming Child Health (TITCH), which is a D4D paediatric network. TITCH works paediatic UK focus. TITCH works across the UK focusing on new medical technology development for children. It was envisaged that the expertise from the NIHR HTC and the TITCH Network would support the Starworks project to be in a position to provide expert research collaboration with direct access to children and their families, clinical specialists in $\mathrm{NHS}$ children's hospitals, and industry.

Given the diversity of participants involved in the network, several issues were identified as being potentially problematic in encouraging collaboration. These included a need to give equal voice to all participants, a potential for conflicting perspectives, a need to elicit issues occurring in everyday life, and a need to engage children in engeging way. These iss engaging way. These issues were an used in Phase Two (engaging workstreams separately in context-specific ways) and in Phase Three (in the considered workshop structure), as detailed below.

\section{PHASE TWO: MULTI-STAKE- HOLDER NEEDS ASSESSMENT} Work Package 2: Objective 1

Consideration of the multiple perspectives of children's prosthesis development and provision has been at the heart of the Starworks project from its inception, and key to Objective 1 within the 18 months of initiating the collaboration, establish a shared and comprehensive understanding of child prosthetic needs.'

Insights were sought from four key stakeholder groups, including:

- Children and Families

- Providers of prosthetic limbs (a diverse, multidisciplinary community comprising clinicians, allied health professionals, scientists ealt prosessions, scier
- Industry

- Academia

The aim of this process was to understand the current status of development and provision, identify opportunities for further research, and in turn inform Phase Three of the project (in line with the initial aims of the collaboration)

As outlined in the table overleaf, each of the four workstreams involved in the needs assessment used a similar combination of methods, including literature reviews, interviews and surveys, with the addition of creative methods to engage children, young adults and family members.

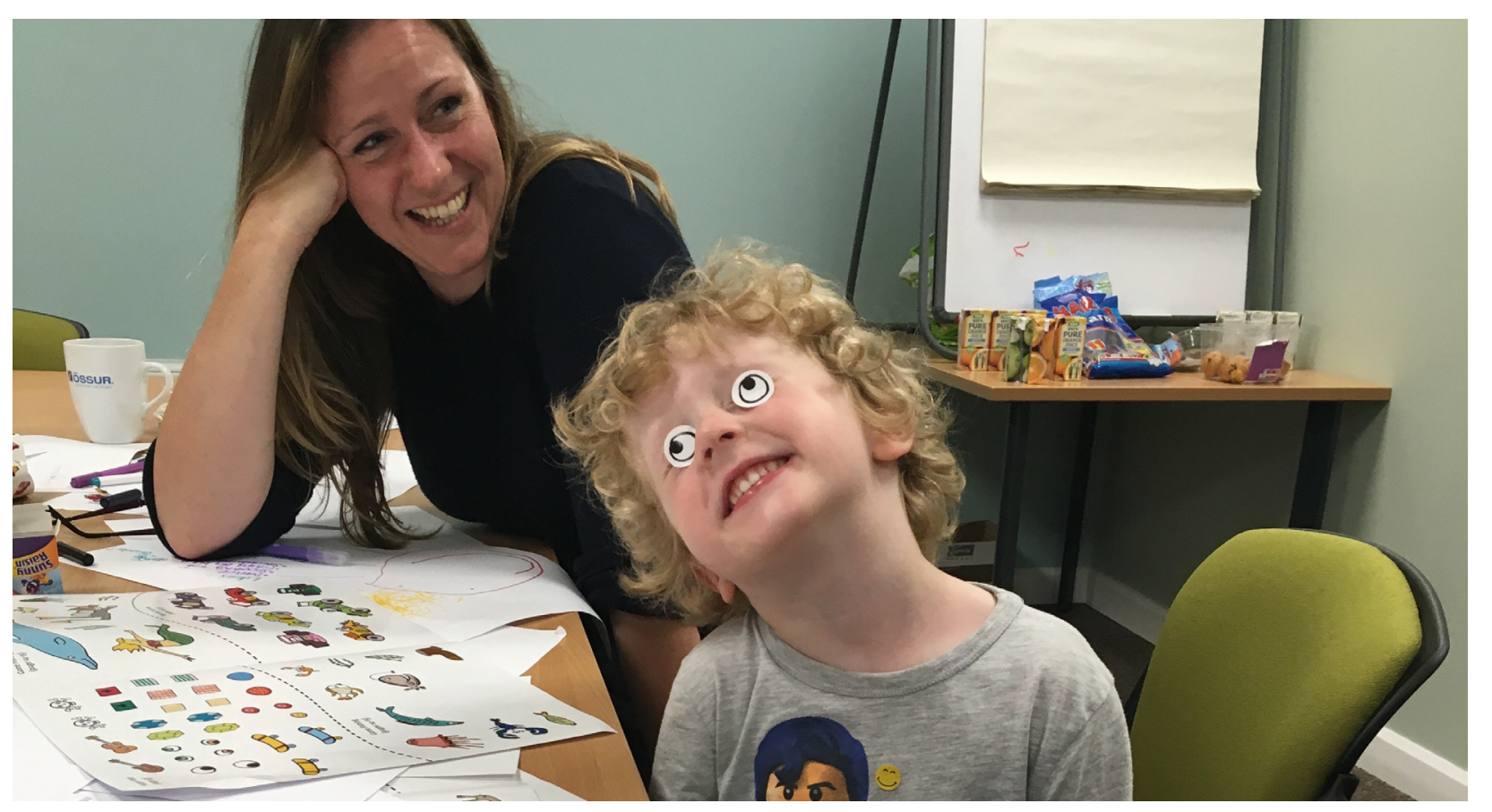




\section{Involving the Multiple Stakeholders}

\begin{tabular}{|c|c|c|c|c|}
\hline Workstream & $\begin{array}{l}\text { Lead } \\
\text { Institution } \\
\text { for delivery }\end{array}$ & Methods & $\begin{array}{l}\text { How many people } \\
\text { were contacted? }\end{array}$ & Response rate \\
\hline \multirow{3}{*}{$\begin{array}{l}\text { Childrens and } \\
\text { Families }\end{array}$} & \multirow{3}{*}{$\begin{array}{l}\text { NIHR } \\
\text { Devices for } \\
\text { Dignity HTC } \\
\text { \& Sheffield } \\
\text { Hallam } \\
\text { University }\end{array}$} & Surveys & \begin{tabular}{|} 
Approx. 1000 surveys \\
were sent to 500 \\
families (2 per family) at \\
5 sites across the UK
\end{tabular} & $\begin{array}{l}10 \text { Children, } \\
4 \text { Young Adults } \\
\text { and } 16 \text { Parents }\end{array}$ \\
\hline & & $\begin{array}{l}\text { Phone calls, individual } \\
\text { contact with stakeholders } \\
\text { and hospital visits. }\end{array}$ & \multicolumn{2}{|c|}{$\begin{array}{l}2 \text { Children, } 6 \text { Parents and } \\
16 \text { Clinical Professionals }\end{array}$} \\
\hline & & $\begin{array}{l}\text { Workshop activities } \\
\text { engaged children and } \\
\text { parents in reflecting on } \\
\text { their wider lives with } \\
\text { prosthetics, identifying } \\
\text { challenges and creatively } \\
\text { generating ideas to } \\
\text { address them. }\end{array}$ & \multicolumn{2}{|c|}{18 Families } \\
\hline \multirow[b]{2}{*}{ Clinicians } & \multirow{2}{*}{$\begin{array}{l}\text { The NIHR } \\
\text { Health } \\
\text { Technology } \\
\text { Cooperative } \\
\text { in Brain } \\
\text { Injury in } \\
\text { conjunction } \\
\text { with Dr. } \\
\text { Stephen } \\
\text { Kirker }\end{array}$} & $\begin{array}{l}\text { Clinical Audit to establish } \\
\text { demand for prosthetics } \\
\text { services and activity limbs }\end{array}$ & $34 \operatorname{limb}$ centres & $11 \mathrm{limb}$ centres \\
\hline & & $\begin{array}{l}\text { Surveys to establish unmet } \\
\text { needs within the prosthetic } \\
\text { service, managers and } \\
\text { medical rehabilitation } \\
\text { specialists and a smaller } \\
\text { survey circulated to the } \\
\text { rehabilitation engineering } \\
\text { community and allied health } \\
\text { professionals }\end{array}$ & $\begin{array}{l}\text { Approx. } 4600 \\
\text { healthcare } \\
\text { professionals }\end{array}$ & $\begin{array}{l}67 \text { full and } \\
\text { partial } \\
\text { responses }\end{array}$ \\
\hline Academia & $\begin{array}{l}\text { NIHR Trauma } \\
\text { Management } \\
\text { HTC, } \\
\text { Birmingham } \\
\text { UK }\end{array}$ & $\begin{array}{l}\text { Review of publicly-funded } \\
\text { research projects in the UK, } \\
\text { using database searches of } \\
\text { funding bodies (addressing } \\
\text { the 'Proactive approach' } \\
\text { detailed in WP4 }\end{array}$ & $\begin{array}{l}\text { Databases included } \\
\text { Research Council } \\
\text { UK Gateway, The } \\
\text { Wellcome Trust, i4i } \\
\text { and SBRI. }\end{array}$ & $\begin{array}{l}94 \text { projects } \\
\text { deemed in } \\
\text { scope }\end{array}$ \\
\hline \multirow{3}{*}{ Industry } & \multirow{3}{*}{ TRUSTECH } & $\begin{array}{l}\text { Desk-based research and } \\
\text { Social Media }\end{array}$ & & \\
\hline & & Online survey & \multirow{2}{*}{$\begin{array}{c}\text { Contacted } 10 \text { key } \\
\text { companies, publicised } \\
\text { through Trustech } \\
\text { Twitter account }(1,392 \\
\text { followers), Linkedln } \\
\text { account ( } 69 \text { followers) } \\
\text { and website. } \\
\end{array}$} & $\begin{array}{l}38 \text { full and } \\
\text { partial } \\
\text { responses }\end{array}$ \\
\hline & & $\begin{array}{c}\text { Telephone interviews with } \\
\text { key players }\end{array}$ & & 13 interviews \\
\hline
\end{tabular}

8

Annual Report to National Institute for Health Research 2017-2018

\section{Findings}

Detailed findings from each workstream can be found in appendices 2, 3, 4 and 5 . For the purposes of this report, the main findings will be discussed in relation to the emergent 4 themes taken forward to inform Phase Three (as stipulated in Work Package 2). These themes were informed by the sharing and discussion of findings from all stakeholders at the Project Reference Group Meeting held in The Wellcome Collection, London, 28th June 2017, and included:

Theme 1: Socket Interface

The interface between the child's residual limb and the interface of their prosthesis was highlighted as a key concern by all workstreams. The main issues include; heat and sweat (which can lead to secondary complications such as developing sores or eczema, and in turn more time out of school for treatment); and fitting (in response to the high growth rate in children, professionals from healthcare and industry proposed flexible, adaptive prostheses, possibly with elements of self-tuning)

The impact of uncomfortable sockets is particularly high in weightbearing, lower-limb prostheses. Children and families explained how such issues can often result children needing to 'rest' their residual limb at certain points in the day, and so need to choose which activities to spend their limited time using their prosthesis. Given that the clinician workstream also highlighted that upper limb prosthesis users comprise two thirds of the overs comprise two thirds of the overal suspension and balance should also be considered for children with upper limb issues.

Theme 2 \& 3: Upper/Lower limb Personalisation \& Adaptation

Aesthetic personalisation or customisation was recognised as a priority for children by parents, clinicians and children themselves. Whilst this was not a key priority for clinicians, this group did recognise the importance of age, weight and gender matched prostheses, as well as adaptability to context of use, particularly in relation to potentially increased uptake and use. Interestingly, there were mixed opinions within the child and family population on whether an 'ideal' or 'good looking' prosthesis was realistic or unusual (i.e. changing the colour at each fitting).

In relation to the issues of growth mentioned above, clinicians suggested a need for modular components, with durable assisted articulating joints, and improved standardization in connector/ adaptor technology to allow a wider selection and choice of prostheses that adapt to specific activities. Current technology and components Current techor wich can be too heavy.

Whilst 3D printing was raised as potential facilitator of bespoke devices in some workstreams, clinicians raised concerns over issues of quality, safety, and a need to better understand the regulatory and quality frameworks that are required to implement this technology and minimize risks. 
Theme 4: Service Journeys

Children described how they enjoy the child-specific aspects of the service (such as play areas, or fun assessments), whilst parents appreciated the friendly approaches of staff they encountered.

Families and clinicians both highlighted issues with regards to long waiting times for appointments, a desire to reduce time taken out of school/work hours, and a need for carers to be well informed for carers to be well informed (particularly with respect to what opportunities/products are available for children). Families also described how first entering the service can be an intimidating experience, as well as a need for information on the child's condition and pathway through the service. Several families highlighted a need for prosthetic provision from earlier ages

(particularly in terms of encouraging young children to wear upper limb prostheses), whilst clinicians also suggested a need to consider the transition from child services to adult services, with continued provision.

Discussion of findings

The findings from all workstreams indicated that most prosthetic

research and provisior aimed at tion of the specific needs of children. These needs include consideration of a higher growth rate, a potential nee for low build heights, and a need for consideration of the non-linear, high-impact movement patterns of children's play (and the impact of prosthetic weight/durability in facilitating this). The clinica workstream also suggested a need for an improved understanding of the biomechanical properties of children's limbs in order to match prostheses accordingly.

Whilst clinical, academic and industry workstream findings largely focus on the importance of performance, comfort and functional suitability of prostheses the inclusion of the child and family voice (assisted by creative methods) raised issues of the impact of the prosthesis on social development. Many issues raised were described in tems of rhether were descibed in terns of whether the prosthesis helped or hindered the child's ability to keep up with their friends or take part in play/sport activities (where the running blades were very popular). A reduced sense of spontaneity also became apparent, largely due to issues with the socket interface (i.e. needing to carry spare liners due to sweat, or choosing when/how to 'spend' their time on their prosthesis before becoming sore).

Children and family members also illustrated a more holistic view of prosthetic use, and how it can impact aspects of daily routine. For example, since some prostheses cannot get wet, children with lower limb prostheses may need help getting in/out of the shower/bath, whilst children using upper limb prostheses may need parents prostheses may need parents to assist in washing, dressing or eating. Clearly, children may want more independence in these tasks as they get older.

As a result, the overarching themes of 'Let kids be kids' and 'Activities of Daily Living' were taken forward as considerations in each of the workshops.
Key lessons learned from

Phase Two

- Clear need for more connectivity between the stakeholders, and engaging with children (a recommendation from industry, healthcare, academic workstreams) to encourage meaningful innovation in this area.

- Need more time/resources allocated to this area of research

- Clinicians and industry professionals expressed a desire for richer research evidence/outcome measurements as well as nationa coordination of child prosthetics research and provision.

- Methodologically, tailoring the approach taken with each stakeholder group was necessary (e.g. a quick and easy survey for busy clinical staff encouraged a higher response rate). Importantly, the creative methods used empowered children of a range of ages to participate, and provided a platform for parents to discuss issues and experiences with their children.

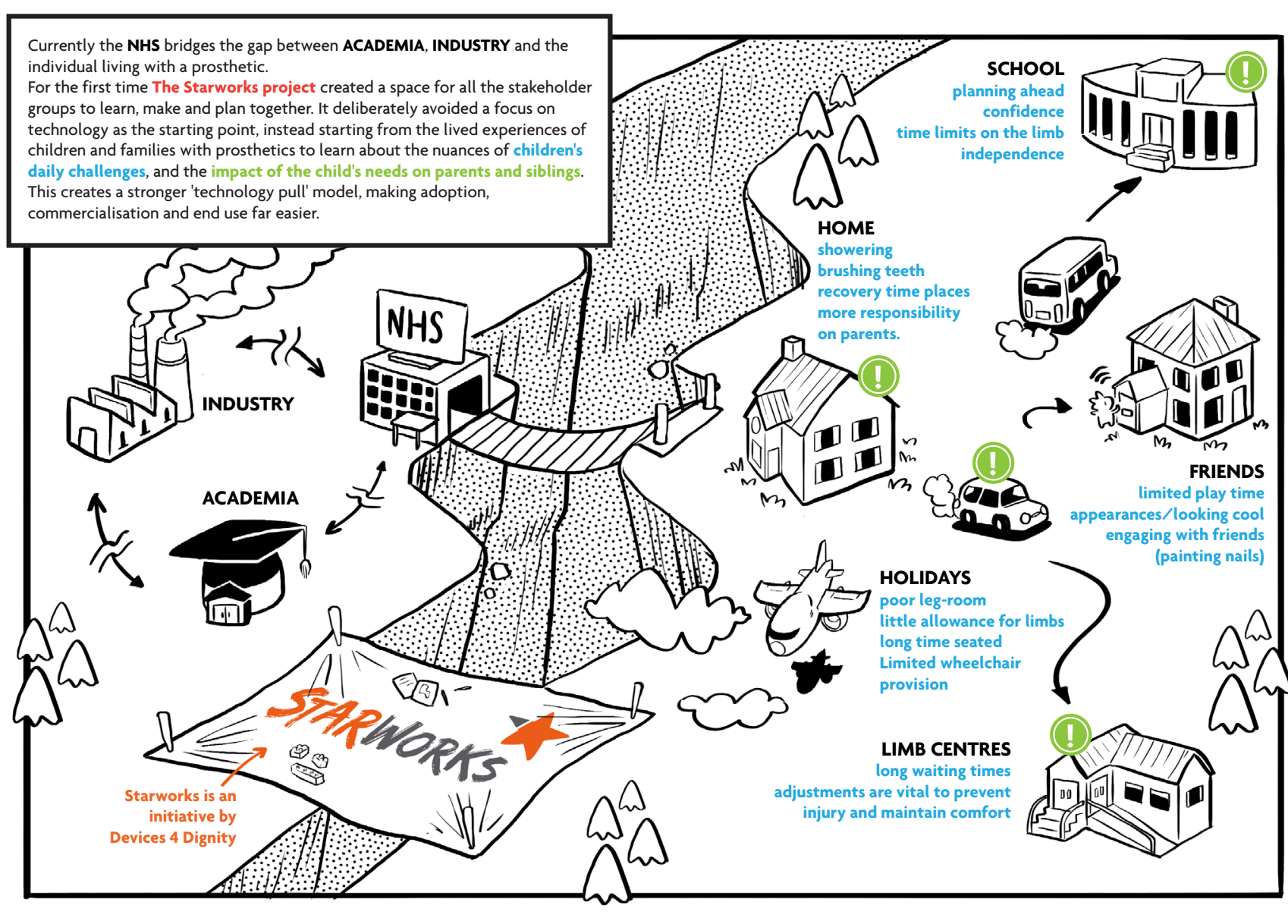




\section{PHASE THREE: STARWORKS SANDPIT EVENTS \\ Work Package 3: Objective 2}

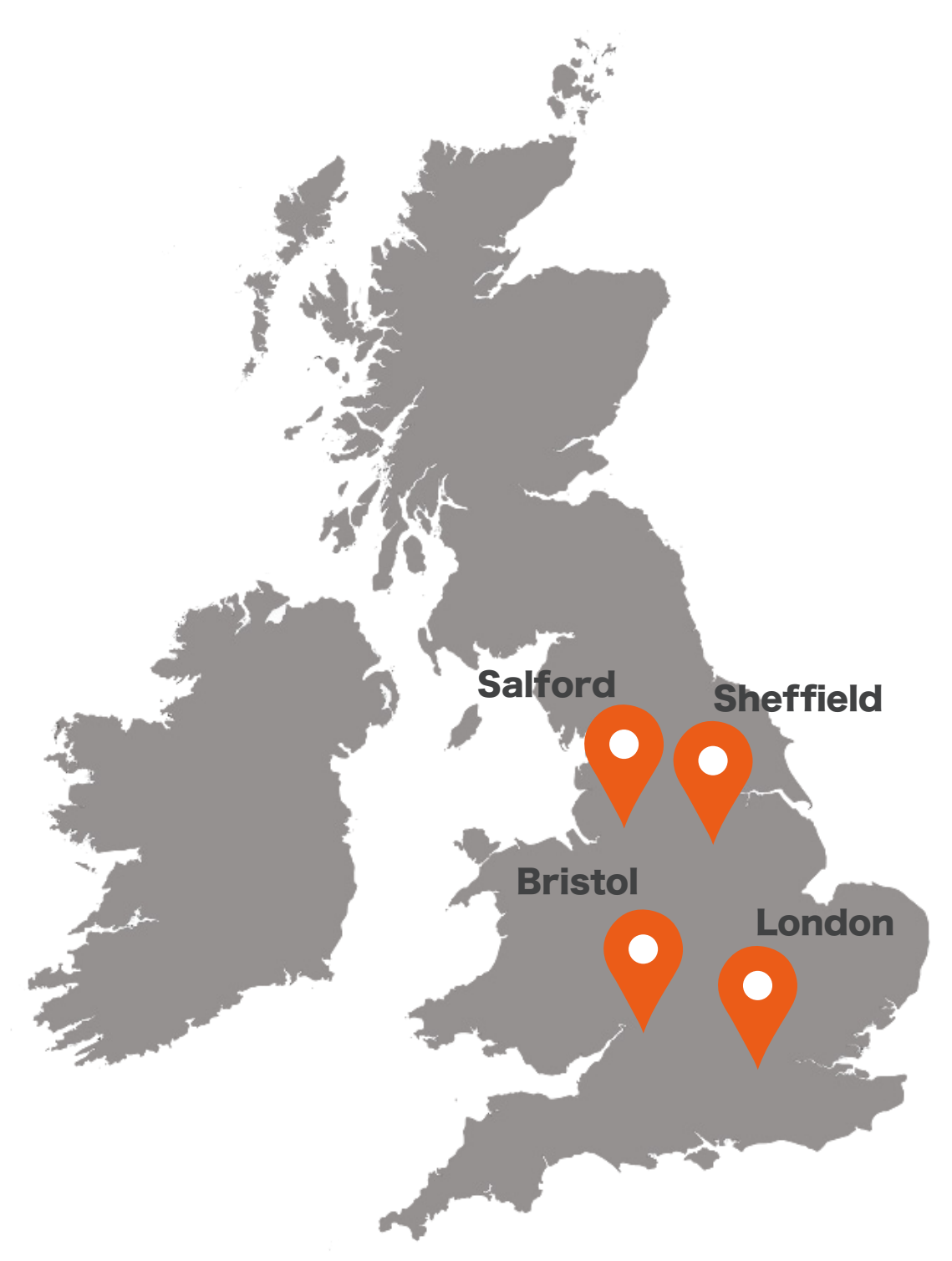

bjective 2 of the original project plan, 'Initiate 4-8 example programmes to set the pace of invention,' was addressed in Phase Three, by planning, organising and facilitating four 'Sandpit' events to explore the challenge areas emerging from Phase Two. To facilitate the participation of as many different delegates as posina different Sendpits were hosted across the Sandits were hosted across the The The Landing (Salford), We the Curious (Bristol), The Wellcom Collection (London) and Ice Sheffield (Sheffield). The Sandpits were well attended with a total of 90 delegates, including:

- 6 young people who use a prosthesis aged from 2 to 15 years old

- 9 family members of young people who use a prosthesis

- 18 delegates from healthcare

- 30 delegates from academia

- 13 delegates from industry

The 72 professional delegates (comprising of 61 individuals) represented 33 institutions.

\section{Workshop structure and outputs}

The structure, rationale, content and outputs of the workshops are best illustrated in the table below:

$\begin{array}{llll}\text { Activity } & \text { Tool } \quad \text { Description } \quad \text { Tool in Use Outputs over }\end{array}$

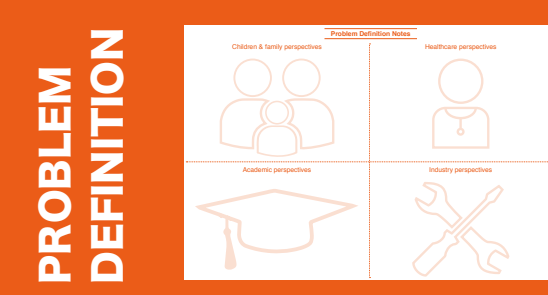

Discuss the workshop

theme from the
perspectives of children,

challenge areas

academics \& industry

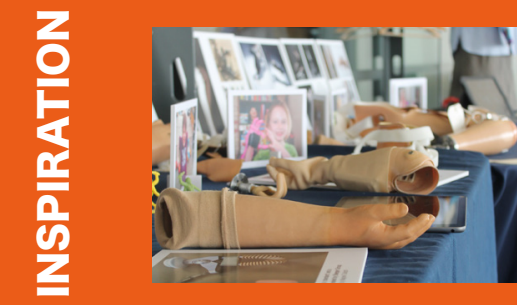

Showcase a range of inspirational materials, projects and research related to child

prostheses, as well as analagous materials to inspire creative thinking

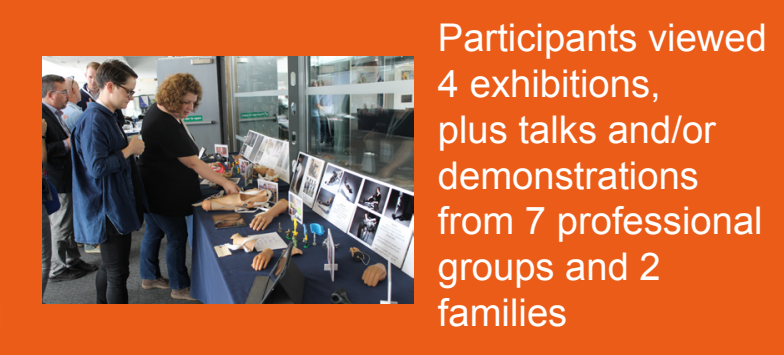

To collaboratively generate as many

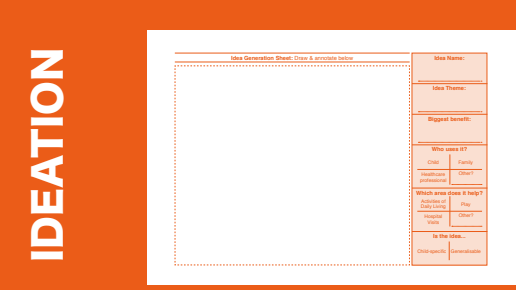

teams, design facilitator. Wild ideas were encouraged from every attendee, then the whole group voted for their top 5 ideas over

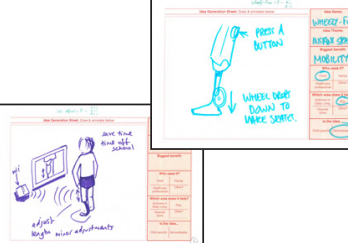
234 ideas mapped onto 59 problem lunch

\section{Once participants self-} select which of the

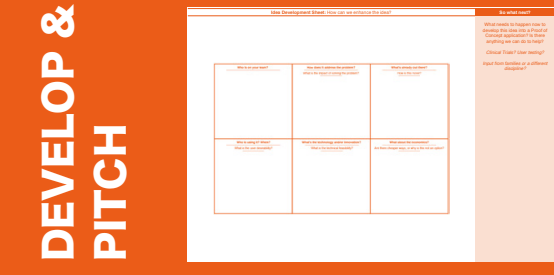
develop the idea further (also highlighting what they don't know at this point). The concept is condensed into an 'elevator pitch' and presented to the group

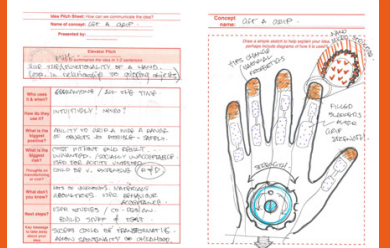

18 pitched ideas, 23 applications to proof of concept funding 


\section{Workshop outputs}

As can be seen in the table on page 15 , the effectiveness of these multi-stakeholder co-design events was also evidenced in the volume of needs identified and ideas generated - 234 in total. After an initia analysis of these ideas, they have been mapped onto approximately 59 problem areas or themes; 15 of these themes were completely new topics previously unexplored. The majority of the newly discovered areas were about a child living his or her life rather than clinical aspects, again demonstrating the potential for innovation within the area of child prosthetics by involving all stakeholders.

These initial ideas, and the materials generated in developing the most popular 4-6 ideas at each event, have been made available to the attending delegates, as well as the feedback data and images taken (with permission) at each event. We are currently exploring options of formally archiving the ideas generated, sorted and accessible by theme, into an open resource for those who wish to enhance children's lives with prosthetics, and to ensure the sustainability of the multistakeholder community generated by the project.

\section{Findings}

The main aim of the project, to 'pump-prime the formation of a Child Prosthetics Research Collaboration,' was met by bringing these diverse groups together to 'ensure there is the ideal balance of 'clinical pull' and 'technical push.' Our feedback forms suggest that the opportunity to creatively and collaboratively explore the problem areas with people from other sectors, including families, was one of the biggest benefits of the Starworks project from the participants' perspectives. Support from partners in Lab4Living, Sheffield Hallam University was important in strategically employing creative workshop methods designed to promote open, equal communication and ideation across hierarchies and disciplinary silos (potential issues identified in Phase One). Please see appendix 6 for 'snapshots' of the Phase Three activities and outputs.

\section{Key lessons learned from Phase Three}

It is important to hold events such as these in a range of locations on both weekdays and weekends. Despite our efforts to generate 'Certificates of Learning' to justify children taking time out of school to attend, children and young people only attended the weekend Sandpit events.

Advertising and Eventbrite information about such events must be clear to lay and multidisciplinary audiences. We found that our original theme 'Service Journeys' did not receive as many applications to attend as other (perhaps more understandable) themed events, and as such changed the name to 'Digital innovations to enhance life with prosthetics' to better encompass the holistic, technologically-enabled focus of that session.

\section{PHASE FOUR: PROOF OF CONCEPT FUNDING}

Work Package 4: Objective 3

To address Objective 3 ('Create the ongoing platform to stimulat and support innovation'), a 'Pronalions for 'Proof of Concept' funding to address key challenges within Child Prosthetics technology and provision was launched in September 2017. Applicants were asked to consider a co-design, cross-sector collaboration, which is evidenced within the submitted applications.

When the funding call closed, we had received 23 high quality project proposals including 14 from academia, 7 from industry/ SME's and 2 from charities. Of these proposals, 7 related primarily to socket improvement; 3 to lower limb development; 9 to upper limb development; and 4 to development of information sources. Further details of the unded projects are oviabr hunded projects are available at https.//Www.starworks-innovation. org.ukl, a detailed breakdown of each award can be found in
Appendix 7 , Key features include

- The themes explored in the Phase Three Sandpit events are evidenced throughout the applications, with a large number focusing on the socket interface as well as lower prosthesis personalisation and adaptability.
- Many applications are focusing solely on upper limb prosthetic applications.

- A small number address cross-sector communication and the journey a child takes through the prosthetics service.

- The majority of applicants have offered significant support in kind and matched funding through partner institutions, and have plans broje beyond the project funding

\section{Evaluation of applications}

The project proposals were allocated to at least three context-appropriate assessors with expertise in at least one of four areas: Parent and child; Prosthetics; Technical; and NHS impact. The assessor team consisted of D4D staff, 3 charity leads (all with personal or parenta experience of limb deficiency), 2 technologists and 5 prosthetist ( 3 from the NHS and 2 from industry). The projects were ranked initially on their scores, but also taking into account the need to put together a balanced and complementary programme of projects, ensuring as wide a coverage of the topics as projects were selected with a to 10 projects were selected with a
requested funding of $£ 423 K$. 


\section{APPROACH TO COMMISSIONING}

A contract letter from $\mathrm{D} 4 \mathrm{D}$ (including individualised research contracts between Sheffield Teaching Hospitals NHS Foundation Trust (as host for NIHR D4D HTC) and each of the institutions of the Principa Investigator of the projects) was developed between D4D and the STHFT Research Governance staff.

\section{Clarification of Proposals}

It was recognised that, while the successful project proposals would define the work to be done to a reasonable extent, in a number of cases there would be some additional detail required to form a complete definition of the work to be delivered. As such, D4D engaged in detailed discussions on the gaps identified in the project proposals, and the ways in which the project teams would clarify and address these. Particular attention was paid to clarity of the project plan budget details, definitions of deliverables and collaboration agreements.

Research Contract Agreement Forms were created for each of the projects, and these together with the Starworks Contract Letters constituted the basis of the contract between the institutions and Starworks/STH.
Once appropriate signatures were received from each project team, a final letter was sent out to the project team to confirm that the project was now authorised to commen 18 and 27-Feb-18).

Although the project plans are dividualised, we estimate al projects will be completed by December/January $18 / 19$.

Monitoring

A core team within Devices for Dignity has taken responsibility for 'light touch' monitoring and support of the projects to ensure they are able to reach their objectives within the time allocated. As of March 2018 all projects have held their kick-off meetings.

Project leaders will be required to submit (to Devices for Dignity) a satisfactory report of progress at an appropriate half-way point of their project in order to receive ane A tompla A template for this report will be provided by the Starworks team and circulated in advance of their individualised deadlines.

Intellectual assets

Although the funded projects are at an early stage, one team has already voiced their intentions to patent their concept once it is refined. In the interests of data protection, we have agreed that this team will not share any IP sensitive information with us as part of their reporting process unti the patent is in place.

We expect several other projects to protect their assets as their projects continue, and we will provide guidance and/or signpost resources to assist this if necessary.

\section{Discussion of Phase Four}

By creating an opportunity for multi-disciplinary teams to innovate $\mathrm{h}$ this area, Phase Four has begu to address the third original aim for the collaboration: 'Identify and support the best advances in research in this field to partne with the NHS to accelerate development towards clinical use ... [and] generate a long-term pipeline of new innovations py providing ongoing access to and idca and idea exchange with nationa networks of experts in the field creating an environment to innovate and collaborate.' The ways in which the collaboration is supporting idea exchange across these national networks is detailed further in the following section.

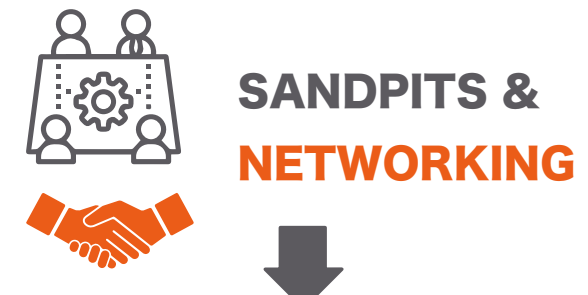

APPLICATION

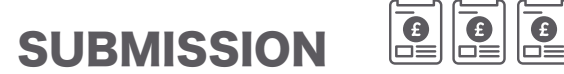

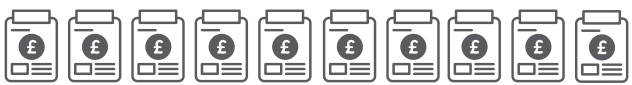

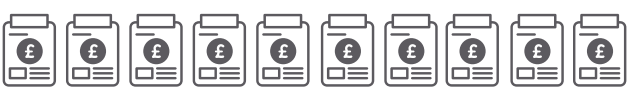

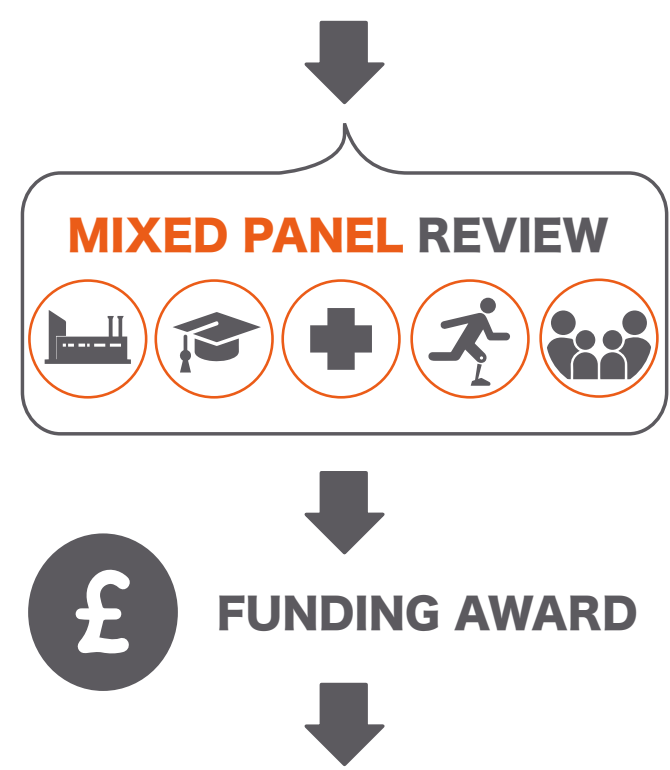

CONTINUED SUPPORT IN

THIS NEW

AREA OF

RESEARCH Devices for Dignity 
PHASE FIVE: MAINTAINING \& GROWING THE NETWORK Work Package 6: Objective 5
Future growth of the NIHR Child Prosthetics Research Collaboration

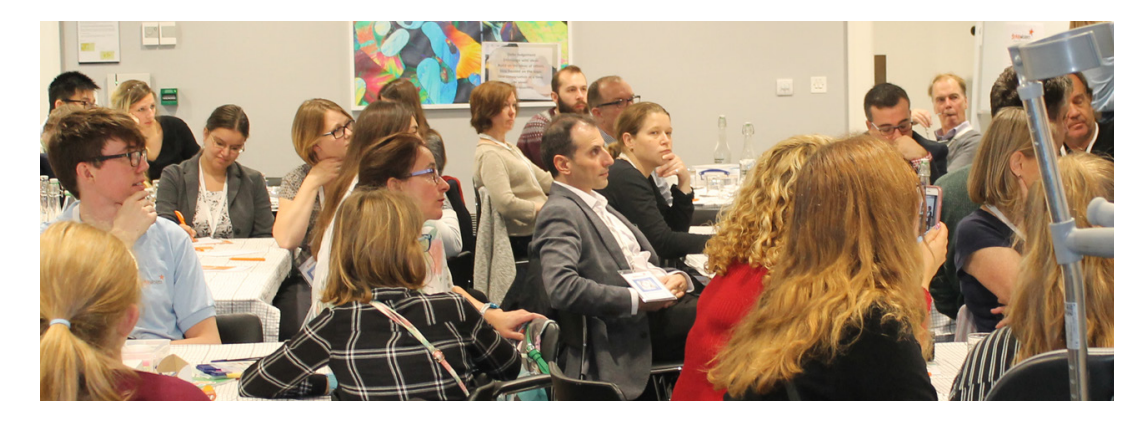

Network growth

Whilst the work described in

Phase Four somewhat addresses

Objective 5 ('Obtain a coherent

set of commitments from relevant

organisations by mid programme organisations by mid programme to ensure that the Collaborative continues beyond the first phase of funding'), the collaboration has also secured additional funding to support this further through a series of networking events between the funded projects and other interested partners. These events will facilitate mutual learning about the diverse portfolio of funded projects, and the sharing of ideas, experiences, resources and problem-solving capacity between project teams.

Dissemination

To ensure continued inclusion of the children and families who are vital to this network, the collaboration commissioned an illustrator to translate some of the main findings (to date) into a visual, engaging format more readily disseminated understood by these groups. Pleast Thease see appendices 8 and 9 . The sharing of images such as project, through our website (see https://www.starworks-innovation. org.uk/) and social media channels (see https://twitter.com/ starworks_cp) contribute to Work Package 5 , particularly $\mathrm{D} 8$, by maintaining a "high profile across social media, press, conferences' throughout the project so far. This will be continued as the collaboration continues.

Throughout the project there has been widespread interest in the approach taken, the findings and subsequent outputs. A number of publications have engaged with the collaboration, resulting in some key outputs:

The Clinical Services Journal with a readership of 30000 led with an article on how to 'Attract Innovation in Child 'Attract Innovation in Child Prosthetics. This included some of the clinicians involved in the collaboration talking about the need to develop new technology and research in the field of child prosthetics.

Children and Young People Now highlights the Starworks Project as an example of best practice with quotes from some of the children and families involved in the project.

The NHS Confederation also focused on one of the clinicians supporting the collaboration and highlighted his work in supporting innovations in child prosthetics.
There is a great appetite to continue this initiative beyond the current funding window. Essential activities that need to be continued or developed include:

Continue to build and shape this collaboration to address the key system and user needs identified

- Ensure the projects initiated in this phase are well supported this phase are well supporter to deliver th

- Industry and clinicians have a need to identify and to continue to identify new areas of need and areas for development; there is a requirement for an on-going mechanism to maintain an updated system of validated unmet needs

- A regular funding call to address specific themes identified within child prosthetics, involving public but also private investors

- Develop a network that shares and encourages open development. This could lead to an open source approach to enable innovators to take the ideas and needs generated through the network, develop them in conjunction with the network, and then share their findings across the network for the benefit of all stakeholders.
As such, two types of investment are required: funds to maintain the network (allowing it to develop and grow) and funds to support individual projects or larger programmes that arise. Supporting these projects further will allow these great ideas prond concepts to reach the market and allow procts further wil allow these great ideas them to be used by children and young people.

Within D4D, we have established the TITCH (Technology and Innovation Transforming Child Health) network with the methodology in place to allow Starworks to support all of the above aims. This national network is centred around children and families, healthcare experts, charities and industry who enable rapid access to key opinion leaders, knowledge, and know-how.

The Starworks child prosthetics project should continue to be developed towards the sustainability of its own network, which includes all stakeholders. This core network, established in recent months, will form the basis of a growing body of interested parties. The ongoing network would help drive forward innovations and provide a platform for the essential and expert multi-stakeholder relationships required to ensure that the very best innovations to ensure that the very best innovations are developed and commercialised for the benefit of children living with a prosthetic limb, and their families.

As word of the Starworks project continues to spread, the collaboration will continue to "offer support to anyone interested in discussing their own ideas for technology development in Child Prosthetics, as outlined in Work Package 4. This has been somewhat addressed in the monitoring and supporting role of the funded projects an detailed in Phase Four, and the addition detailed in Phase Four, and the additional 


\section{PATIENT AND PUBLIC INVOLVEMENT, ENGAGEMENT AND PARTICIPATION}

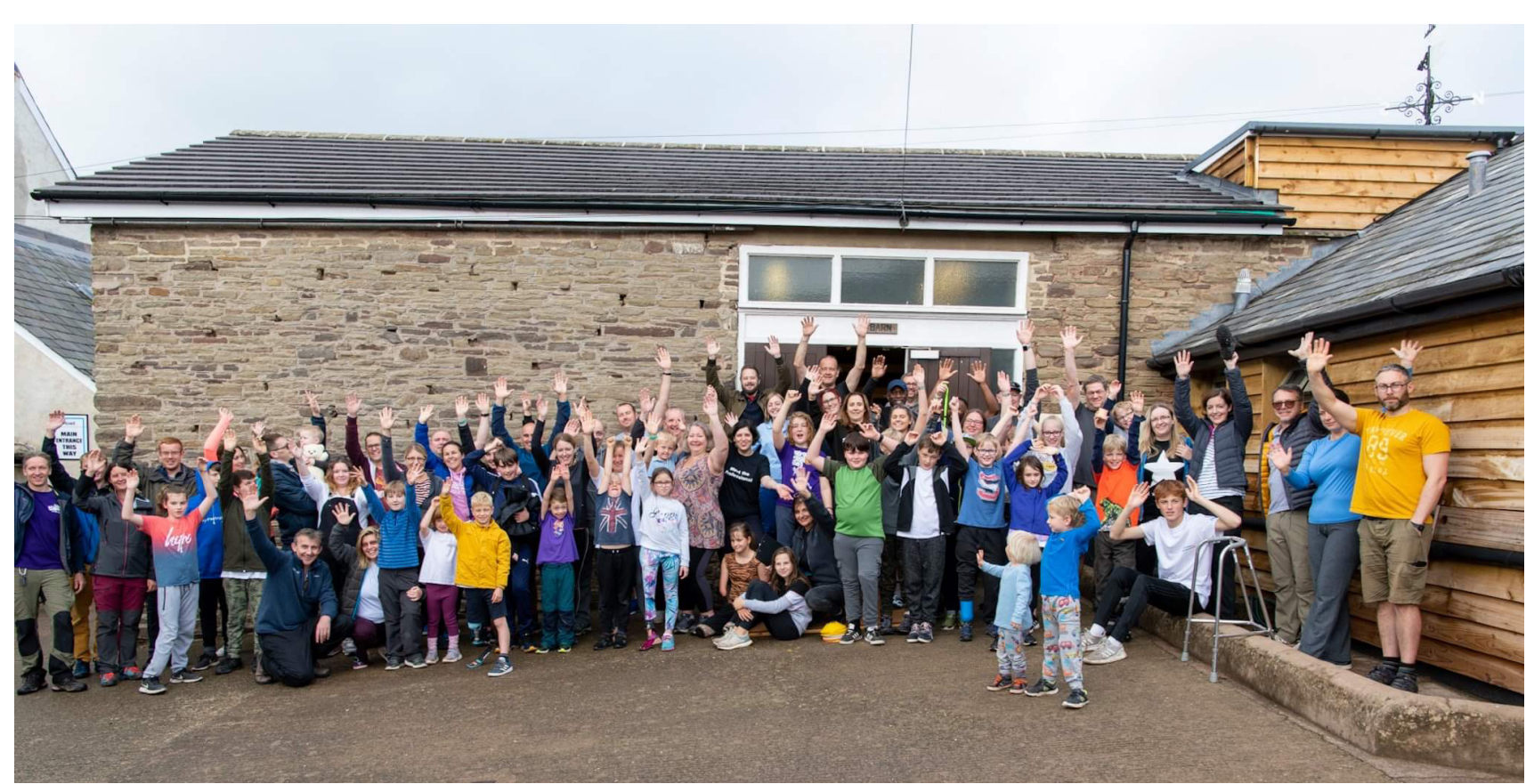

As is clear throughout this report, Patient and Public Involvement and Engagement (PPIE) has been a central concern of the collaboration. This section will summarise the methods used and added value of such activities in three key stages of the project; the needs assessment of child prosthetics research and provision; national, multidisciplinary Sandpit events; and the setting up of 10 'proof of concept' projects to explore innovations in this area.

Needs Assessment of Child Prosthetics Research and Provision

Multiple, creative methods were chosen and bespoke tools designed to account for the challenges of a national patient population and the particular needs of children (i.e. short, sharp, fun activities), including:

- Visits to prosthetic clinics to elicit context-specific knowledge through discussions with children and families in waiting rooms, or observing the appointment itself.

- Creative workshops with children and family members that focussed on exploring children's daily routines, wider life issues and priorities, and the challenges posed by their prosthesis within them
- Three separate surveys were developed for children, young adults and parents, with the former facilitating rich responses through drawing activities. These surveys could also be used as a platform for discussion between parents and children if filled in together.

In terms of added value, it was found that the use of multiple, creative methods that empowered parents and children (of a range of ages) to share their unique knowledge generated findings that were otherwise unarticulated by other workstreams. These findings included a more holistic view of prosthetic use that considers its impact on daily routines and other family members, as well as the social side of the child's growth and development and the importance of uninterrupted, spontaneous play.

\section{Sandpit Events}

A series of four Sandpit events were arranged to bring children and family members together with academics, clinicians and industry experts to collaboratively and creatively explore key challenge areas within child prosthetic research and provision. Child and family attendance was encouraged through the choice of multiple venue locations across the country, hosted on both weekdays and weekends. The workshop structure focussed on ensuring all participants' voices, experiences and ideas were considered equally, and explored creatively with bespoke supporting tools, empowering child and family attendees to participate comfortably.

The added value of eliciting the child and family voice in this stage is evidenced in the volume and holistic nature of ideas generated in the 4 Sandpits - 234 in total, some of which related to previously unexplored topics. Professional participants regularly stated (via feedback forms) that the opportunity to work with other stakeholders, including families, was one of the biggest benefits of the Starworks project.

\section{Proof of Concept Funding}

Applications to the Proof of Concept funding scheme were reviewed by at least 3 context-appropriate assessors with expertise in at least one of 4 areas: Parent and child; Prosthetics; Technical; and NHS impact. Devices for Dignity are also offering support to the funded projects in terms of networking with interested families. Although the projects are in their early stages, the inclusion of parent and child perspectives in their selection adds value to the project by ensuring the proposals aim to meet rea needs of real children. 


\section{TOP THREE ACHIEVEMENTS \\ DURING THE 2017/2018 \\ FINANCIAL YEAR}

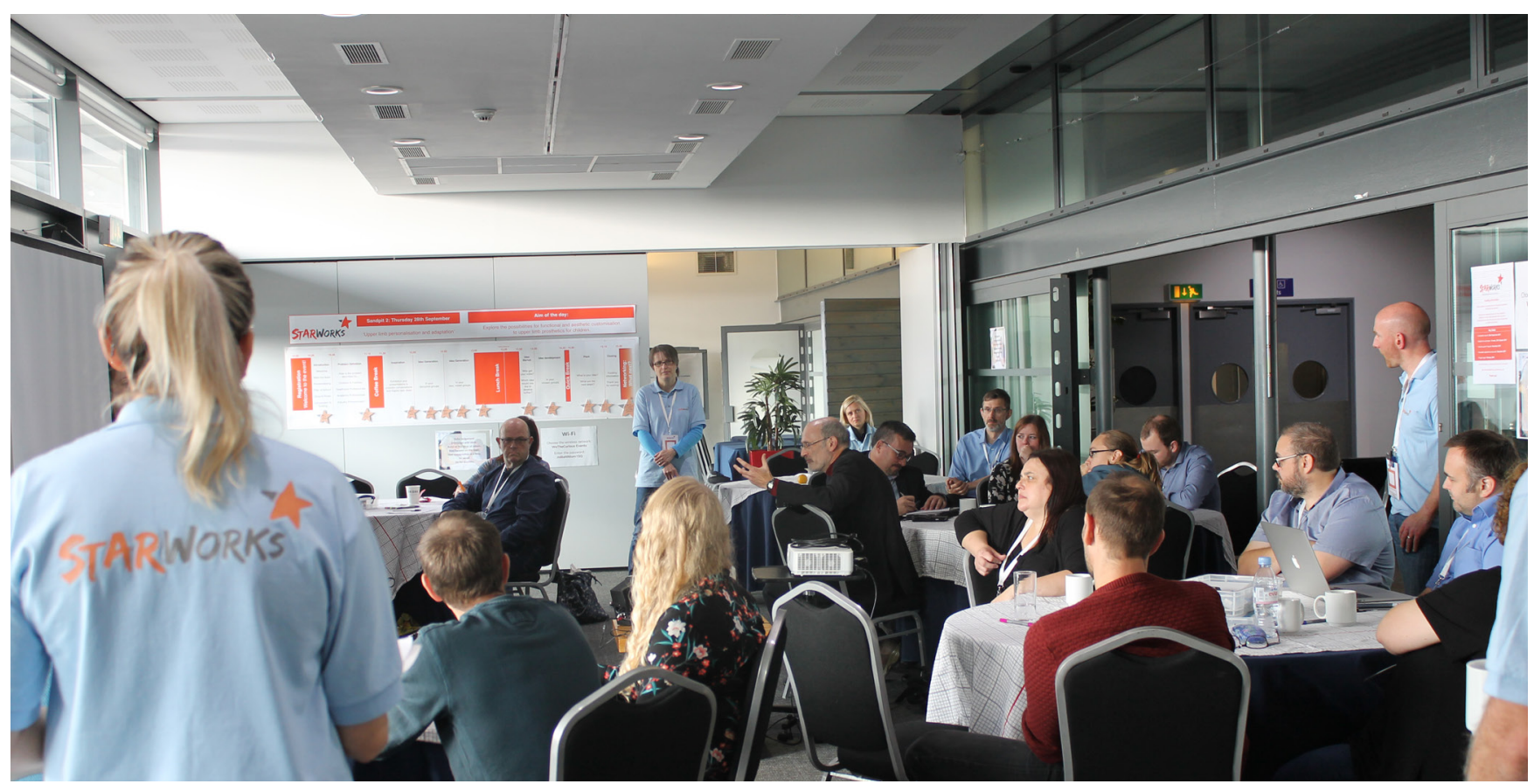

The identification of system-wide needs in child prosthetics from the perspective of all stakeholders, who were seen as equal partners with a significant role to play in developing effective innovations for children with limb loss

A unique approach that treats all stakeholders as equal and places children at the centre of innovation, as evidenced through our 4 sandpit events and our continued network approach

The funding of 10 high quality projects, which involve all stakeholders and seek to address unmet needs that will ultimately improve child prostheses (some of which were identified through and by the Collaboration)

\section{DISCUSSION}

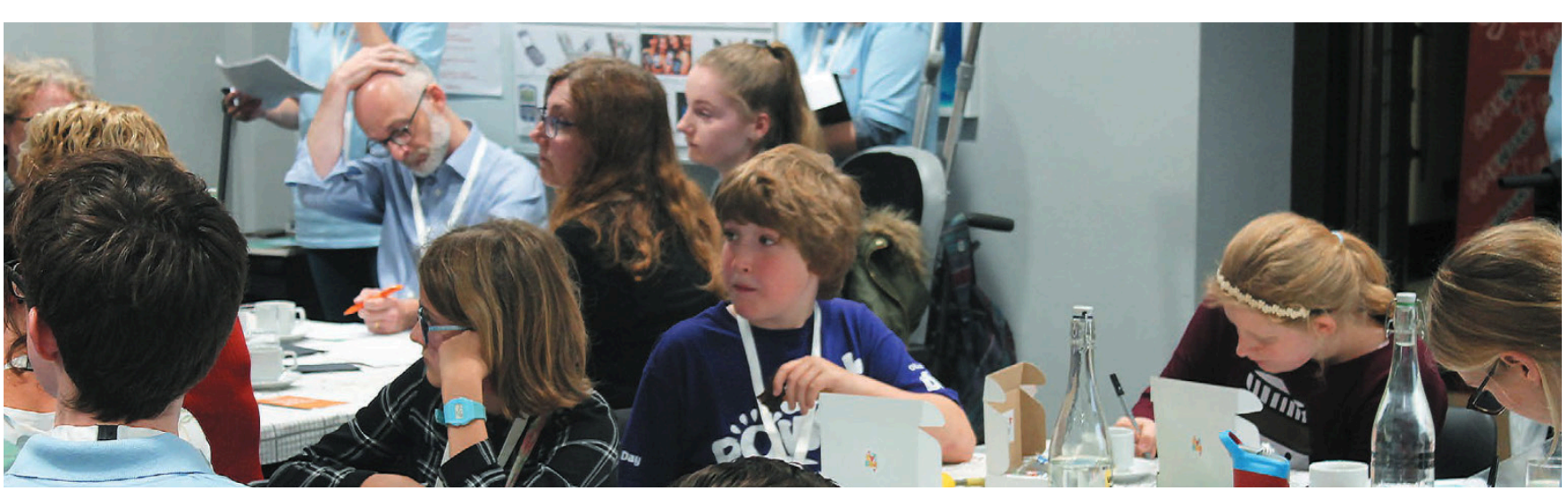

In the Needs Assessment and Sandpit events discussed previously, approximately 56 individual children and family members were involved, evidencing the collaboration's commitment to meaningful, active involvement of these key stakeholders. Their unique contributions have encouraged a participants to take a more holistic view of child prosthetic research and provision, taking into account children's lived experiences and priorities.

The collaboration has also facilitated patient and public engagement (which 'Involve' describe as the provision and dissemination of information and knowledge about research). This has been evident in the maintenance of a strong online presence via dedicated Starworks website pages (https://www. starworks-innovation.org.uk/) and twitter (@starworks_cp), as well as extensive promotion through partners (including @Devices4Dignity and @ TITCHinnovate). The project has Teen doumented in publications such as The Clinical Services such as The clinical Services Journal, Children and Young People Now, and The NHS Confederation.

Outcomes from Sandpit events were scanned and uploaded (with permission) to an online repository shared between Sandpit participants, demonstrating the collaboration's desire to maintain an open network approach, building transparency and capacity within it. To make the project outputs more accessible to children, several key findings have also been translated into illustrations (see appendices 8 and 9) and shared via the channels described above. 


\section{Appendix 1: Signposting original Work Packages (WP's) and Deliverables}

The following table aims to summarise how the original WPs have been addressed in the NIHR Child Prosthetics Research Collaboration so far, and where further details of this can be found in the main report.

\begin{tabular}{|c|c|c|c|}
\hline Work Package & Deliverable & $\begin{array}{c}\text { Summary of } \\
\text { progress }\end{array}$ & $\begin{array}{c}\text { Section(s) in } \\
\text { main report }\end{array}$ \\
\hline $\begin{array}{l}\text { WP1: Management and } \\
\text { Governance }\end{array}$ & $\begin{array}{l}\text { Establish Project } \\
\text { Reference Group } \\
\text { (PRG) and Project } \\
\text { Executive Group, } \\
\text { report to D4D } \\
\text { Steering committee } \\
\text { throughout the } \\
\text { project, and annual } \\
\text { report to NIHR. }\end{array}$ & $\begin{array}{l}\text { Achieved: Actively } \\
\text { involved four key } \\
\text { stakeholder groups } \\
\text { (clinicians, } \\
\text { academics, industry } \\
\text { experts, and children } \\
\text { and families), and } \\
\text { established } \\
\text { partnerships with } \\
\text { NIHR Brain Injury } \\
\text { HTC and NIHR } \\
\text { Trauma } \\
\text { Management HTC. }\end{array}$ & $\begin{array}{l}\text { 'Phase One: } \\
\text { Establishing the } \\
\text { network' } \\
\text { See pages * _ *. }\end{array}$ \\
\hline \multirow[t]{3}{*}{$\begin{array}{l}\text { WP2: Needs Assessment } \\
\text { and Identification of } \\
\text { Opportunity } \\
\text { (Objective 1) }\end{array}$} & $\begin{array}{l}\text { D1: Agreed themes } \\
\text { for detailed } \\
\text { exploration }\end{array}$ & $\begin{array}{l}\text { Achieved: Each } \\
\text { workstream took a } \\
\text { context-specific } \\
\text { approach according } \\
\text { to which of the four } \\
\text { the key stakeholder } \\
\text { groups (listed above) } \\
\text { they were engaging. }\end{array}$ & $\begin{array}{l}\begin{array}{l}\text { 'Phase Two: Multi- } \\
\text { stakeholder needs } \\
\text { assessment' }\end{array} \\
\text { See pages * - *. }\end{array}$ \\
\hline & $\begin{array}{l}\text { D2: Each theme will } \\
\text { produce a report } \\
\text { detailing the current } \\
\text { situation in that topic } \\
\text { identifying areas } \\
\text { where improvements } \\
\text { are needed }\end{array}$ & \multirow{2}{*}{$\begin{array}{l}\text { Achieved: each } \\
\text { workstream } \\
\text { submitted a report } \\
\text { on their findings and } \\
\text { discussed them at } \\
\text { the Project } \\
\text { Reference Group } \\
\text { Meeting held in The } \\
\text { Wellcome Collection, } \\
\text { London, } 28^{\text {th }} \text { June } \\
\text { 2017. This discussion } \\
\text { informed the choice } \\
\text { of } 4 \text { key themes to } \\
\text { take forward as well } \\
\text { as two overarching } \\
\text { considerations } \\
\text { applicable to each } \\
\text { theme. }\end{array}$} & \multirow[t]{2}{*}{$\begin{array}{l}\text { Discussion of Phase } \\
\text { Two findings. } \\
\text { See pages *-*. } \\
\text { Full reports available } \\
\text { in appendices ***. }\end{array}$} \\
\hline & $\begin{array}{l}\text { D3: Key topics } \\
\text { selected to develop } \\
\text { through four } \\
\text { workshops }\end{array}$ & & \\
\hline $\begin{array}{l}\text { WP3: Workshops } \\
\text { (Objective 2) }\end{array}$ & $\begin{array}{l}\text { D4: Prioritised list of } \\
\text { unmet needs in each } \\
\text { topic }\end{array}$ & \multicolumn{2}{|c|}{$\begin{array}{l}\text { Achieved: } \\
\text { - Insights from } 4 \text { stakeholder groups were } \\
\text { collated under the } 4 \text { main themes to inform }\end{array}$} \\
\hline
\end{tabular}




\section{Starworks report, Child and family needs analysis, Sheffield}

\section{Introduction}

The NIHR Devices for Dignity Healthcare Technology Co-operative (HTC) is currently leading a multi-stakeholder investigation into child prosthetic technology and service provision; the NIHR Child Prosthetics Research Collaboration. This Collaboration has been made possible by a funding dedicated to the provision of new sports prosthetics for children in the NHS) and involves input from four main stakeholder groups, children and their families; NHS clinicians and limb centres; Industry experts; and the R\&D community.

The initial phase of this collaboration has focussed on understanding the needs and opportunities for these stakeholder groups. Lab4Living, a design and healthcare research centre within Sheffield Hallam University, was approached to work with children, young adults a their families to understand their experiences of child prosthetic technology and service given below.

\section{Methodology}

\subsection{Data sources}

Data was gathered during April and May 2017 using a variety of methods, including workshops, hospitities vists, surveys, phone calls and individual contact with stakeholders. Throughout these grandparents and siblings, although a range of clinicians (including consultants, prosthetists. counsellors, doctors, centre managers, physiotherapists and nurses) were also consulted when the opportunities arose. Further details of each of these activities, and the stakeholders involved, are given below.

\subsection{Data collectio}

a. Workshops

\begin{tabular}{|c|c|}
\hline Centre & Number of families participating \\
\hline Stanmore & 15 \\
\hline Bristol & 3 \\
\hline
\end{tabular}

Table 1: Number of participants at each workshop event

The workshop activities included

- 'Advice wall' - using speech bubbles to quickly capture advice that children and parents

would give to ohers (shown in fig. 1 below).

'Mapping my world' - asking children and parents to write/draw all the different parts 政, then reflecting on these areas to discuss how their prosthetic helps or hinders them and what challenges they have

Daily living timeline -2 below). emotional highs and lows, then reflect on the reasons for them.

- Medal of thanks - children were asked to make a medal for someone they wanted to enk who has helped them in their journey through the prosthetics service, and to

Survey-led discussions - here researchers went though surveys (discussed below) individually with children and parents, expanding on the questions where appropriate.

Whilst some of these activities were conducted individually, others engaged groups of families together, prompting further discussion on topic unanticipated by the researchers (see fig 3).

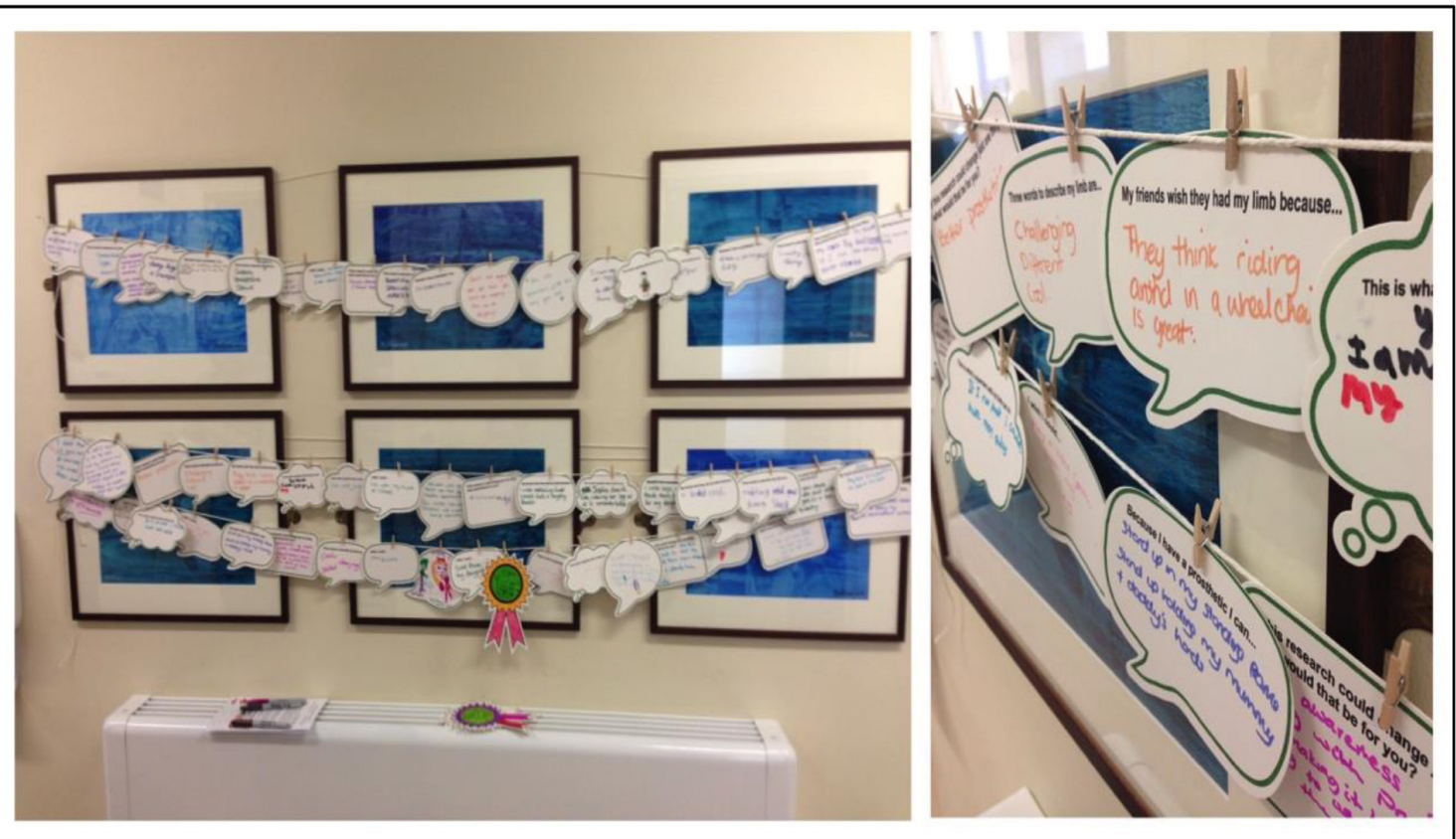

Fig. 1: The Advice Wall Method

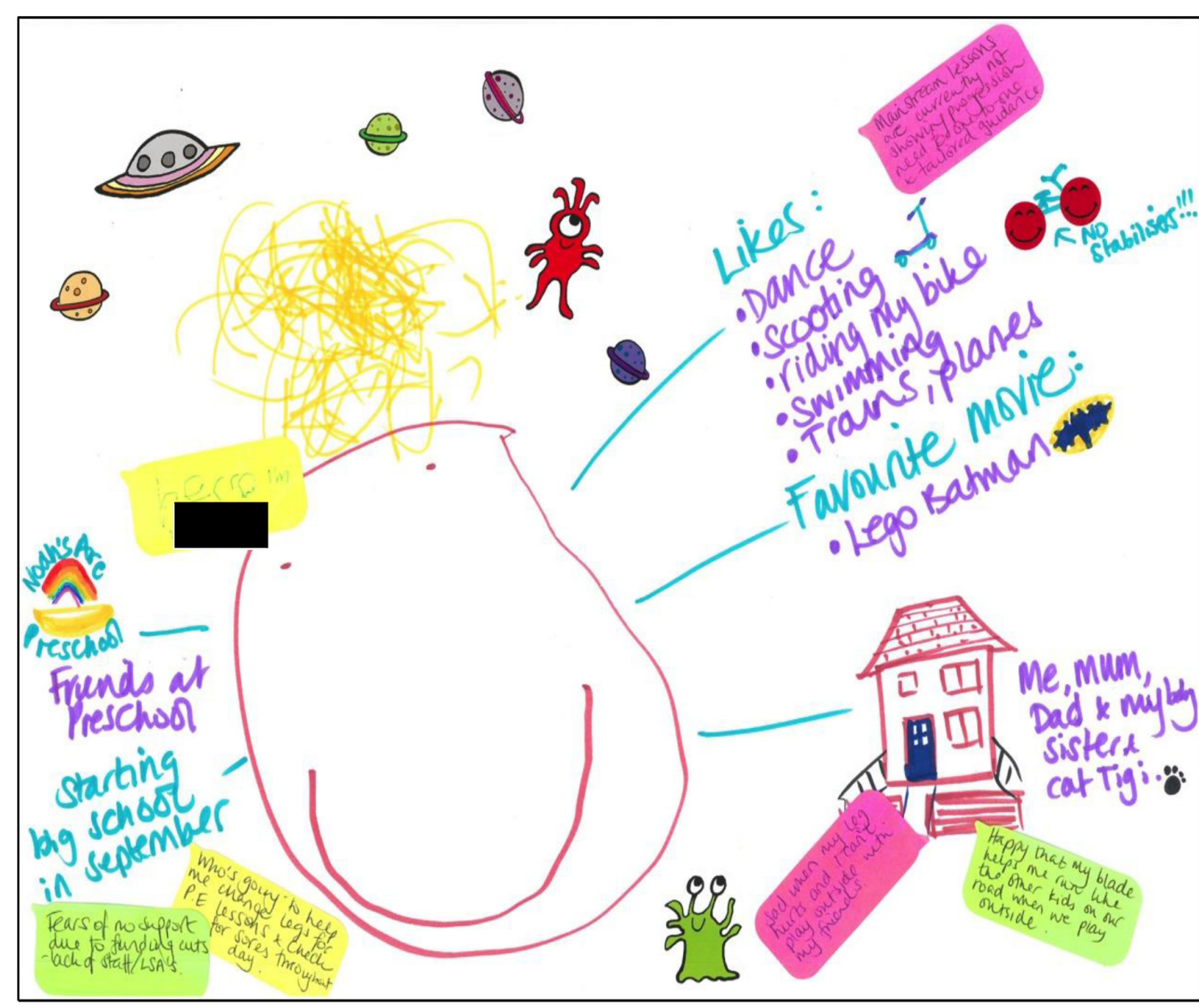

Fig. 2: An example of the 'Mapping my World' method, as completed by a 4 year old boy who uses a lower limb prosthetic. He has drawn himself and described the main areas of his life (using stickers and notes from his mother. Key points (such as challenges or emotional events) are narrated and discussed by his mother using post-it overlays. 


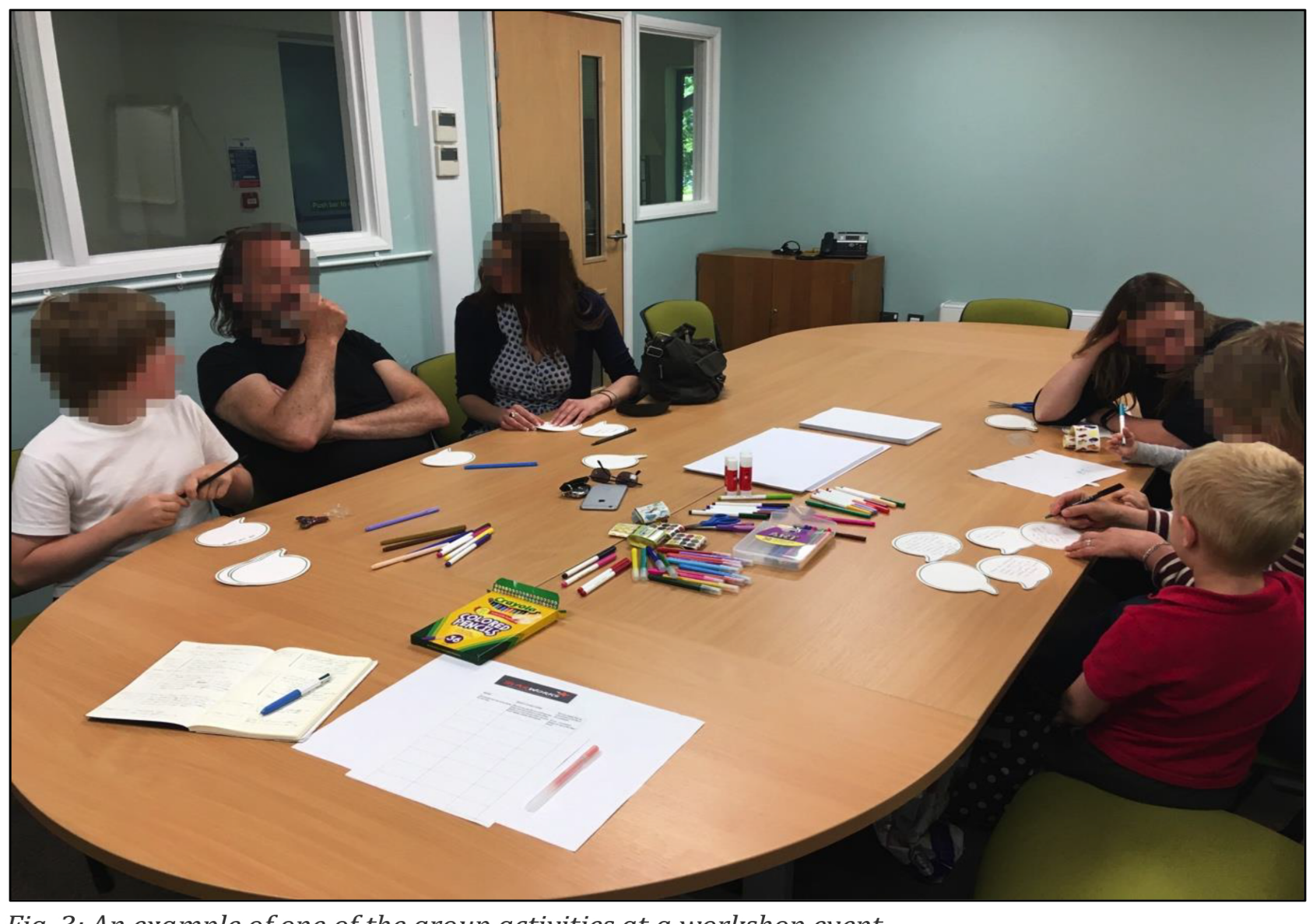

Fig. 3: An example of one of the group activities at a workshop event.

$$
\text { b. Surveys }
$$

phree separate surveys were designed by the research team to target child, young adult and parent perspectives of the child prosthetic technology and service provision available. The survey questions asked participants to describe their experiences (rather than satisfaction) of their journeys to date, and also included questions that aimed to encourage creative thinking (see the examples in fig. 4 below). The surveys are available at

http://devicesfordignity.org.uk/starworks $\mathrm{cp} /$, and physical copies will be available during the group presentations on $28^{\text {th }}$ June 2017.

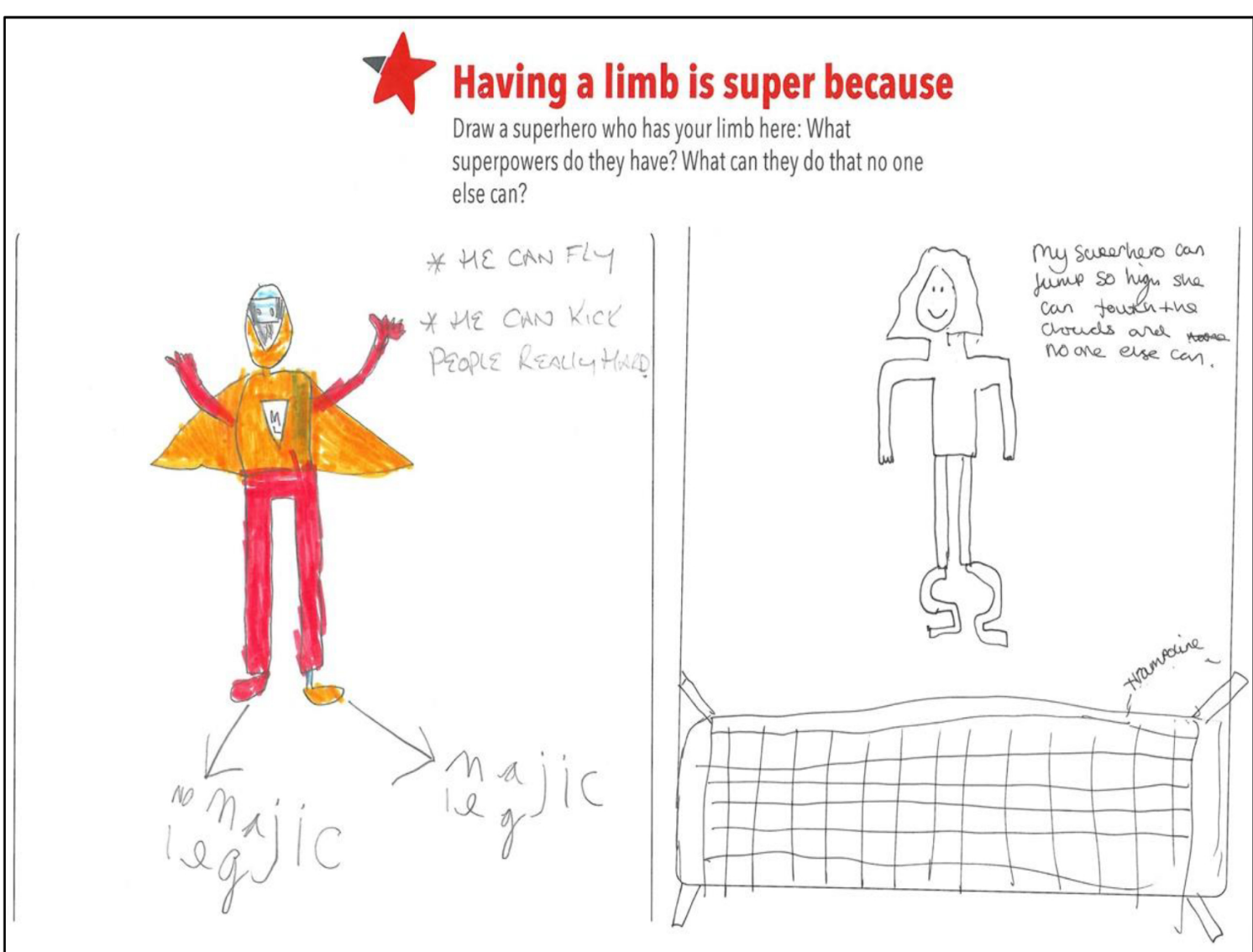

Fig. 4: Two examples of children's drawings of superheroes who have the same prosthetics as them

In total, approximately 1000 surveys were sent to 500 families at 5 sites across the UK distributed by the healthcare professionals at each site, as detailed in table 2 below:

\begin{tabular}{|c|c|c|c|}
\hline \multirow{2}{*}{ Centre } & \multicolumn{3}{|c|}{ Number of surveys sent } \\
\cline { 2 - 4 } & Children & Young Adults & Parents \\
\hline Sheffield & 39 & 44 & 90 \\
\hline Stanmore & 75 & 75 & 150 \\
\hline Brighton & 17 & 17 & 34 \\
\hline Bristol & 15 & 15 & 30 \\
\hline Manchester & 100 & 100 & 200 \\
\hline
\end{tabular}

Table 2: A breakdown of how many surveys were sent to each centre across the UK (approximately).

The surveys were also available online at the link above, which was distributed to an estimated network of 400 prosthetists and orthotists.

The survey response rate, as of 19/06/17 is shown in table 3 below. Some surveys were returned after the deadline date ( 8 in total) and as such were not included in the main analysis, although they will be summarised at the end of the findings section below. 


\begin{tabular}{|c|c|c|c|}
\hline Participant & $\begin{array}{c}\text { Type of } \\
\text { prosthetic }\end{array}$ & Number & Subtotal \\
\hline \multirow{2}{*}{ Child } & Upper limb & 3 & \multirow{2}{*}{10} \\
\hline & Lower limb & 7 & \\
\hline \multirow{2}{*}{ Young adult } & Upper limb & 0 & \multirow{2}{*}{3} \\
\hline & Lower limb & 3 & \\
\hline \multirow{2}{*}{ Parent } & Upper limb & 3 & \multirow{2}{*}{11} \\
\hline & Lower limb & 8 & \\
\hline & & & 24 \\
\hline
\end{tabular}

- Themes were added to the whiteboards using post-it notes (as many as possible), which were then collated under common headings

Table 3: Survey response rate from children, young adults and parents as of 19/06/17.

Other

Other activities largely consisted of informal face-to-face contact prior to/atter workshops,

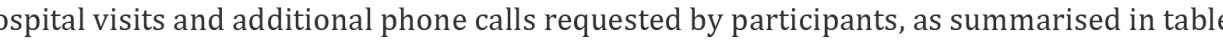

\begin{tabular}{|c|c|c|c|}
\hline \multirow{2}{*}{ Type of activity } & \multicolumn{3}{|c|}{ Number of participants involved } \\
\cline { 2 - 4 } & Children & Parents & Healthcare professionals \\
\hline Hospital visit - meeting clinicians & 0 & 0 & 5 \\
\hline Hospital visit - meeting patients & 2 & 3 & 2 \\
\hline Informal discussions (n=5) & 0 & 0 & 8 \\
\hline Phone calls (n=4) & 0 & 3 & 1 \\
\hline
\end{tabular}

Table 4: A summary of additional research activities and participants involved.

\subsection{Data analysis}

Group Analysis Day

Notes from each research activity were transcribed into word documents by the research team tial themes during an analysis day at Sheffield Hallam University through the following steps:

- Responses to the main survey questions were collated on large whiteboards, followed by data from other research activities:

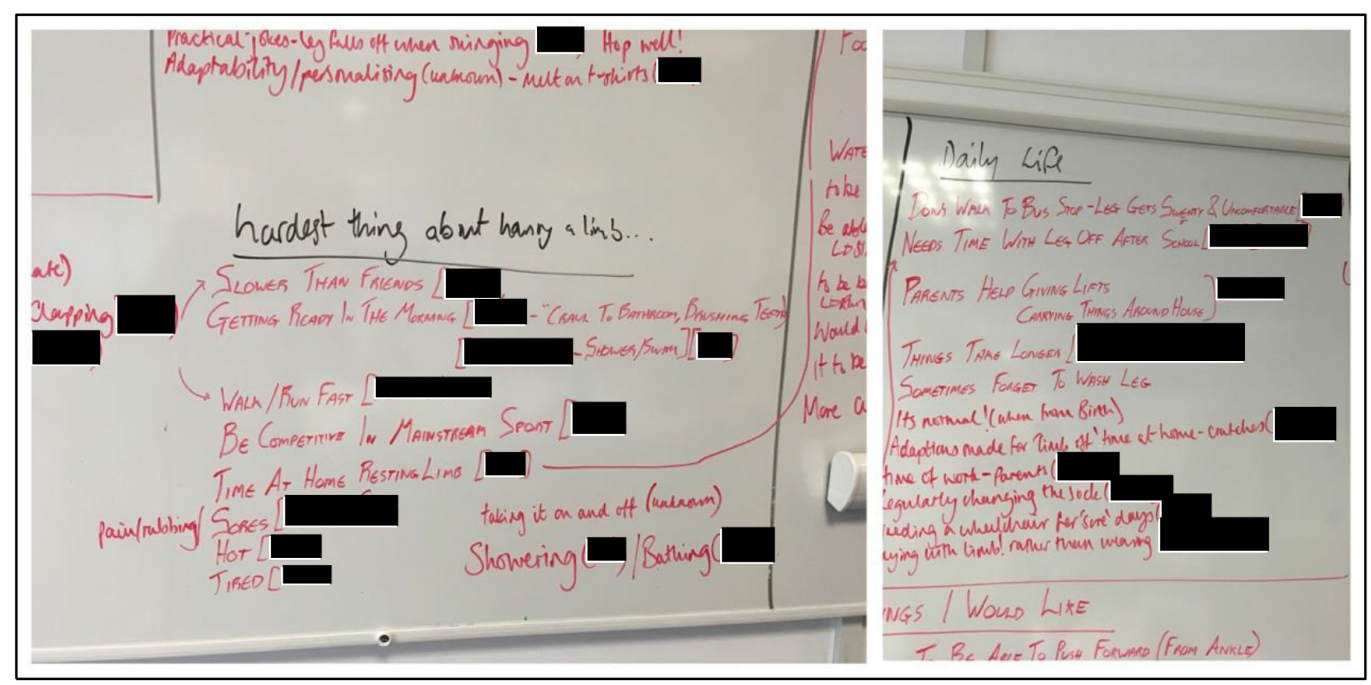

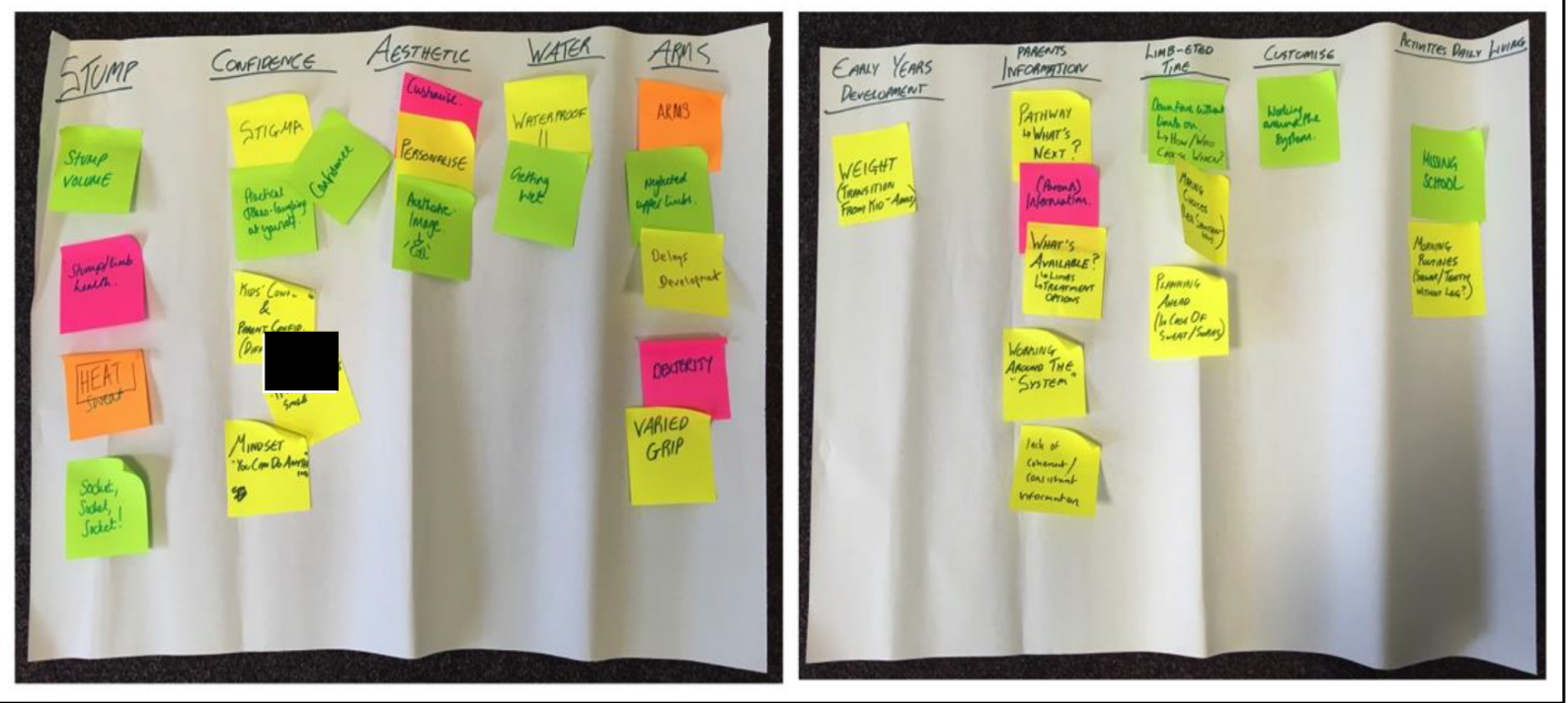

These initial themes, agreed by the research team, were then used as the basis of the in-depth qualitative analysis using NVivo (a qualitative data management and analysis software used to explore and discover insights in sources such as survey responses or interview transcriptions), described below.

NVivo Analysis

To begin, the data transcriptions (including survey responses, workshop and phone call summaries) were imported into the NVivo software as well as the initial themes established in the data analysis day. The coding process, used to understand the scope and impact of issues arising from the data further, can be summarised as follows:

- Reread each data transcription to enhance familiarity with it

- Assign as many themes (known as 'codes') as possible to each phrase of interest in each data source in turn, generating new codes as and when necessary.

- Revisit each code; editing the placement of codes, consolidating similar codes and removing redundant codes

- Revisit each data source to add to any new or altered codes

- Generate summary report (shared amongst the research team)

For clarity, the themes established on the data analysis day and the themes emerging from the coding process will be presented and explained separately in the following findings section. 


\section{Findings}

31 Analysis day themes

\begin{tabular}{|c|c|c|}
\hline \\
\hline \multicolumn{3}{|l|}{$\begin{array}{l}\text { Analysis Day themes } \\
\text { Nome }\end{array}$} \\
\hline Sports & 17 & 27 \\
\hline Service & 12 & 25 \\
\hline O Child speciific & 7 & 9 \\
\hline$\bigcirc$ Long matiting times & 6 & E \\
\hline Early Years Development & 11 & 17 \\
\hline Limited time on limb & 11 & 15 \\
\hline Customise & 9 & 14 \\
\hline Daily activities & 9 & 14 \\
\hline Arms & 5 & 13 \\
\hline Aesthetic & 5 & 12 \\
\hline O Stump & 6 & 7 \\
\hline O Information [parents) & 4 & 7 \\
\hline Superpower & 4 & 7 \\
\hline Balance & 1 & 2 \\
\hline Water & 1 & 1 \\
\hline Shower or bath & 6 & 7 \\
\hline Swimning & 4 & 7 \\
\hline . & 3 & 4 \\
\hline $\mathrm{O}$ Conffidence & 0 & 0 \\
\hline O People look or question (niegative) & 7 & 8 \\
\hline Hawing hurnour & 3 & 3 \\
\hline Advice to be confident & 2 & 2 \\
\hline Confidence with others & 1 & 1 \\
\hline Bullying & 1 & 1 \\
\hline
\end{tabular}

ig. 5: A screenshot of the NVivo software summary of the Analysis Day Themes, showing how many data sources mentioned each theme, and how frequently.

Each theme shown in the summary above will now be described in further detail.

Sport

$70 \%$ of the surveys returned mentioned sports, in terms of what the child or young adult likes, how they describe themselves, what the limb allows them to do and also in terms of what they' like to do better. The most popular sports included football, swimming and cycling. Some children mentioned not being able to do PE, or deciding ad-hoc if they do PE each day at school.

Service

Several parents described being apprehensive about entering the prosthetics service at first, and that staff should remember that it is a scary transition. Other parents wished for a more 'personal
service' and for more information (see below).

Children, young adults and parents all described the long waiting times in their appointments, and (mostly) disliking taking the time out of school.

Child participants picked up on the 'child specific' aspects of the service as their favourite parts (i.e. being able to play before the appointment, having fun tests to do with their healthcare professionals), whilst some parents described a need for a more child-friendly environment/process (perhaps due to surveys being returned from multiple centres).

"When I visit the physio he has lots of cool assessments and play things it's fun." Rory, a young child using an upper limb prosthetic

Many participants described how friendly the staff are at their local centre, and the positive effect this had on their experiences or on children wanting to go back for their next appointment.

Limited time on the limb

Each category of participants mentioned needing to remove the prosthetic at strategic points in the day. Time on the limb can be seen as precious, and worth spending on the highest value activities (i.e. being driven to school to maximise time walking comfortably in the day). Severa result of putting the limb on as late as possible (i.e. brushing teeth) and in the evening when taking it off for a rest (i.e. parents needing to carry young children or the things they need around the house).

"We live $0.9 \mathrm{~m}$ from bus stop to school, I think [he] would walk if he didn't have the prosthetic. He can walk that distance, but leg gets sweaty and feels uncomfortable then throughout the day. After a day at school he needs time with prosthetic off, so does limit evening activities." Father of a young adult using a lower limb prosthetic.

Many participants ( 3 children, 1 young adult and 2 parents) described having difficulties in showering or bathing since their limbs can't get wet. For example lower limbs are needed for balance/mobility and upper limbs are needed for shampooing, etc. One parent described installing a shower seat for ease.

Whilst 1 child and 2 parents described similar difficulties for swimming, one young adult described the usefulness of their swim limb. The Bristol workshop also highlighted that not al families know what equipment their child is entitled to, such as the swim limbs.

Customisation

Whilst aesthetic customisations are described positively by many participants ( 4 children, 1 young adult, 2 parents and the 3 families at the Bristol workshop], functional customisations were occasionally described as a necessity (i.e. needing to alter the functionality of the limb at home by shaving down areas of the socket that rub after the appointment) or missing in the stard as is the model for glasses provision).

Aesthetic

There appear to be mixed opinions from parents between disliking the look/feel of a prosthetic and embracing the possibilities for customisation. This is also mirrored in the children's speech bubbles at one workshop - some describe an 'ideal' leg as being 'realistic', whereas some like being able to change the colours etc.

Early years development

This was a concern for parents of children with both upper and lower limb prosthetics. Although one parents described his daughter as being at 'top of her ability' by being introduced to her prosthetic leg at a very early age, parents of children with upper limb prosthetics described difficulties in clapping, crawling, or even just getting the child to wear it. 
Confidence

Corstandably, several participants mentioned how they disliked people staring and/or askin questions ( 5 children, 3 parents). 0 n the other hand, other participants described humour as a Deful in combatting bullying and as important for

Stump

A child or young adult's stump is mostly discussed in terms of being hot/sweaty/needing washing (see 'common difficulties' below).

Information for parents

Both workshops (Bristol and Stanmore) highlighted a desire to have been given more information, on conditions and treatment options, in a timely manner. Some parents also decribed the importance of not being forced into a decision.

\subsection{Emergent themes}

\begin{tabular}{|c|c|c|c|}
\hline \\
\hline \multicolumn{4}{|l|}{$\begin{array}{l}\text { Emergent themes } \\
\text { \& Name }\end{array}$} \\
\hline O Individual, interesting points & 14 & 25 & \\
\hline Walking and running & 16 & 23 & \\
\hline School & 14 & 16 & \\
\hline Flay with friends & 14 & 15 & \\
\hline Networking & 6 & 13 & \\
\hline Like running blade, it's last & 5 & 10 & \\
\hline Positive mindset & 5 & 10 & \\
\hline Want to run faster or better & 7 & 9 & \\
\hline OTreatment decisions & 4 & 7 & \\
\hline O Children & 2 & 2 & \\
\hline O Parents & 2 & 2 & \\
\hline Many limbs & 5 & 5 & \\
\hline Planning ahead & 4 & 5 & \\
\hline O Parental difificulties & 2 & 2 & \\
\hline Common difficulties & 0 & 0 & \\
\hline . Hot and or sweaty & 9 & 11 & \\
\hline Pain [Sore, rubs] & 7 & 10 & \\
\hline Showering & 4 & 5 & \\
\hline Getting used to new limb & 4 & 5 & \\
\hline Heawy & 3 & 4 & \\
\hline Sores & 3 & 4 & \\
\hline Inclines & 2 & 2 & \\
\hline Itching & 1 & 2 & \\
\hline Long sitting or space to sit & 1 & 1 & \\
\hline
\end{tabular}

Fig. 6: A screenshot of the NVivo software summary of the Emergent Themes, showing how many data sources mentioned each theme, and how frequently.

Each theme shown in the summary above will now be described in further detail, however it should be considered that some of these themes reinforce those established on the Analysis Day.

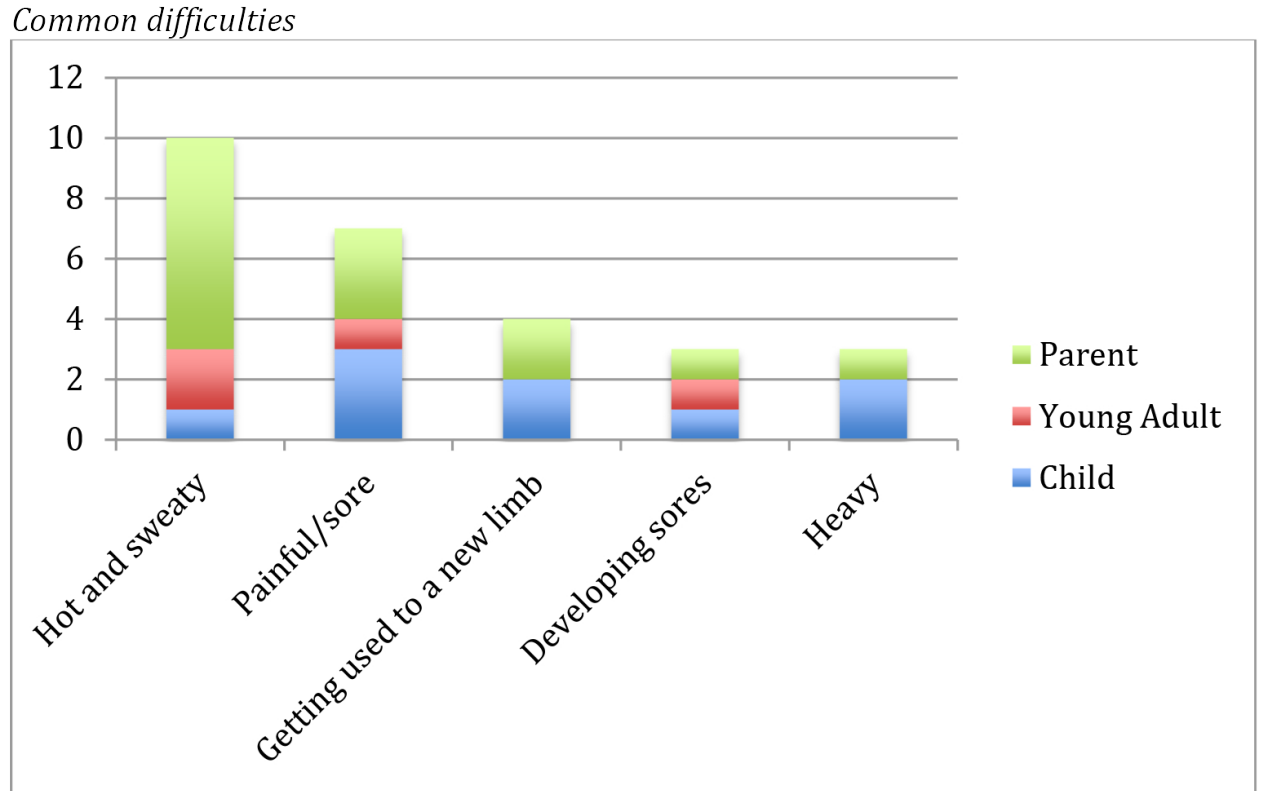

Fig. 7: A summary of the most common difficulties described by children, young adults and parents concerning the interface between the stump and prosthetic limb.

Here some of the issues relating to why children or young adults sometime require time off their prosthetic limb are given more detail, where heat and sweat is the most common reason identified.

Walking and Running

It isn't surprising that this was one of the most frequent codes in responses from families with lower limb prosthetics, but interestingly it is often described as being both enabled and limited by the prosthetic (many children want to be able to walk further or to run faster, to play with their friends and for sports).

Playing with friends

As with 'walking and running' above, playing with friends is a clear priority and also described as being enabled and limited by the prosthetic. This is in terms of physical activity and also in terms of other children asking questions about their limb. Indeed, children in the surveys and in the Bristol workshop were very enthusiastic about their blade limbs, as they allow them to run very fast and keep up with their friends.

Schools

As well as lamenting the time needed out of school for appointments or surgeries, etc.

participants also described the various ways schools work to include and support children with prosthetics (i.e. specialised chairs or giving them a pass to leave classes 5 minutes early to avoid the rush)

Networking

There was a strong desire from parents for their children to meet others of a similar age with a prosthetic limb, and also to meet other parents who are going through similar journeys. Interestingly, this was not mentioned in the children's surveys, although one young adult described wanting to meet more people with the same condition as herself (note, not just someone who uses a similar a prosthetic limb).

Positive Mindset

Although not necessarily a 'need', it is worth noting that many of the children's advice bubbles at Stanmore and Bristol were words of encouragement that anything can be achieved. Some parents in the workshop and surveys have described their amazement at their children's ability to get involved, with one stepfather saying this mindset would be useful to teach others. 


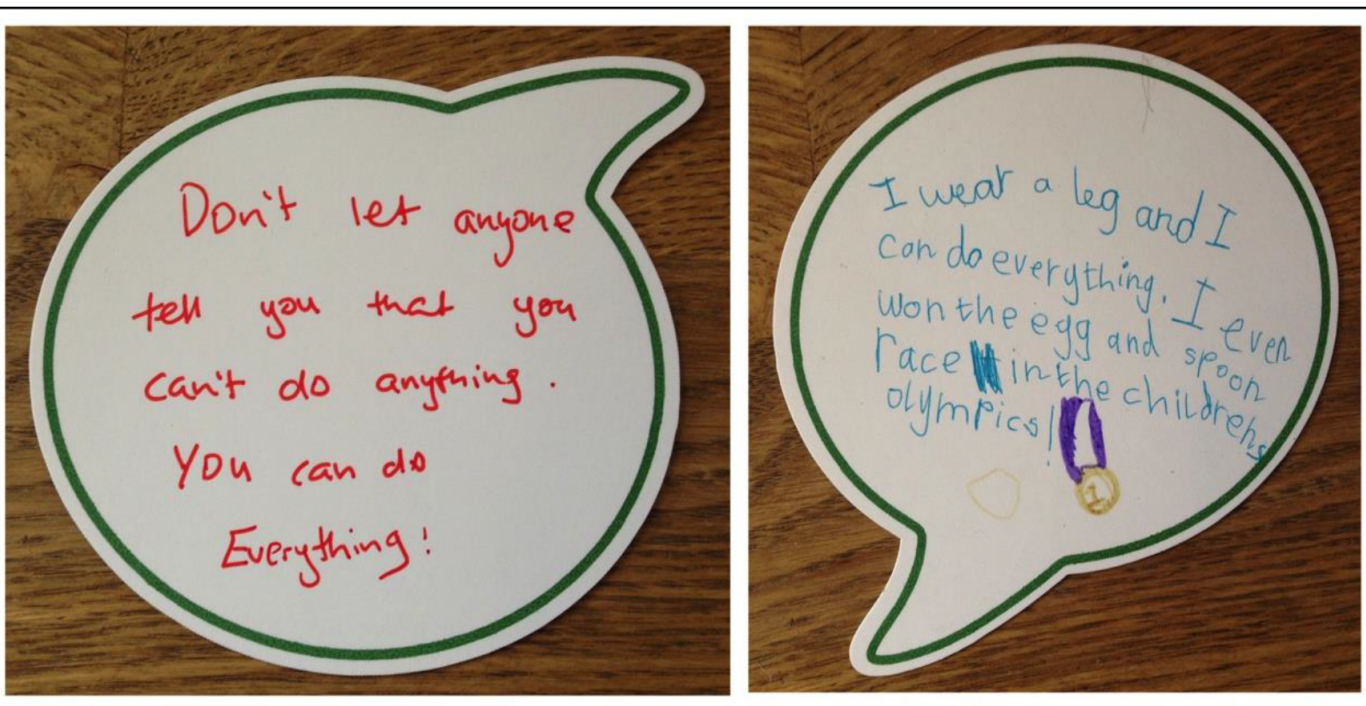

Fig. 8: Children's encouragement for others using prosthetic limbs.

3.3 Delayed responses

thodology section of this report, some survey responses continued to be rearned the scope of which is summarised in the following table:

\begin{tabular}{|c|c|c|c|}
\hline Participant & $\begin{array}{c}\text { Type of } \\
\text { prosthetic }\end{array}$ & Number & Subtotal \\
\hline \multirow{2}{*}{ Child } & Upper limb & 1 & \multirow{2}{*}{2} \\
\cline { 2 - 4 } & Lower limb & 1 & \multirow{2}{*}{1} \\
\hline \multirow{2}{*}{ Young adult } & Upper limb & 1 & \\
\cline { 2 - 3 } & Lower limb & 0 & \multirow{2}{*}{5} \\
\hline \multirow{2}{*}{ Parent } & Upper limb & 2 & 8 \\
\cline { 2 - 4 } & Lower limb & 3 & \\
\hline & & & \\
\hline
\end{tabular}

Although these reports were not included in the NVivo data analysis, it was found that the

responses largely discussed and corroborated some of the main themes above, such as:

- Heat and sweat in the socket, plus problems associated with this such as pain, rubbing,

skin issues (6 parents, 2 children and 1 young adult)

The need to take time off the limb because of these heat- and sweat-related issues (1

parent and 1 young adult)

The limb can be too heavy ( 1 child, 1 young adult, 1 parent)

Children like the ability to customise their prosthetic, and can be proud to show this off to their friends (3 parents)

Children and young adults need help with showering/bathing ( 1 child, 1 young adult and 1 parent), as well as other activities of daily living - particular children using upper limb
prosthetics ( 2 parents and 1 young adult).

\section{Conclusion}

Given the range of data sources and personal, conversational nature of the responses, it is

perhaps unsurprising that a vast range of topics have been raised. As such, the research te

including concerns over the interface between the stump and prosthesis; activities of daily living. the prosthetic service journey; and how to "let kids be kids.'

4.1 Interface

Given that $41 \%$ of the surveys returned to us specifically mentioned heat and sweat at the interface between their stump and prosthetic as a problem, this is one of the key areas of need we suggest to take forward. Issues related to this (such as pain or developing sores) have been discussed above and often lead to needing time with the prosthetic limb off, to allow it to rest or cool down, as a matter of routine. For children or young adults, this means they may need to chose which activities to spend their time with their prosthetic on, or may need to factor in this 'downtime' if they wish to take part in evening activities after a day at school.

Additionally, the issues of heat and sweat may also lead to secondary complications (such as eczema), resulting in additional time off school seeing other professionals (such as a dermatologist) or restricted activity when the limb cannot be worn.

Three separate parent surveys also described how this 'downtime' puts them in the role of thei child's 'runner', collecting the items their child needs through the evening or even carrying younger children around the house.

As such, it is suggested that improvements in prosthetic technology that help to reduce this issue of heat and sweat around the stump could have far reaching effects, including overall health, friends, on holiday, etc), reduced time off school and reduced demands on parents.

\subsection{Activities of daily living}

Difficulties in washing were raised in a significant proportion of the survey responses and also verbally during workshop activities. For children or young adults with lower limb prosthetics, this manifested in terms of getting in and out of the shower or bath, as their prosthetics were not waterproof or suitable for this activity. For children or young adults with upper limb prosthetics, showening and other activities of daily living (such as washing their hair, getting dressed, cutting food, putting toothpaste on a brush, using the toilet, etc) can require assistance from parents.

This is perhaps an area to prioritise for teenagers and young adults (who use either upper or lower limbs prosthetics), who may feel more strongly about requiring this care. Other related activities, whilst not is child reaches puberty begins menstruating).

\subsection{Service journey}

the surveys and workshops considered the service provision as well as the prosthetics themselves, and as such a consideration of the prosthetics service as a journey is the third proposed area of interest.

Whilst some participants gave general comments about their experiences visiting the hospitals (i.e. liking the children's play areas or disliking long waiting times), others expressed a wish for more information from the beginning of their journey in the prosthetics service, on the child's condition and/or all of the treatment options available (as appropriate). Further discussion of this during one workshop suggested that a record of the service journey could be used to look back (i.e. to refer to and/or share with other healthcare professionals, or as a source of encouragement 'to see how far you've come') but also to look forward (i.e. to see what decisions need to be made, and when).

Several sources suggest that there may be a lack of provision for children entering the prosthetics service from birth or at a very early age. Whilst some parents describe needing some form of prosthetic earlier than they received it (for example, one parent made their ow rudimentary wooden leg for their child who seemed ready to start walking), others describe difficulties in encouraging their child to wear the prosthetic provided for them (see below). 
'She find everything harder with it, that's part of the battle with getting her to use it. At present it's more of a hindrance than a help... Alice's prosthetics isn't really a part of our everyday lives. It lives in her bedroom or play room and she "plays" with it more than actively wears it when were out and about or at nursery.' Mother of a young child who uses an upper limb prosthetic.

The knock-on effects of how the prosthetic limb may or may not affect a child's early years development appears to be one key area of conflict between a prosthetist and a child's parents. Whilst the healthcare professional may be most concer a chout the child's posture, parents min truggle to 'enforce' the use of the limb and pers simply wish it to be lighter so the child will use it more. As shown in the exam prosthetic provision, where children may have already adapted to some extent prior to using prosthetic limb.

In summary, then, considerations of how to help children and their families see and engage in the service journey from an early stage, in terms of knowledge (i.e. through providing further information or mapping out the service journey) or in day-to-day life (i.e. helping parents to the years development in the best way for their child) is a further area of interest proposed by this study.

\section{4 'Let kids be kids'}

differences between adult and child prosthetic provision, the differences references were also highlighted during our review, which can be summarised

- The wish to reduce the time taken out of school by hospital appointments was raised by children and parents, as well as the ability to play with their friends (during school tim and out of it).

- The ability to customise the aesthetics of their prosthetics was important to many participants.

- The need to plan ahead (i.e. bringing the right equipment and accessories for different activities) and consider the potential consequences of activities (i.e. the need to include periods of rest, as described above) also suggests a sense of reduced spontaneity for children growing up with prosthetic limbs. This can be considered an important part of playing and socialising with friends, and whilst it is a less tangible or measurable effect of prosthetic use, it arguably warrants serious consideration moving forward.

As such, this area of interest suggests that it is not only the functional, practical ways in which world as they grow, but also the social and unplanned elements of their play and development.

On a less serious note, the team in Sheffield were pleasantly surprised by the role of humour in the lives of some of the participants involved in the review, which may not have emerged in an adult context. During one visit observing and conversing with two children and their families in their routine hospital appointments, the whole group was brought together by discussing and laughing about the tricks and jokes the children (two boys aged 13 and 10) had played with their prosthetic legs. This topic also resonated with other participants in workshops and was raised independently in survey responses, as well as the value of humour in accepting the limb more generally.

'We have always been open about Mary's limb which has resulted in a lot of humour! Mary 'owns' her disability in a positive way.' A mother of a young adult using a lower limb prosthetic.
So, whilst the topic of healthcare provision is inevitably a serious issue, 'letting kids be kids' may also involve leaving room for children to take ownership of their limb in fun ways.

\section{Limitations}

It should be acknowledged that the parents and children who chose to respond to surveys or attend workshops may be more proactive in their healthcare, and as such may bring a particular bias to the data described above.

Additionally, the team in Sheffield feel that there may be a discrepancy in opinions between the children, young adults and parents of children who have been born requiring a prosthetic, and those who have entered the prosthetics service later in life. This difference in perspective and/or needs may need to be considered as this project continues.

Finally, some of the themes described above may be more prominent than suggested by the number of responses attributed to them, as some parents chose to complete a survey on behalf of describing the experiences of very young children whose opinions cannot yet be sought. 
Child Activity Prostheses - R\&D Priorities Report The Providers Perspectives

Peter Jarritt - NIHR Health Technology Cooperative - Brain Injury, Dept Neurosciences, Cambridge University, Cambridge

Stephen Kirker - Consultant Rehabilitation Medicine, Cambridge University Hospitals, Cambridge

\section{Executive Summary}

This report summarises the findings of a series of surveys designed to ascertain: -

1. The number of children currently registered with prosthetic service providers, the types of prosthesis currently used and the interest and demand for new or additional activity prostheses.

2. The unmet needs of the patient/service provider from the service provider perspective.

3. The R\&D priorities arising from the provision of activity prostheses to children

The following are the key findings of the project: -

1. All responding centres had informed their patient base of the opportunity to receive a sports/activity limb.

2. There are potentially 500 ( $64 \%$ of 2016 census) children in England that have an interest in or would benefit from a lower limb activity prosthesis

3. There are potentially 442 (36\% of 2016 census) children in England that have an interest in or would benefit from an upper limb activity prosthesis/fitment.

\section{R\&D Priorities}

4. Adaptive, flexible and self tuning prostheses that respond to growth

5. Impact and Outcome Studies for those using activity prostheses on well being and residual tissue health.

6. Improved fitting and adaptive socket designs.

7. Improved articulating joints and new material technologies.

8. Age, weight and gender matched prostheses especially ensuring prosthesis weights are appropriate.

9. Cosmetics and personalization of prostheses to enhance use and uptake.

10. Options and limitations for bespoke devices. Safety and regulatory issues.

11. National monitoring of prosthesis usage and clinical outcomes to monitor and optimize service delivery.

12. Impact of Gait Analysis on prosthesis use and management as a tool to minimize complications and fitting/review times.

Communication with carers remains a vital issue to ensure that they are aware of the opportunities available to children with limb loss and for service configurations that minimize the disruption to both patient and carer activities such as work and schooling.
A national patient level monitoring programme, as has been developed for some implanted prosthetic jonts is required

\section{Introduction:}

The NIHR Health Technology Cooperative in Brain Injury in conjunction with Dr. Stephen Kirker were approached by Devices for Dignity to undertake a review of service provider $R \& D$ priorities to support the Department of Health initiative for the supply and development of activity prostheses for children.

At the outset, the project group felt that the emphasis of the project should be on the factors that affect the provision and development of activity prostheses rather than focus solely on one element such as 'running blades'. It could not be assumed that all children would require a particular prosthesis. An encouragement to an active lifestyle would require a

multidisciplinary and multi-institutional approach to ensure that children were provided with appropriate opportunities to experiment, receive practical support and tailored education and training in the use of a prosthesis. Furthermore, the impact of the introduction of increased levels of activity on residual limbs and associated tissues remain unknown, together with the ensuing impact on service providers. It was recognized that certain activities would need additional equipment such as specialist wheelchairs. This issue was not specifically addressed and further work is required to understand the barriers to sports and/or physical activities for disabled children. Because of these considerations, the project took a very broad view of the unmet needs that could and should be considered in relation to activity prostheses for children.

This short project was aimed at understanding the unmet needs in the delivery of activity prostheses to children from the perspective of the rehabilitation provider community. This is a diverse, multi-disciplinary community comprising clinicians, allied health professionals, scientists and engineers, service managers and administrators.

The project was not principally focussed at service delivery issues but rather at issues of utility and effectiveness of the prostheses available and provided. In understanding the unmet needs these have been analysed and reconstructed as priorities for research, development and innovation. However, an effective prioritization process requires a knowledge of demand and the relationship of development initiatives on service delivery.

Limited data is available about the number of children with limb loss, their level of limb loss and their age distribution but there is no information about demand for prostheses to support sporting and exercise activities. A review of service providers was undertaken by the specialist Services Commissioners in May 2016

This survey sought to ascertain the number of paediatric limb loss patients registered in England tabulated by prosthetic centre and age range. (See appendix 1). Data was available from 34 centres and identified a total of 2016 children with prostheses. The distribution with age was reported as follows:- $0-5$ years, 382; 6-10 years, 488; 11-15 years, 550; 16-19 years, 596. Of these children $788(39 \%)$ were identified as lower limb loss of which $587(75 \%)$ were identified as single limb and $201(25 \%)$ as double limb.

This survey did not request data about the type of prosthesis provided or requested or the likelihood of demand for limbs to support activities other than daily living. It does, however provide an insight into the potential maximum demand for prostheses in this age group. 
In the light of the limitations in this data it was decided to try and undertake a review of demand alongside the analysis of unmet needs in the service.

This report details the methodology used in undertaking the review, it seeks to prioritize the R\&D and innovation opportunities and to support a wider analysis of existing academic and industrial activiting

\section{Methodology:}

The project considered three streams

4. The determination of the number of children currently registered with prosthesis service providers, the types of prosthesis currently used and the clinicians opinion about whether the child would benefit from, and expressed interest in, a new sports or activity prosthesis.

5. A survey of staff groups in the provider space to understand unmet needs from their perspective

6. The R\&D priorities arising from the provision of activity prostheses to children.

\section{Potential Demand}

The determination of the size of the client group and their potential demand for services was conducted through a direct mailing to the available 'Service Manager Network' and doctors working in amputee rehabilitation. The circulation was cross checked against the directory available from the Limbless Association at (http://www.limbless-

association.org/index.php/directory/nhs-disabled-services-centres ) It was known that many of the service providers are owned or linked to private sector providers who are contracted to provide services to the NHS. To facilitate the return of data the commercial partners were contacted directly to ensure patient information could be extracted from databases as rapidly as possible and in a standardized format. The process adopted is shown in figure 1.

This element of the project was registered as a 'service evaluation' at Cambridge University Hospitals so that the data could be published as necessary.

The data request form is attached in Appendix 2. Whilst the process specified required the service providers to work with patient identifiable data, the final returned datasets were all anonymized and were analysed to provide age orouped data and information regarding existing prostheses.

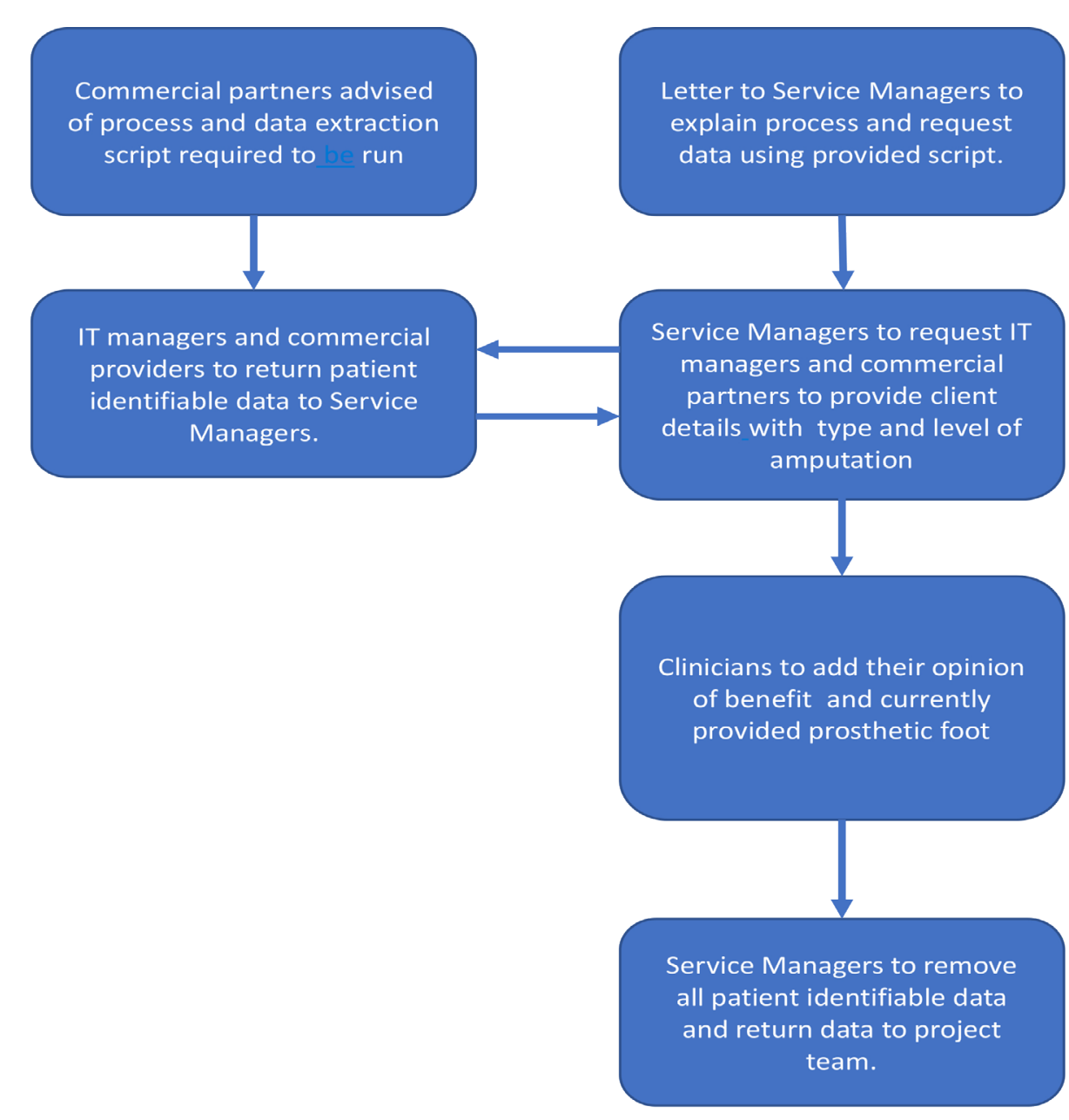

Figure 1 Service User data acquisition process.

The numerical data was supplemented with questions to the service managers in relation to Their response to the $\mathrm{DH}$ initiative to provide activity prostheses to children. Centres were specifically asked if they had communicated with their client group, what the response levels had been, what specific prostheses they made available and whether they imposed any limitations. The centres were finally asked to indicate any resource limitations which would

Unmet Needs Assessment 
The surveys of staff groups were conducted using three surveys managed via Survey Monkey. Initially the surveys were targeted at prosthetic service managers, consultants in rehabilitation medicine and medical rehabilitation specialists and a smaller survey circulated to the rehabilitation engineering community via a professional network. All recipients of the
survey details were asked to circulate further to their own networks and colleagues. However, the project oversight group felt that this circulation potentially excluded a large element of the workforce and that a further survey should be developed and circulated to the allied the workforce and that a further survey should be developed and circulated to the allied Amputee Rehabilitation (BACPAR) and the British Association of Prosthetists and Orthotists (BAPO) The surveys were referenced on the project website

(http://devicesfordignity.org.uk/starworks cp/) and input sought from the widest possible community. It is estimated that the survey details were circulated to more than 4600 individuals

To gain the widest possible participation, the collection of the personal details of the respondents was optional although the professional group of the respondent was required. The surveys remained accessible for 24 weeks.

All three surveys asked questions directed at ascertaining unmet needs and priorities for research and development. To segment the responses questions were asked to elicit the unme needs as voiced by the parents and carers of patients, service delivery issues that impacted on the provision of activity limbs and the key priorities for research and development.

Respondents were given the option of 4 priorities in each category.

Some more specific questions were asked of the service manager group regarding the curren status of the service provided to children and service delivery issues that impacted on or limited the quality of the service provided. These questions inchuded details of the wider integration of prosthetic services to sports clubs, schools and other organisations providing activities for children.

\section{Findings: quantitative and qualitative}

\section{Service Delivery and Potential Demand}

Despite repeated efforts the collection of a comprehensive dataset for paediatric amputees, their current limb prescription and potential for an activity limb proved to be impossible with the resources available to the service providers. Returns were received from 11 of the 34 2016 survey. The current survey recived single patient level data from 674 children for the 2016 survey. The cure in data returns. (One potential explanation is that the 2016 data returned data about number of limbs affected (ather than individual patients). Lower limb loss was reported in $44 \%$ of the patients returned compared with $39 \%$ in the May 2016 survey. The data are summarized in

\begin{tabular}{|c|c|c|c|c|}
\hline Age Range & Blank Returns & $\begin{array}{l}\text { No Interest or } \\
\text { benefit }\end{array}$ & $\begin{array}{l}\text { Potential } \\
\text { Interest }\end{array}$ & $\begin{array}{l}\text { Already } \\
\text { Supplied }\end{array}$ \\
\hline & & & & \\
\hline $\mathbf{0 - 4 . 9}$ & 11 & 40 & 7 & 2 \\
\hline $\mathbf{5 - 9 . 9}$ & 14 & 26 & 31 & 3 \\
\hline
\end{tabular}

\begin{tabular}{|c|c|c|c|c|}
\hline $\mathbf{1 0 - 1 4 . 9}$ & $\mathbf{1 2}$ & $\mathbf{3 8}$ & $\mathbf{2 4}$ & $\mathbf{9}$ \\
\hline $\mathbf{1 5 - 1 8}$ & $\mathbf{1 8}$ & $\mathbf{2 7}$ & $\mathbf{3 4}$ & $\mathbf{5}$ \\
\hline
\end{tabular}

interest/applicability of activity prostheses by age range.

\begin{tabular}{|c|c|c|l|c|}
\hline Age Range & Blank Returns & $\begin{array}{l}\text { No Interest or } \\
\text { benefit }\end{array}$ & $\begin{array}{l}\text { Potential } \\
\text { Interest }\end{array}$ & $\begin{array}{l}\text { Already } \\
\text { Supplied }\end{array}$ \\
\hline & & & & \\
\hline $\mathbf{0 - 4 . 9}$ & 14 & 55 & 5 & 2 \\
\hline $\mathbf{5 - 9 . 9}$ & 18 & 51 & 26 & 2 \\
\hline $10-14.9$ & 19 & 52 & 42 & 1 \\
\hline $15-18$ & 11 & 53 & 26 & 1 \\
\hline
\end{tabular}

interest/applicability of activity prostheses by age range.

For the returning centres, the number of activity limbs currently issued for lower limb loss is 19. Where the reply was not left blank, a current interest/potential was reported for $42 \%$ of the amputees leaving $58 \%$ for whom there was considered no interest or potential for benefit from an activity limb. There was a wide range in the provision of higher activity components from existing budgets between centres: one large centre only supplied Seattle Childs Play feet, except for a rare exception, whereas others reported children having a range of high activity feet e.g. Ossur AllPro, Cheetah Xplore, College Park Truper, Blatchfords Echelon, Elation, Elite and Esprit feet, OttoBock Trias, Rush, Proflex Xc and a variety of Flexfoot models. Hence children at some centres may have more to gain from enhanced funding than at others, where they may already have access to high activity feet suitable for everyday walking as well as running.

For the patients with upper limb loss, only 1 centre returned significant data regarding supplying attachments for activities/sports with a total of 6 devices being supplied. Where the reply was not left blank, a current interest/potential was reported for $32 \%$ with $68 \%$ reported as no interest or potential for use. Of the 99 upper limb amputees thought to benefit from a sports prosthesis, 25 from one centre wanted a bicycling arm or appliance. It should be noted that many NHS centres have routinely supplied these for many years, from existing budgets.

Several reasons were given for the lack of interest/potential benefit, including the age of the patient and the individuals personal interest in using a prosthesis, hever, the returns afe not comprehensive and cannot provide ad variability in the proportion ind a a ing an interst in activity limbs between centres and this vauld suct in the would suggest different levels of engagement between provider centres. In general, very few

Extrapolating this return data to the population of patients identified for England in 2016 the potential demand for sports/activity limbs would be:-

$$
\begin{array}{ll}
\text { Upper Limb } & 392 \\
\text { Lower Limb } & 330
\end{array}
$$


This data does not reflect whether the patients have single, double or multiple limb loss. These numbers do not reflect the total number of running blades or prosthetic attachments that will be required to support the activity interests of the patients but it does provide a baseline against which uptake can be measured.

\section{Unmet Needs Assessment and R\&D Priorities}

As of the date of this report, there have been a total of 67 full and partial responses to the surveys. The distribution of responses by profession is shown in figure 2 . Whilst this a relatively limited response from such a wide circulation there is significant agreement among respondents. As such this is believed to be a representative response for a much wider group. Importantly there is limited overlap with industrial and academic stakeholders among the responders.

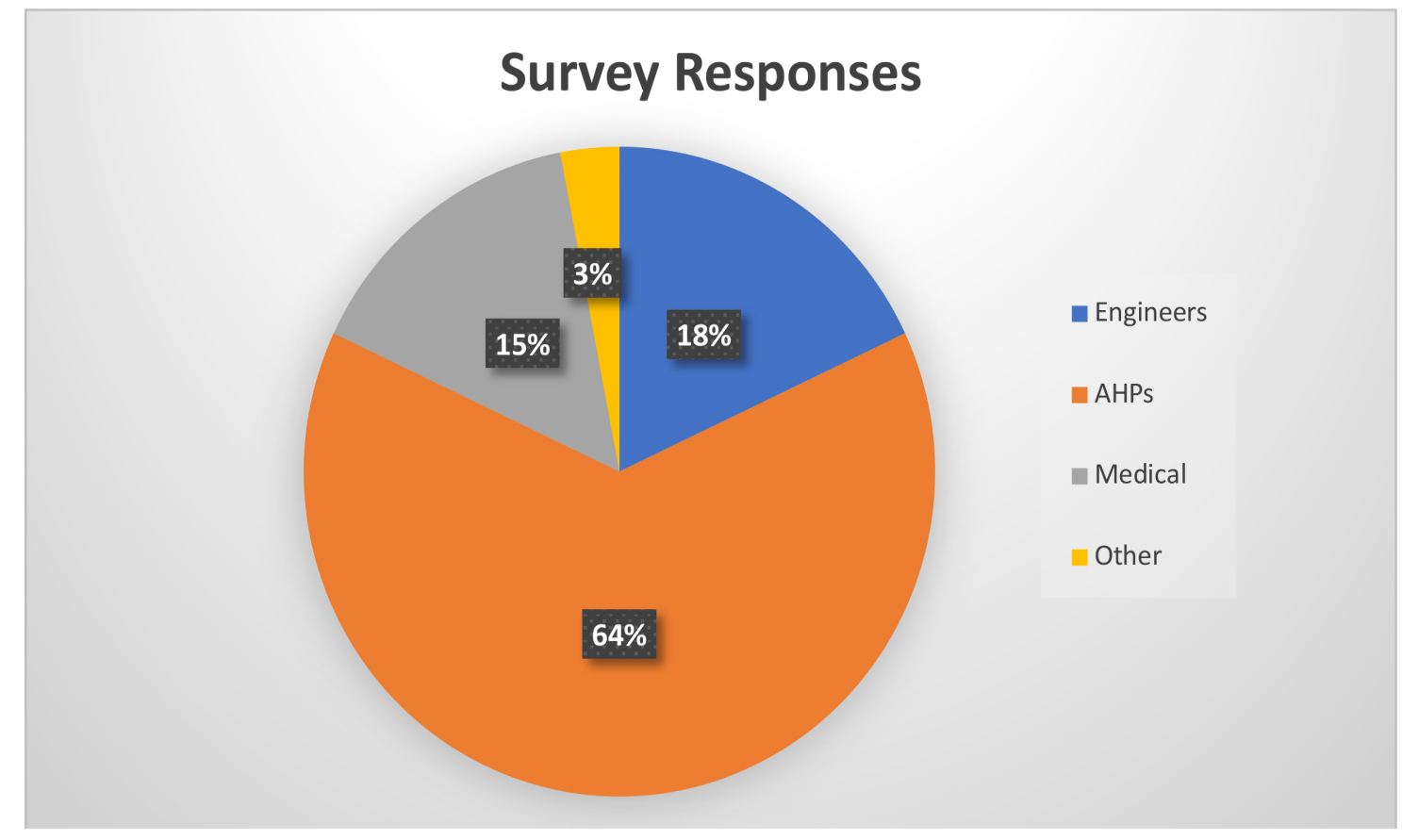

Figure 2 Survey responses by Professional Group

\section{Key issues raised by parents and carers.}

The surveys initially asked what were the 4 key issues raised by parents and carers with the service providers. Whilst this will not necessarily reflect the priorities of parents and carers does provide a perspective on what service providers believe are the key issues for these stakeholders.

A summary of the responses is shown in figure 3 .

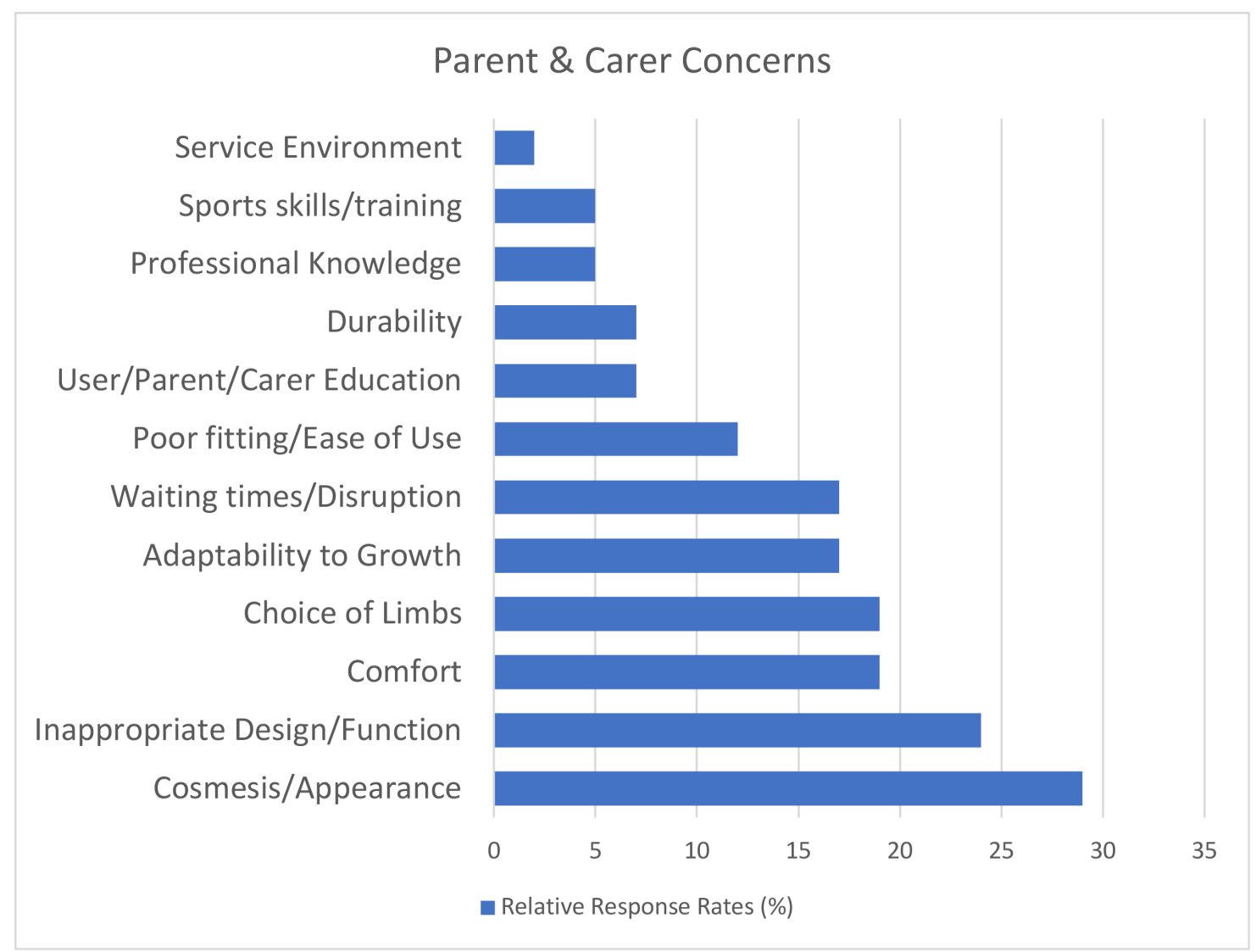

Figure 3 Parent \& Carer issues from provider perspective.

Whilst such a summary is helpful is visualizing the concerns of parents and carers hidden within the categories is more specific detail as to the key issues. The range of

componentry/technology that is available to support growth is a fundamental issue. There are limitations depending on the site of an amputation and the required build length. There are limitations imposed by the size of the components as users progress through childhood and

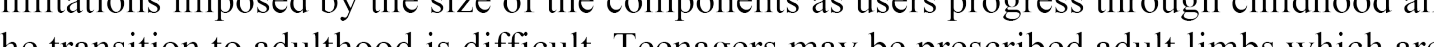
the transition inapproprately heave difficulties with choice of limb due to limits imposed in construction. There is a clear request for more customized componentry and prostheses perhaps supplemented by 3-D printing as a manufacturing methodology. This is particularly relevant for upper limb and hand prostheses.

\section{Challenges to Service Provision in delivery of activity limbs}

The service providers were asked to identify 4 key issues that would need to be addressed within the service delivery model to facilitate a quality activity limb service.

A summary of the responses is shown in figure 4 
Challenges to Activity Prosthesis Service Delivery

Validated outcome measures to evaluate

service

Lack of sports facilities and integration with schools and clubs

Unknown impact on child and residual imb of increased activities

Learning and training for prescribers and users

Better integration with sports facilities/external agencies

Information resources regarding product availability

mproved information for parents and teachers

Transition from child to adult and continuity of provision.

Increased resources for production administration, appointments, support

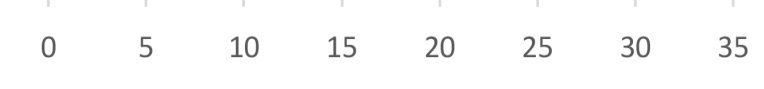

- Relative Response Rates (\%)

Figure 4 Challenges to Service Provision of Activity Limbs

Whilst the overriding concern in providing this service was resources both in respect to time and staff to deliver the increased user contact time there were strong concerns in relation to the required integration with schools and sports clubs and the management of responsibilities in relation to the use of an activity prosthesis and the impact of increased activity on user/residual limb welfare. There will be a need to increase physiotherapy and occupational therapy resources in the community to deal with some of these issues. There is limited knowledge in the clinical workforce of working with children to develop interests in sports and other activities and it is unclear if sports clubs and other institutions can provide this resource.

\section{Enablers to Improved Access and Service Delivery}

As well as research and development priorities there will be issues that have an immediate impact on service delivery. If provided these would enable the improved delivery of services in a much shorter time frame than a $R \& D$ project.

A summary of the responses is shown in figure 5 .

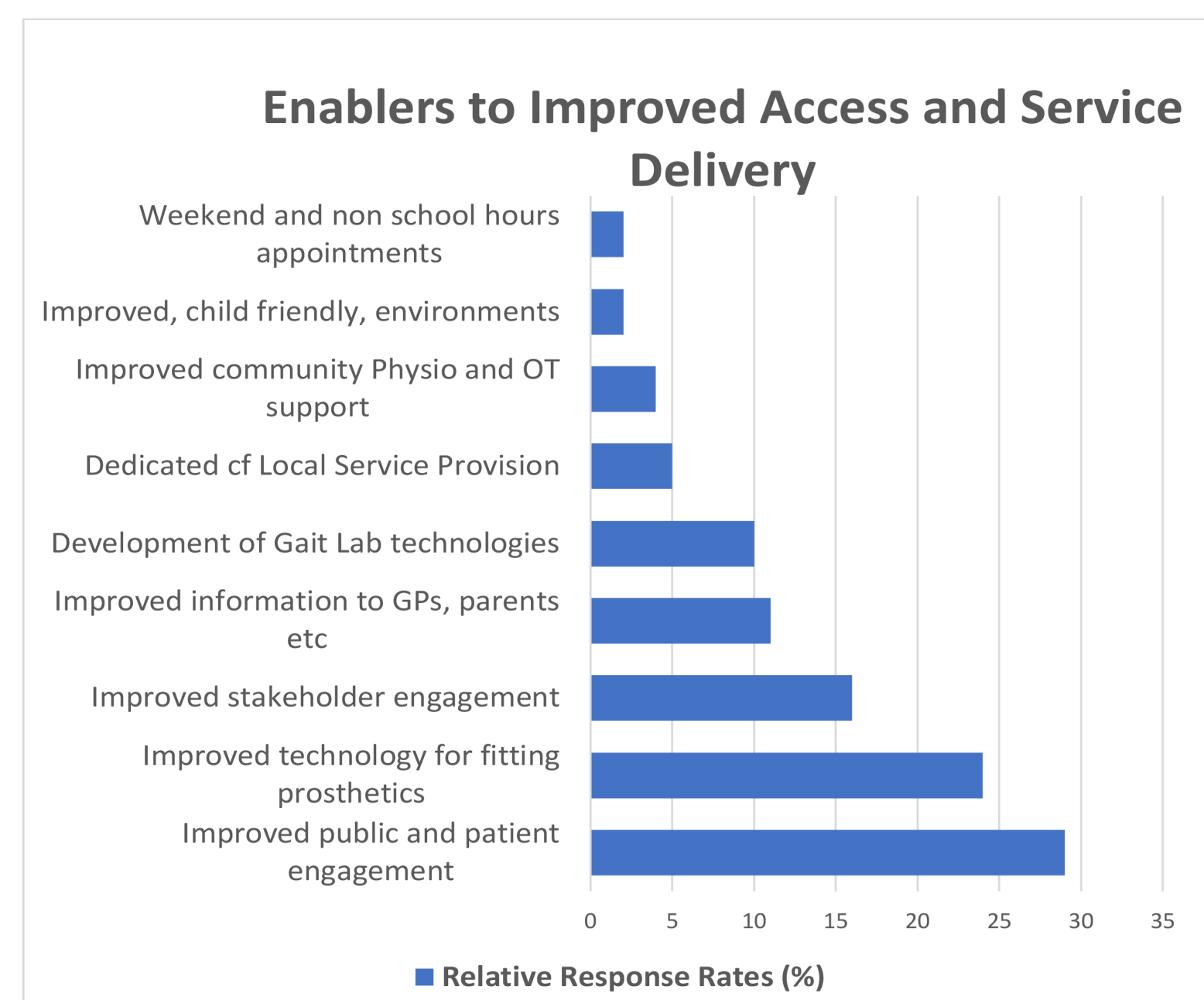

Figure 5 Enablers to Improved Access and Service Delivery

A summary of the responses to this question indicates that key enablers are improved patient and public engagement as well as improved technology offerings. The need for better communication between providers, researchers and manufacturers was also key to identifying and implementing needs of the parents and users.

There was an overarching concern to enhance quality and outcomes through the rigorous evaluation of technologies, developing an understanding of national needs and best practice through the dissemination of structured data and the development of national guidelines. Improvements in technologies was paramount and these have been reflected in the priorities for research and development.

There was some concern over the way in which services were delivered both in terms of the environment and the need to avoid disruption to schooling by providing out of school hours 
appointments. This is also related to decisions regarding centralized specialist centres compared with more local provision and the resourcing of community based Physiotherapy and Occupational Therapy support to facilitate more local services.

\section{Research and Development Priorities}

All surveys asked respondents to identify 4 key priorities for research and development projects to inform future research calls to support activity prostheses for children. Although the survey focussed on children many of the priorities are generic and applicable to all age groups.

A summary of the key responses is given in figure 6 .

\section{Research \& Development Priorities}

Impact of Gait Analysis on prosthetic use and management

National monitoring of prosthetic usage and clinical outcomes.

Options and limitations for bespoke

$$
\text { devices }
$$

Cosmetics and personalization of prosthetics

Age, weight and sex matched prosthetics

mproved articulating and new material technologies

mproved fitting and adaptive socket designs.

Impact and Outcome Studies

Adaptive, flexible and self tuning technologies

$$
\text { - Relative Response Rate (\%) }
$$

Figure 6 Key Research and Development Categories

A more in depth analysis of these topics provides a richer context for R\&D in activity prostheses for children.

\section{Adaptive, flexible and self tuning technologies}

The issue of growth throughout childhood and the provision of limbs that would effectively 'grow' with the user were of paramount concern. Limb components need to be adjustable rather than requiring complete replacement alternatively more modular systems should be developed that would allow components to be re-used to avoid the 'single patient use' stipulations. There is a known problem in relation to the level of amputation and the space remaining to construct and fit prosthetic components. There is a clear need for 'low build height' prostheses for younger children.

Where children have multiple prostheses optimized for particular activities there needs to be improved standardization in connector/adaptor technology to allow a wider selection and choice of prosthesis. Multiple manufacturers do not share a standard connector thus limiting choice.

The goal of a self-adjusting/tuning prosthesis is regarded as an important end point.

\section{Impact and Outcome Studie}

The potential for improved access to activity prostheses was matched by a call to undertake impact and outcome studies from several perspectives. These included physical, emotional, physiological and psycho-social benefits/dis-benefits as well developmental physiology and associated body image. It was felt that the psychological and general health impact of sports participation with and without a sports prosthesis should be analysed including a review of the existing older amputees engaged in activities.

The lack of understanding of the biomechanical properties of children's limbs and matched prostheses was highlighted. The growing skeleton has significantly different properties than an adult skeleton. The impact of this in relation to activity prostheses requires significantly more research. This needs to be linked to an improved understanding of how children move and utilize residual limbs as part of their developmental process. Studies should be initiated to understand the long-term effects of prosthesis design (see sect should be initiated to un National monitoring).

\section{Improved fitting and adaptive socket designs.}

The method of manufacturing and fitting sockets remains a key issue especially where growth is a major factor over short timescales. Adjustable and multi-layer sockets were suggested. Lean and inexpensive manufacturing methods are required. The properties of liners in relations to perspiration in high activity environments for children were seen to be of concern. Whilst predominantly focussed on lower limb loss the problems of upper limb prostheses should not be overlooked. Some respondents pointed out that upper limb prostheses comprised two thirds of the problem and then methods of suspension should be included in the development process. Overall it was felt that existing technologies had not been designed for children.

\section{Improved articulating joints and new material technologies}


Improvements in articulating joints is a continuing priority. Issues of robustness of current designs when used by children is a concern. It must be pointed out that in general durability of products in the child environment is an overarching problem. This is linked to the introduction of new material for manufacture that offer reduced weight of components, enhanced durability and the production of more waterproof prostheses. The incorporation of inexpensive electronics into prosthesis manufacture was also requested. Most emphasis was placed on the introduction of microprocessor adapted knees and improved ankle joints. Improving ergonomic design is a priority.

\section{Age, weight and gender matched prostheses}

The requirements of the user change throughout childhood especially through peer pressure and the transition from childhood to adulthood. At present, there is little consideration to design for specific age ranges and for male and female users. This is linked to the next requirement where enhanced opportunities for personalization is a requirement. Teenage users were seen as particularly important although the transition to an adult user is an area of on-going concern. The size and weight of the user either places limitations on available products or causes providers to use adult product ranges. The need to deliver better solutions for breast-aware and upper limb suspension systems was highlighted.

\section{Cosmetics and personalization of prostheses}

Whilst not seen as the most important aspect of prosthesis design by the provider community the need for improved cosmetic design is an important issue. The issue of size, colour, personalization and adaptability to context of use should be considered in the manufacture and supply of prostheses to children.

\section{Options and limitations for bespoke devices}

Within this category were requests to consider the role of new methods of manufacture in the delivery of bespoke and improved functionality to prostheses. 3-D printing is perceived to be a potential solution; however, issues of quality and safety of product are major concerns. Further work is needed to understand the regulatory and quality frameworks that are required to implement this technology and minimize risks. Such technology would potentially permit much more customization of prostheses and area of application suggested were in partial hand items, the introduction of more electronic control systems and expanding componentry ranges.

\section{National monitoring of prosthesis usage and clinical outcomes.}

Alongside the need for impact and outcome studies is the requirement to implement a national monitoring system. This already exists for rehabilitation in relation to major trauma in the form of the ORION database (Obex Technologies). Such tools could readily be extended to include monitoring of interventions and outcomes with the specification of some standardized outcome measures, and maintenance of a live registry of patients with limb loss attending NHS centres.

\section{Impact of Gait Analysis on prosthesis use and management}

At present the fitting and maintenance of prosthesis in adults and children is labour intensive and relies on the skills of the prosthetist. Gait laboratories are slowly being introduced in a limited number of centres. Their role in the management of multiple prostheses in the child population should be further investigated. Movement analysis will provide an understanding of the limitation of prosthesis design as well as help children maximise their abilities and fitness. They may also assist with training programmes for use of prostheses.

On a more fundamental level there is a need to understand the types of movement that children make or try to make. Children do not just move in a forward and backwards direction but will make sideways and circular movements. Movement analysis will allow this to be characterised and incorporated in prosthesis design and fitting.

\section{Conclusion: research priorities and key messages.}

This short exploratory project highlights, above all else, the lack of data regarding prosthesis service provision to children. There is no central registry of the use of prostheses and any associated issues. From the perspective of the service providers, a range of issues have bee identified both in relation to service provision and in terms of areas where improvements need to be identified through research and innovation. Nine specific areas for research activities have been identified for potential funding:-

1. Adaptive, flexible and self tuning prostheses that respond to growth

2. Impact and Outcome Studies for those using activity prostheses on well being and residual tissue health.

. Improved fitting and adaptive socket designs.

4. Improved articulating joints and new material technologies.

5. Age, weight and gender matched prostheses especially ensuring prosthesis weights are appropriate.

Cosmetics and personalization of prostheses to enhance use and uptake.

7. Options and limitations for bespoke devices. Safety and regulatory issues.

. National monitoring of prosthesis usage and clinical outcomes to monitor and optimize service delivery.

. Impact of Gait Analysis on prosthesis use and management as a tool to minimize complications and fitting/review times.

Without good baseline data it will not be possible to evaluate the potential benefit and impact assessment, including detrimental side effects, of any technological advances. The survey has identified that the number of children that could benefit from activity limb fitting is relatively dentified that the number of children that could benefit from activity limb fitting is relatively R\&D pou for population. Repristhesis already supporting the major trauma centres. 


\section{Appendix 1}

NHS England Specialist Commissioners Survey Data May 2016.

\begin{tabular}{|c|c|c|c|c|c|c|c|}
\hline \multirow[t]{2}{*}{$\begin{array}{l}\text { Prosthetic } \\
\text { Centre }\end{array}$} & \multirow{2}{*}{$\begin{array}{l}\text { Total No. } \\
\text { Of } \\
\text { Children }\end{array}$} & \multicolumn{4}{|c|}{ Age Range } & \multicolumn{2}{|c|}{$\begin{array}{c}\text { No. of Lower Limb } \\
\text { Children }\end{array}$} \\
\hline & & $0-5$ & $6-10$ & $11-15$ & 16-19 & S & Double \\
\hline Plymouth & 29 & 7 & 9 & 5 & 8 & 7 & 6 \\
\hline Hull \& EY & 5 & 0 & 3 & 1 & 1 & 3 & 3 \\
\hline Oxford & 137 & 29 & 29 & 34 & 45 & 34 & 12 \\
\hline Sussex & 43 & 11 & 13 & 10 & 9 & 16 & 2 \\
\hline Cleveland & 32 & 11 & 7 & 6 & 8 & 8 & 2 \\
\hline Nottingham & 74 & 9 & 24 & 25 & 16 & 17 & 5 \\
\hline Wolverhampton & 0 & 0 & 0 & 0 & 0 & 0 & 0 \\
\hline Leeds & 95 & 9 & 24 & 28 & 34 & 20 & 21 \\
\hline Isle of Wight & 1 & 0 & 0 & 0 & 1 & 0 & 0 \\
\hline Roehampton & 264 & 20 & 37 & 77 & 130 & 36 & 8 \\
\hline Norwich & 49 & 11 & 14 & 15 & 9 & 18 & 5 \\
\hline Newcastle & 89 & 18 & 21 & 26 & 24 & 27 & 9 \\
\hline $\mathrm{RNOH}$ & 173 & 40 & 48 & 46 & 39 & 74 & 26 \\
\hline Cambridge & 51 & 13 & 15 & 13 & 10 & 15 & 2 \\
\hline Dorset & 30 & 15 & 3 & 3 & 9 & 11 & 3 \\
\hline Bristol & 30 & 9 & 9 & 9 & 3 & 28 & $\frac{3}{2}$ \\
\hline Manchester & 163 & 36 & 47 & 46 & 34 & 48 & 31 \\
\hline Exeter & 48 & 3 & 15 & 11 & 19 & 18 & 3 \\
\hline $\begin{array}{l}\text { Preston } \\
\text { Preston }\end{array}$ & 71 & 15 & 25 & $\frac{11}{17}$ & 14 & 23 & $\frac{3}{6}$ \\
\hline Leicester & 25 & 5 & 6 & 7 & 7 & 8 & 0 \\
\hline Aintree & 37 & 11 & 15 & 7 & 4 & 15 & 7 \\
\hline North Cumbria & 12 & $\frac{11}{2}$ & 2 & 6 & $\frac{4}{2}$ & 7 & 2 \\
\hline Harold Wood & 105 & 16 & 23 & 22 & 44 & 23 & 4 \\
\hline Birmingham & 282 & 50 & 56 & 92 & 84 & 67 & 20 \\
\hline $\begin{array}{l}\text { Sheffield } \\
\text { Shint }\end{array}$ & $\frac{202}{82}$ & 29 & 18 & 19 & $\frac{84}{16}$ & 35 & 8 \\
\hline Wirral & 38 & 6 & 13 & 7 & 12 & 8 & 4 \\
\hline Crystal Palace & 43 & 5 & 10 & 17 & 11 & 15 & 10 \\
\hline Colchester & 5 & 0 & 1 & 1 & 3 & 3 & 0 \\
\hline Luton & 3 & 2 & 1 & 0 & 0 & 3 & 0 \\
\hline $\begin{array}{l}\text { Kent \& } \\
\text { Medway }\end{array}$ & 0 & 0 & 0 & 0 & 0 & 0 & 0 \\
\hline Derby & 0 & 0 & 0 & 0 & 0 & 0 & 0 \\
\hline \multicolumn{8}{|l|}{ Northampton } \\
\hline \multicolumn{8}{|l|}{ Portsmouth } \\
\hline Stoke & & & & & & & \\
\hline TOTAL & 2016 & & & & & 587 & 201 \\
\hline
\end{tabular}

Appendix 2

\section{Patient Data Collection Pro-form}

\begin{tabular}{|c|c|c|c|c|c|c|c|c|}
\hline \multicolumn{9}{|c|}{ Sports Prostheses for Children Data Requirements } \\
\hline Patient Name & $\begin{array}{l}\text { Hospital } \\
\text { Number }\end{array}$ & $\begin{array}{l}\text { Age at } \\
1 / 3 / 17\end{array}$ & $\begin{array}{l}\text { Sex } \\
(M / F)\end{array}$ & $\begin{array}{l}\text { Amputated } \\
\text { Limb } \\
\text { (UL/LL) }\end{array}$ & $\begin{array}{l}\text { Level of } \\
\text { Amputation }\end{array}$ & $\begin{array}{l}\text { Side } \\
\text { (L/R) }\end{array}$ & $\begin{array}{l}\text { Type of Foot } \\
\text { Currently } \\
\text { Supplied }\end{array}$ & $\begin{array}{l}\text { Would patient } \\
\text { benefit from Sports } \\
\text { Limb (Y/N) }\end{array}$ \\
\hline & & & & & & & & \\
\hline & & & & & & & & \\
\hline & & & & & & & & \\
\hline & & & & & & & & \\
\hline & & & & & & & & \\
\hline
\end{tabular}


Trauma Management

Healthcare Technology Co-operative
WHS

\section{National Institute for} Health Research

\section{NIHR Child Prosthetics Research Collaboration}

\section{Report from the Trauma Management HTC, Birmingham UK}

Introduction.

is a considerable amount of research work being undertaken in academia and industry to develop new prosthetics devices and control systems; however it is currently unclear to what exten this research considers the needs of children requiring prosthetic limb devices. Underrepresentation of children in these research efforts may lead to new developments failing to mee th users such as lightweight designs or different control interfaces. Trauma Management HTC (TMHTC) was engaged to survey the current publically funded research in the field of prosthetics to identify current advances and also any areas specifically investigating children's prosthetics. Additiona information has been provided from the TMHTC direct experience with a number of projects investigating children's prosthetic devices and other sources identified by the Project Reference Group.

This work is intended to be paralleled by an assessment of the military provision of prosthetic limbs. The military experience of the design and use of robust prostheses for use by active participants $m$ ay be informative for childhood prosthetics. TMHTC has not yet successfully engaged with the military rehabilitation services and continues to pursue potential contacts to gain further understanding of progress with military prostheses which could be applicable to the wider population.

\section{Methodology}

Whe fically funded research projects in the UK are available through searchable web-based databases. The Research Councils UK Gateway lists all projects funded by the BBSRC, MRC, EPSRC, MRC, STFC AHRC and Innovate UK. The Wellcome Trust, i4i and SBRI produce searchable annua reports databases, and details of European funding through Horizon 2020 are also available. Each of these databases was searched for any projects mentioning the term 'prosthe*'. Results were reviewed and details including the organisation, lead investigator and brief project summary recorded in an Excel spreadsheet to be made available to the Work Package leads and the Project Reference Group. Studies that mentioned "prosthe*" only as a potential future use of the technology were not recorded. A total of 94 relevant projects were identified and the public summaries reviewed to identify the key objectives of each project. The resulting reports were summarised into the key areas of active research. The nature of the search results was not compatible with quantitative or qualitative research.

\section{Results - Key Research Areas Supported By UK Public Funding.}

Improved Processing of Neural Signals.

Several studies were funded to understand how auditory signals are processed in order to enable the design of better prosthetic hearing devices and while not directly relevant to limb prostheses the understanding of neural signal processing generated may prove useful. Professor Andrew Rees

Trauma Management

Healthcare Technology Co-operative
WHS

National Institute for

Health Research projects are looking at speech recognition in noisy environments with Dr Jennifer Bizley (UCL) conducting an animal study to characterise the hierarchy of the auditory cortex for processing speech and Professor Christopher Kays (University of Glasgow) examining how visual inputs, ie seeing the speakers face, can improve auditory processing. Finally Professor Joachim Gross (University of Glasgow) is measuring how emotional cues are recognised and processed in order to improve cochlear implants.

Dr Marco Davare (UCL) is investigating the connections between the premotor cortex and propriospinal system with the spinal cord. These connections are involved in hand grasping control and could identify new targets for prosthetic controls. Dr Davare is also investigating connections between visual input, touch and grasping control which could lead to better prosthetics design. A similar approach by Professor lan Forsythe (University of Leicester) who is investigating brain plasticity and it's implication for neural therapies. Dr Timothy Gregory Constandinou (Imperial College London) is developing small, primitive neural interfaces for prostheses control.

Improved Control of Prostheses.

Two projects described attempts to improve prosthetic limb control by using either Transcranial Magnetic Stimulation to control stimulation of specific regions of the brain (Professor John Rothwell, UCL) or by finding new materials to improve the neural connections and reduce signal loss (Dr Kianoush Nazarpour, Newcastle University). Dr Nazarpour also has a project intended to improve sensory feedback to the patient by developing new technologies. More natural and intuitive control of prosthetics is also the aim of Dr Luca Citi's (University of Essex) work to develop novel decoding algorithms for myoelectric prostheses. Novel manufacturing processes are also being investigated by Professor Marc Desmulliez (heriot-Watt Universty) who is non-conductive substrates. Improved control of prostheses may benefit from a better understanding of biological limb control and could indicate new targets for neural controls. These natural processes are being investigated by Dr Guillaume Hennequin (University of Cambridge) and by Dr Andrew Jackson (Newcastle in guiding rehabilitation by enhancing adaptive plasticity.

Better Prosthetic Limb Design.

Dr Appolinaire Christian Etoundi (University of the West of England) is using the anatomy of the human knee to design novel prosthetic limbs and artificial knees. More efficient lower limbs which improve gait and optimise energy use are being designed using smart process by Professor Abbas Ali Dehghani-Sanij (University of Leeds) and by improved design and use of hydraulics by Professor David Howard (University of Salford). In a similar vein, Dr Kianoush Nazarpour (Newcastle University) is investigating ways to improve the feedback from prostheses ankle joints to aid patient stability and generate mechanical power. Improved prosthetics design will be aided by new manufacturing methods such as a devir under investigation by Dr Liam Grover (University of Birmingham). 
Trauma Management

WTS

Healthcare Technology Co-operative

\section{National Institute for Health Research}

Trauma Management

Healthcare Technology Co-operative
NHS

National Institute for Health Research
Aesthetics And Comfort.

Different approaches are being pursued to make more life-like prosthetic limbs using new materials by Mr Graham Michael Pullin (University of Dundee) or by developing a 3D spectral imaging system to deliver exact matches to skin colour. The latter appears to involve two projects from Professor Sophie M Wuerger (University of Liverpool) and Professor Julian Michael Yates (University of Manchester). Improving the fit and comfort of lower limb prostheses is being addressed by D Alexander Dickinson (University of Southampton) and the University of Strathclyde (lead investigator not detailed) who are assessing new ways to measure the stump so better fitting sockets can be designed more quickly. An alternative approach is to strengthen the skin covering the stump and $D$ Claire Alexandra Higgins (Imperial College London) is investigating methods to grow planar skin in the stump area. Users may reject prostheses as unworkable and Professor lan Anthony Ashcroft technologies available to personalises devices and reduce rejection.

Although not exactly a comfort issue, artificial implants do have a lifespan and may require further surgeries to replace them. Professor Balasubramaniam Vaidhyanathan (Loughborough University) is developing nanostructured materials with improved lifespans that reduce this need, which may also apply to any implants required to use of control prostheses.

\section{Other Projects Not Directly Related.}

Prosthetic limbs are commonly not affordable or unsuitable for sustained use and maintenance in developing countires. A collaboration with funding for sites in India (Professor Dibakar Sen, Indian Institute of Science) and Oxford (Professor Alison Noble, University of Oxford), will develop new designs and ready them for commercial manufacture. Professor Cristopher Nester (University of Salford) has funding to develop a 3D printing technology for personalised foot orthotics.

\section{Additional Information From HTC Contacts.}

Trauma Management HTC is working with several groups with interests in child prosthetics who currently have no funding and so would not be included in the searches. Team Unlimbited (http://www.teamunlimbited.org/) are a charity that produces 3D-printed prehensile hands and lower arms for children (and some adults) aged 4-16 years. Their designs are open source and completely mechanical in operation. They might be interested in funding to further develop the designs and to access the NHS. Open Bionics (https://www.openbionics.com/) are creating low cost bionic hands (many with colourful themed designs to appeal to children) and do custom 3D printing. The West Midlands Rehabilitation Centre (R\& Director Dr Clive Thursfield) works with child and adult amputees and can produce bespoke devices. They are interested in further research to build picture of attitudes towards prosthetics to overcome the high rate at which users fail to engage with their prosthetic limbs. All three are more geared towards upper limbs at present but may provide some useful insights from the perspective of working with children. Dr Ramesh Munjal (Sheffield Teace. TMHTC has had recent contact with Polybionics, a company dor a VR prost sics traning (https://www.polybionics.com/)

\section{Information From Other Sources.}

A 2014 report to the Parliamentary Limb Loss Group about the Clinical Technology Foundation Degree at London South Bank University described a number relatively simple bespoke devices designed by prosthetic technicians to satisfy specific needs of individual patients. These projects highlighted the importance of the prosthetists in delivering devices and also the engagement with the recipient for what they want from the device. The autumn 2016 Blesma newsletter reported on a survey of how and why members do or do not use the activity service. $70 \%$ of respondents had not taken part in the activities programme due to medical reasons, travel difficulties, lack of confidence and family commitments. Those that did take part were overwhelmingly pleased. Further investigation of the reasons underlying the lack of participation in activities may inform better development of prosthetic devices that support more active lifestyles.

Conclusions.

Public research funding continues to support a broad range of projects targeting different aspects of prosthetics within the UK, with a substantial focus on the development of more effective myoelectrical devices and the mechanisms required to effectively control them. There appears to have been little consideration for the needs or usage of such devices by children. The main areas supported by research funding can be grouped into several key areas including improved understanding and processing of neural signals; improved control of prosthetic limbs through training and understanding of biological limb control; improved design of prosthetic limbs including reduced power consumption and better materials; and the development of more aesthetically pleasing, more comfortable or more personalised prosthetic limb designs.

Comments from the WMRS and Team Unlimbited and the West Midlands Rehabilitation Service have indicated that many children do not want fully functional myoelectric limbs and/or find them difficult to use - and many adults feel the same. Engaging with children may stimulate new ideas for training programmes, feedback mechanisms, or less complex myoelectric devices that are better suited to children's needs. Such research may also benefit those adult users who reject the use of complex myoelectric prosthetic limbs. Continued work with the Military may offer an insight into what barriers they have faced on a practical level and also what advances have been made with improving the access and usability.

\section{Recommendations.}

The next step would be to identify key researchers within the different areas, discuss the above findings and identify whether they have considered working with children in the development of prostheses. If not, it would be important to discern what has prevented them from doing so. Equally, if they have, it would be useful learning to identify what they did and how effective this was. TMHTC will report any real or perceived obstacles to engaging with children raised by the researchers and clinicians as well as success stories which could contribute to future learning. The Project team could then consider providing help and advice to the researchers/ clinicians to assist in future project design with service user involvement and funding applications. 


\section{INTRODUCTION}

On the 20th September 2016 the Department of Health announced a total of $f 1.5 \mathrm{M}$ funding for child prosthetic research and technology. This comprises $£ 750,000$ for provision of new sports prosthetics for children on the NHS, and $f 750,000$ for the NIHR Child Prosthetics Research Collaboration, led by the NIHR Devices for Dignity Healthcare Technology Co-operative (HTC), to speed up the

development of new prosthetic technologies specifically for children.

One of the initial objectives of the Collaboration is to undertake a needs assessment and identification of opportunities from the perspective of the identified stakeholder groups:

- Children and their families

- NHS clinicians and limb centre

- Industry

- R\&D community (including academia, military provision and national research centres)

TRUSTECH were commissioned to deliver the Industry element of work package 2 of the NIHR Child Prosthetics Research Collaboration plan.

\section{PURPOSE}

The purpose of this activity is to identify the needs from within the prosthetic industry in order to stimulate new research and collaborations, accelerate new developments and to raise the profile of the prosthetics community.

This needs assessment report will focus on understanding not only the current and future industry needs/requirements, but also current areas of excellence and barriers to implementation.

\section{METHODOLOGY}

A variety of methods were employed to gather information and seek opinion from the industry sector. Primarily these included: desk based research; an online survey; telephone interviews with key players; and the utilisation of platforms such as Twitter and Linkedln.

\section{KEY QUESTIONS}

The first step in the process was to construct specific questions and surveys to collect the information. This was accomplished in collaboration with the sponsor of the project to ensure compatibility with project aims and other work-streams. At the outset TRUSTECH also sought the opinion of a senior representative from the Blatchford Group who had previously been involved in collaborative research in this area. This enabled a question set to be formulated that would be both appropriate to the audience and informative to the sponsor group.

The focus for the initial survey questions centred around:

The needs from within the prosthetic industry in order to;

- stimulate new research and collaborations

- accelerate new developments

- raise the profile of the prosthetics community

Throughout this activity, specific consideration was given to the 5 " $C$ 's" of living with a prosthetic limb:

- Choice

- Comfort

- Capability

- Comesis

- Caring

This needs assessment report will focus on understanding not only the current and future industry needs/requirements, but also current areas of excellence and barriers to implementation.

\section{ACTIVITY METRICS}

The survey was launched on the 7th April 2017 and was closed on the 315t May 2017.

TRUSTECH identified a number of companies to target in order to gather responses. These companies were recognised as key operators in the field of prosthetics or companies who were embarking on research and development connected to the field.

Industry Targets

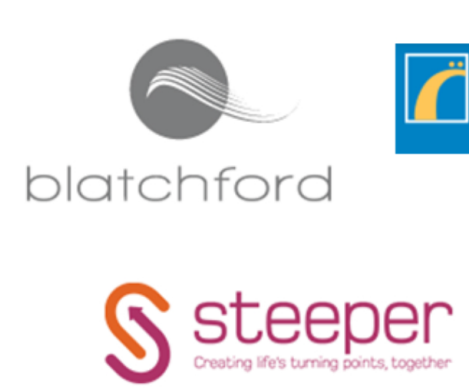

ottobock. orthopaedic

\section{ÖssuR.}

(C) opcare

The Survey was publicised through a range of channels including Twitter and Linkedln with the final metrics from this activity as follows:

Tweeted from the TRUSTECH Account (1,392 followers). 
12 tweets

- 5,633 impressions

- 42 re-tweets

- 35 clicks

- 21 likes

- 11 mentions

TRUSTECH also re-tweeted an additional 13 related tweets

\section{Linkedin - 69 followers}

- 1 post

260 Impressions

- 4 clicks

- 4 interactions

\section{TRUSTECH Website}

1 post: NIHR Investment in Child Prosthetics Research Collaboration

\section{SURVEY METRICS}

At close, the survey had received 28 Completed Responses and 10 Partial responses containing

usable data. The breakdown of responses in relation to their sector was as follows:

- 23 responses from Industry

- 13 responses from the University Sector

- 2 responses from NHS

The non-industry responses that were collected indicated instances of collaborative work with industry.

\section{IN-DEPTH INTERVIEWS}

Once the survey was closed, TRUSTECH selected a number of participants who had expressed a willingness to participate in further research activity to approach for more in-depth interviews. The purpose of these interviews was to further investigate the views and opinions that had been expressed within their survey responses. When selecting who to approach, TRUSTECH endeavoured to ensure that the major companies operating in this field were all given an opportunity to

contribute. Additionally, TRUSTECH also identified value in also approaching smaller companies with links to activity in this field such as companies developing expertise and experience in the field of $3 D$ printing for prosthetic product development.

A total of 13 people have been interviewed as part of this process with opinions provided by a range of personnel from the following companies:

- The Steeper Group (3)

- Blatchfords (3)

- Ottobock (2)
- Ossur (1)

- Opcare (2)

- Open Bionics (1)

- 3D Life Prints (1)

\section{FINDINGS}

Survey respondents were asked to list any barriers they have encountered that have prevented any involvement in the development of products in the child prosthetics field. The responses gathered can be categorised as follows:

\section{Low patient numbers / RO}

this was the most cited barrier and examples provided include: "We have been developing paediatric products but it is a niche market for our company - low volumes." "Commercial viability." "Cow patient numbers make meaningful research difficult without collaboration with other centres." "Clearly smaller market-not so lucrative for investment returns."

"Cimited numbers of children, with as wide a range of requirements as the adults.

"Commercial viability of investment for a market of 2000 child amputees."

"Creates a cost effectiveness issue that is hard to finance."

"Opportunity as the numbers are so low."

"Lack of direct demand."

"Product development is difficult - small sizes and extreme activities."

- Available time / Resource

Eq - "Available time and resources to dedicate to the research needed"

Access to experts / clinicians

Eg- "Shortage of prosthetist and especially with children interest and expertise."

- Funding

Eg - "Lack of funding to support area."

- Market Acceptance Eg- "Acceptance of innovative solutions."

Bringing products to market - Ethics / CE Marking$$
\text { Eg- "CE marking." }
$$

- Other

$E q$ - "lack of coordination and prioritization in the sector."

The survey then asked respondents to list the main priorities to help stimulate new research and collaboration in the field of child prosthetics. The responses gathered can be categorised as follows:

\section{- Joint working / Collaboration / Co-ordination}

this was the most cited barrier and examples provided include "National clinical coordination."

"Collaborations with the right people (design, engineering, material science, etc.)" "Alternative viewpoint - not from that of trained prosthetist but from userfecipient perspective." "Joint working between prosthetic centres to increase cohort sizes for research." "Collaboration with NHS clinics to produce funded studies with young amputees." 
"Partnerships with parents and children with limb loss."

- Funding

$g$ - "Funding to trial new fitting processes (current fitting processes can lead to traumatic experiences - kids hate having plaster casts!)"

- Research / Evidence \& Outcome Measurement

$E g$ - "Easier recruitment of children participants for research."

- Addressing child growth

Eg- "Methods / tech to address rapid growth of the child."

- NHS Routes to Market

Eg - "Secured NHS funding for prescription of these products."

- Awareness raising / Education

$E g-$ "Conferences and workshops to simulate knowledge and clinical experience exchange."

Eg - "User day organisations to get kids into activity and sport."

- Manufacturing / Materials \& Technology

Eg- "new ways of making effective but low cost devices (such as rapid prototyping approaches)"

Eg- "Use of additive manufacturing techniques."

Respondents were asked to list the steps that could be carried out to help accelerate new developments in the field of child prosthetics. The responses gathered can be categorised as follows:

\section{- Funding}

along with Collaboration / Engagement, this was the most cited barrier and examples provided include:

"Provision of funding opportunities for research and development."

"Financial incentives- grants."

"Funded Feasibility studies / competitions."

"Funding to encourage industrial $R+D . "$

"Funding to motivate manufacturer to develop those products."

"Fund start-ups who are breaking new ground with new materials and smaller devices."

- Collaboration / Engagement

Eg- "Engagement with industries outside prosthetics."

"Create stronger lins between industry and academia."

$g-$ "Better relationships between start-ups doing cutting-edge development and NHS prosthetists fitting

Eg- "Multicentre collaboration with universities."

- R\&D

Eg- "Focus the government resources in developing what the children in Lower limb need."

Eg- "Rapid prototyping trials."

$E g-$ "Advance research into mechanical testing of materials, structures, etc. to ensure safe design and provision of prostheses."

Eg- "Research into the current situation (including objective data on use/non-use of prostheses)."

- National co-ordination / Planning / Governance

Eg- "agreed national coordination / direction."

E - "Setting up a dedicated forum for specialists in the field, similar to TIPS for upper limb prosthetics."

- "Links to the GCRF strategy."

- "A well-documented and defined clinical pathway."

Eg- "Specialist position created to collate developments in progress and improve communication."

- Awareness raising / Education
Eg - "Networking events of key stakeholders with academics, companies etc. who would be able to drive the project."

Eg- "Workshops for industrial and academics interested in the area."

Eg- "Frequent interactive review sessions."

\section{- NHS Routes to Market}

$g$ - "A faster adoption process for the NHS. Once the NHS has evidence children prefer stylised bionic hands and the devices are cost effecive, thro necds to be an easier way for prosthetists to prescribe devices to patients." Eg- "Promise to supply products through the NHS."

- Materials / Componentry / Technology

Eg - "Socket Interface Tissue stabilization through growth changes in volume/size."

Eg - "Additive Manufacture customization and bespoking for accurate fit \& prescription."

Eg- "Look to additive manufacturing to accelerate."

Survey participants were asked to list the measures that they believe could help to raise the profile of the prosthetics community in order to increase resources for the care of child amputees and the frequency of review. The responses gathered can be categorised as follows:

\section{- Awareness raising activity / Education / Changing Perceptions}

this was considerably the most cited barrier and examples provided include: "Television programmes that show children using their prostheses."

"Changing the attitudes around disability by making prosthetics cool."

"Paediatric Amputee games."

"Raise the profile of the work done in NHS centres to rehabilitate children - the press usually focus on failures of the NHS and how the private services have stepped in."

"High profile case study showing impact of having optimum fitting and functioning prosthesis."

"Children with amputations being mascots at football matches and information about charities at half time." "Having research covered by world renowned news outlets."

"Participation in sports at all levels to raise general public awareness."

\section{- National co-ordination}

$g$ - "establishing a national body with power and influence.

$E g-$ "Better representation from the National Association (BAPO)

Eg - "Government/policy backing."

$g-$ "Discussion in parliament-Associate Parlimentary Limb Loss Group."

Eg- "Agreed national targets and standards."

Eg- "NHS ENGLAND Marketing including REACH input."

- Funding

Eg - "Promotion by Government through SBRI / Innovate UK Funding."

Eq - "establish dedicated funded research programme (international!!!!"

- Collaboration

$g-$ "Giving children them the choice/option colour themes."

Eg - "Collaboration between manufacturers, hospitals and researchers."

Eg - "Effective open collaboration (avoiding commercial barriers and academic competition)"

- Research / Evidence

$E g$ - "More research in the area with dissemination to the prosthetics and clinical communities."

Eg- "Effective coordination and collection of data (case studies, trials, etc.)"

Eg- "A strong research network."

\section{- Product Technology / Development}

Eg- "Self adjusting their prosthesis while growing will reduce the service care cost."

Eg - "Offering prosthetics that are fashionable." 
$E g$ - "With customized adjustable interface that provide dry skin and natural suspension less visit needed." - Centres of Excellence

Eg- "work on a network of children's treatment centres."

Eg- "Centres for Paediatric Excellence in Prosthetics."

The survey also sought to establish if industry would be receptive to OPEN Access research in order to encourage collaboration and the sharing of intellectual property for the benefit of the child amputee. Respondents were asked if they would have any objections to this.

$64 \%(18)$ of respondents indicated that they wouldn't have any objections whilst the remaining $36 \%$ (10) indicated that they were Not Sure. None of the respondents indicated that they would have objections. These results need to consider if the people providing the responses to these questions have authority to determine company attitudes towards the sharing of intellectual property and are at this stage just indicative of individual attitudes as opposed to industry policy.

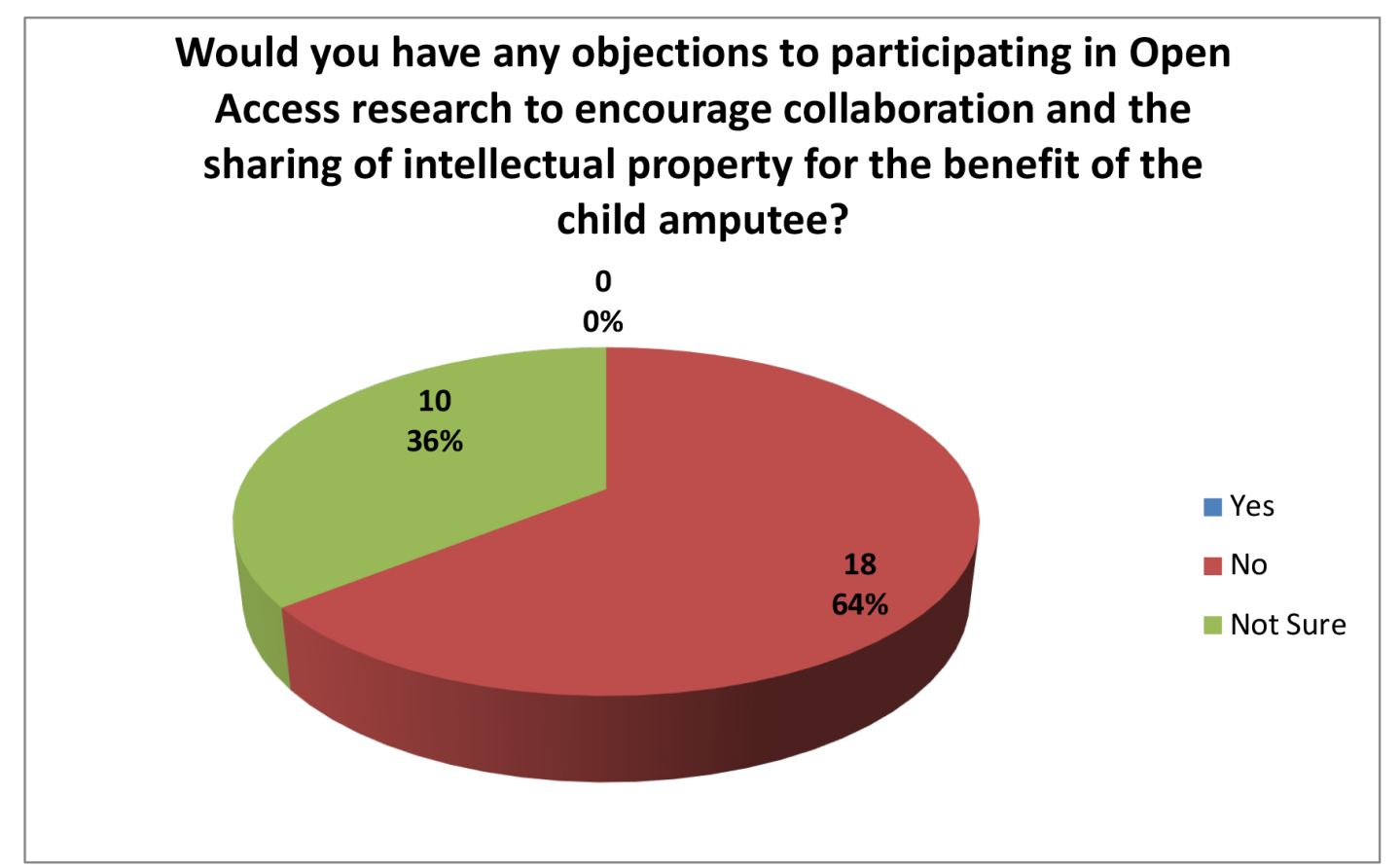

RESULTS FROM IN-DEPTH INTERVIEWS

Open-Bionics

Key Products - Brunel Hand - https://www.openbionics.com/shop/brunel-hand

The company is an award winning start-up who have been developing bespoke 3D printed bionic hands for adults. The company is seeking to offer the products to children ( 8 years and above) after identifying a gap in the market and are moving into the discovery phase to learn more about the target patient groups requirements. As part of this process they have interviewed amputees and prosthetic users and have conducted market research to establish the relative importance of different issues. Design specifications will be based around the findings of this market research activity. They have developed partnerships with Disney in order to incorporate images and branding and product designs associated to the Iron Man and Star Wars film franchises. 
Appendix 6: Snapshots of Phase Three Sandpit Events
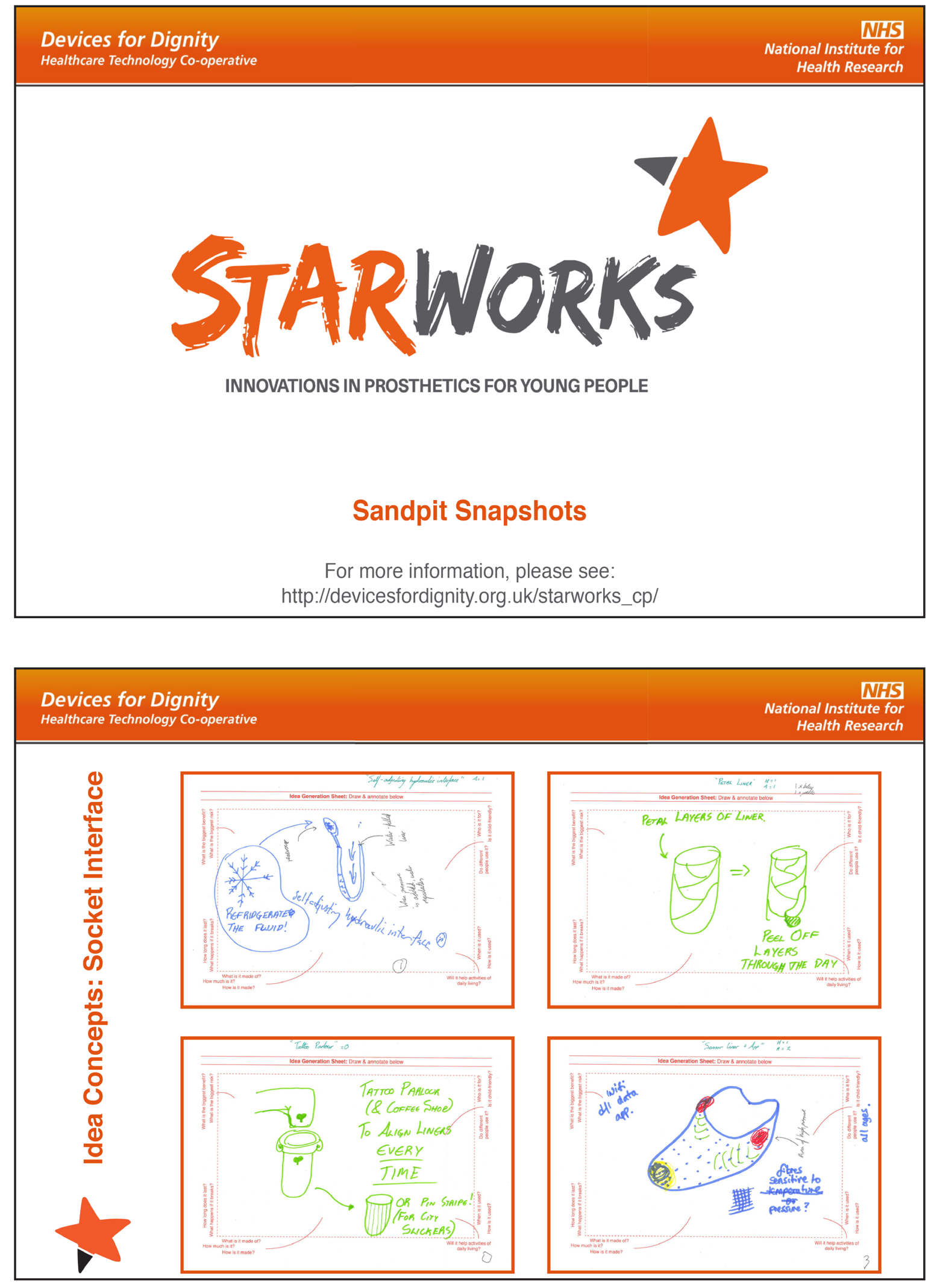
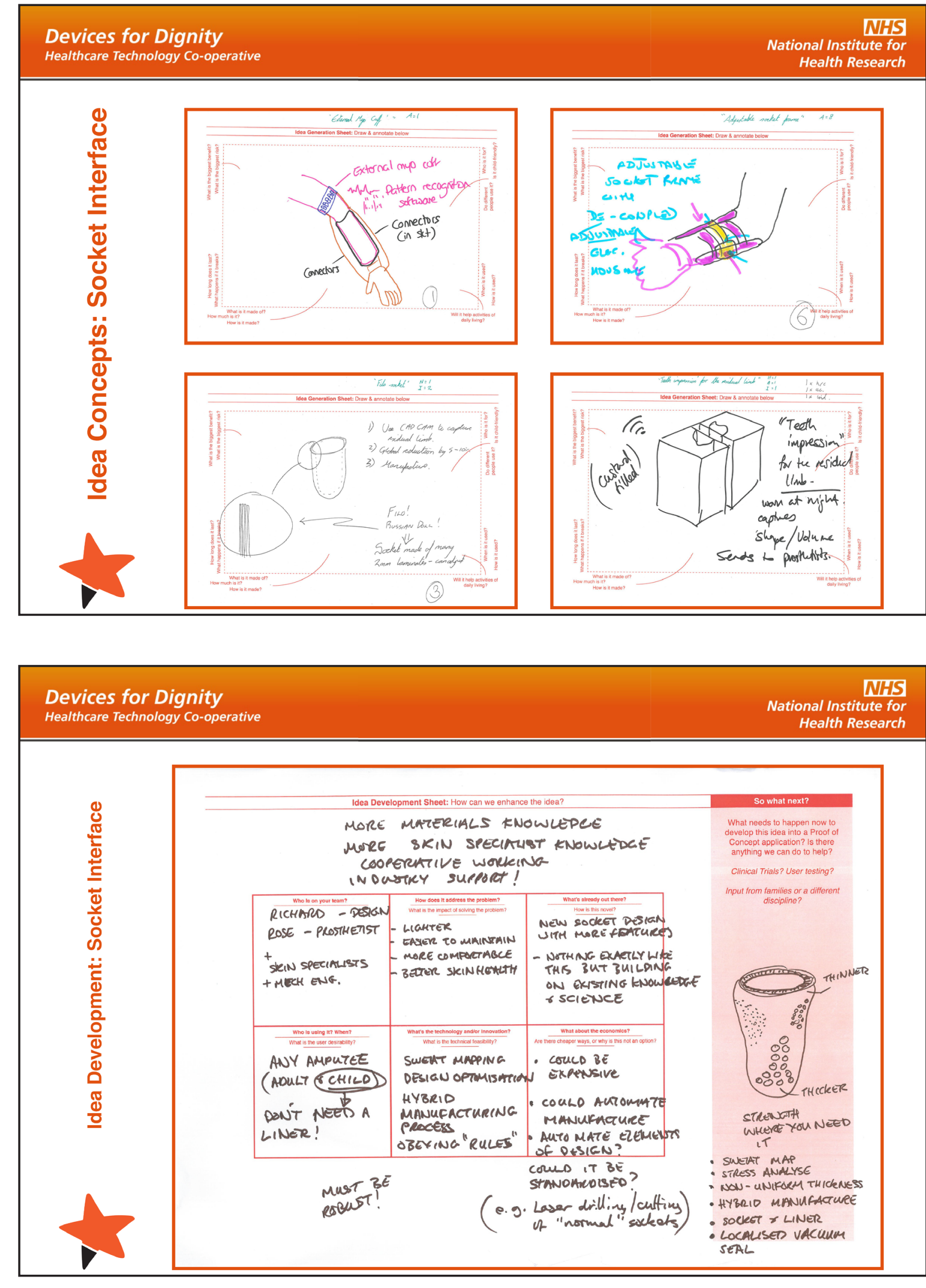

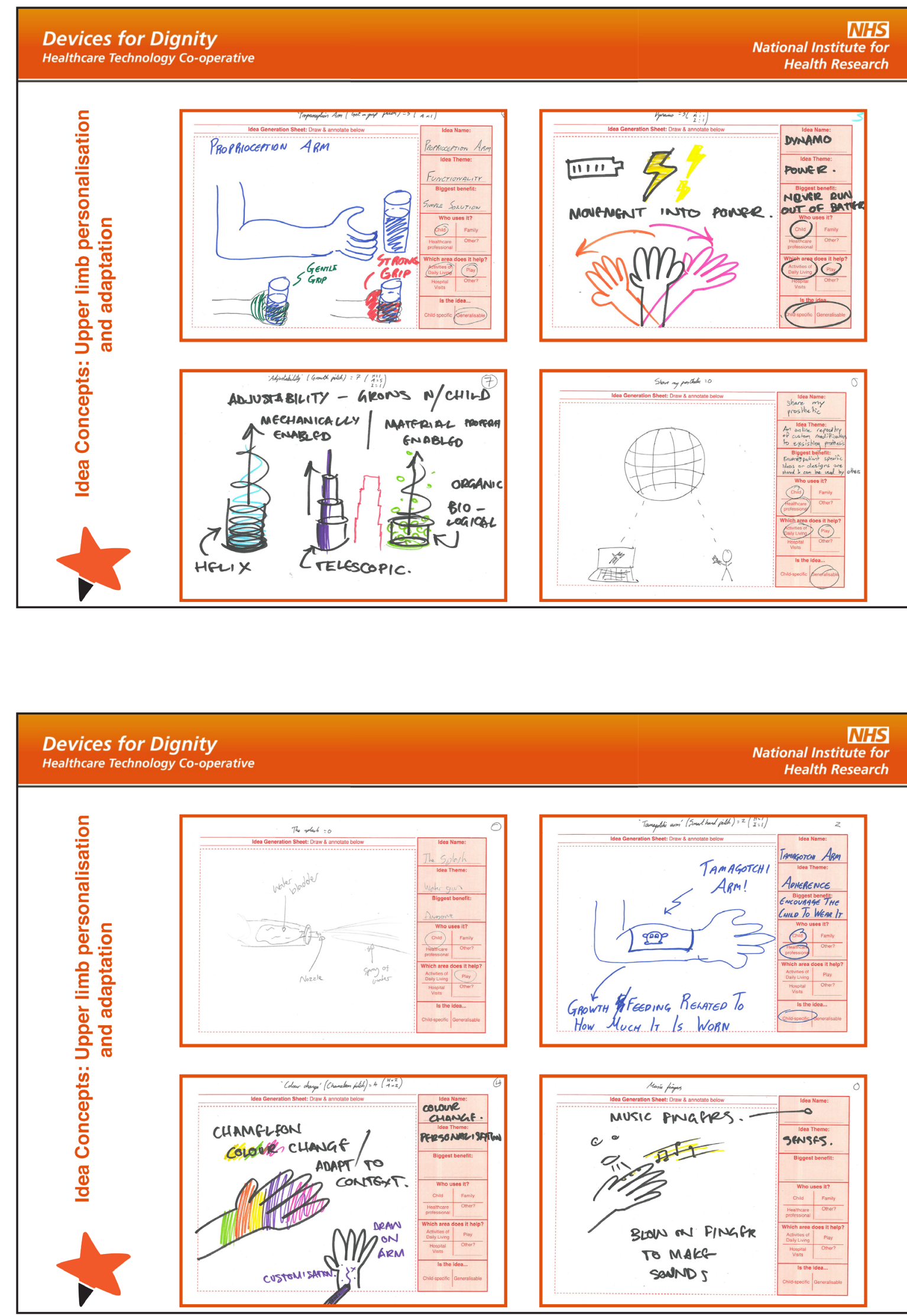

Devices for Dignity
Heath
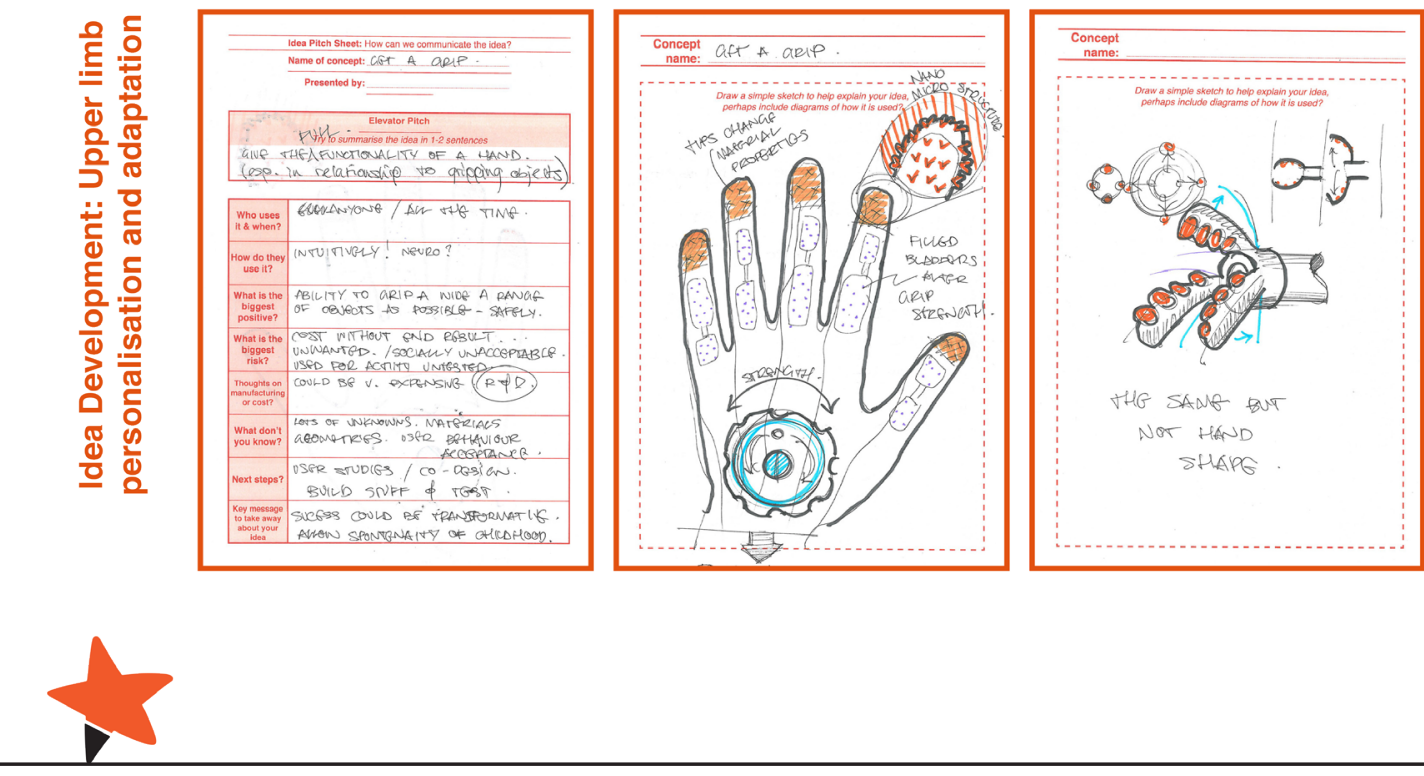

Devices for Dignity
Healtherer Technology Co-operative

National Institute for
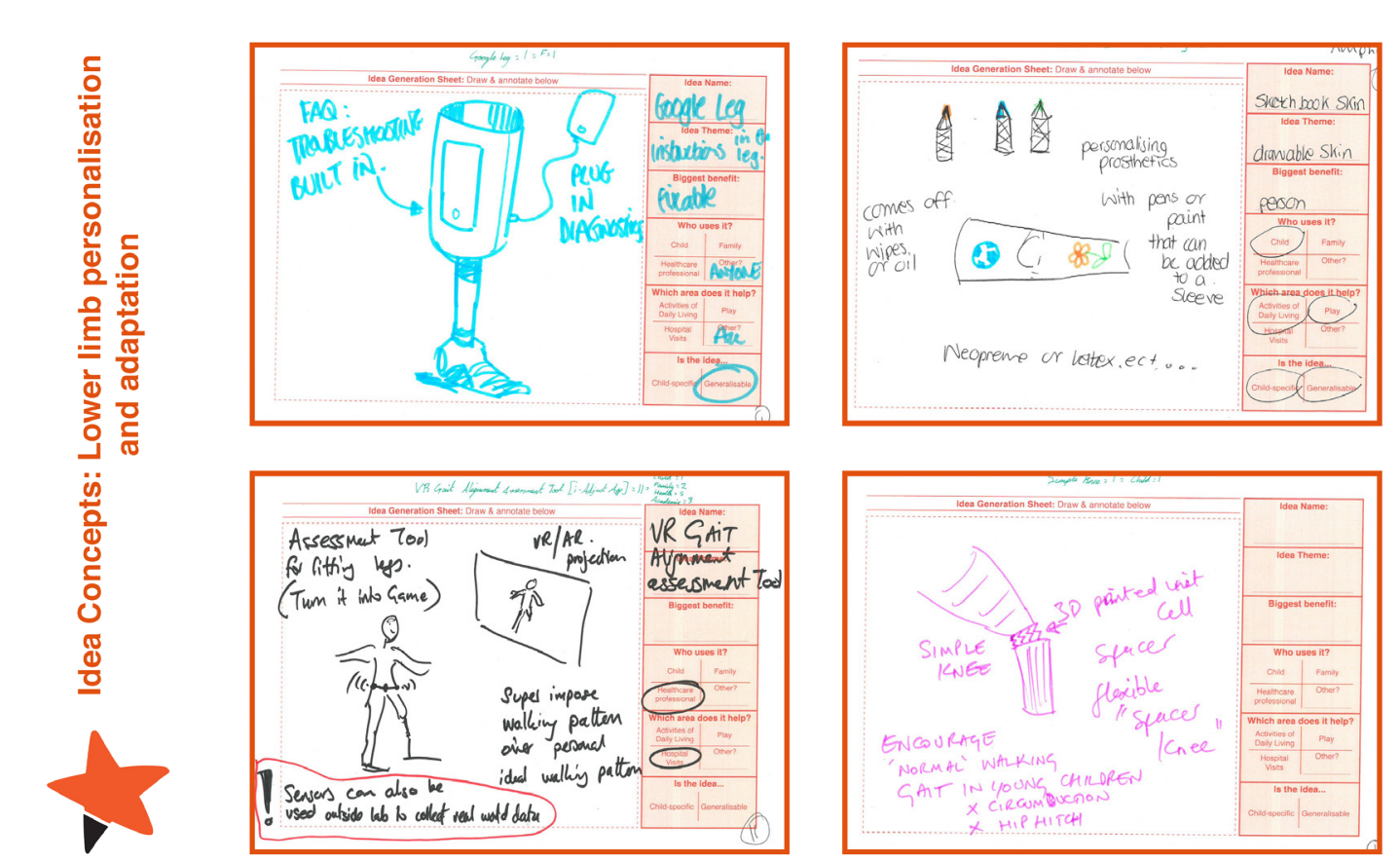

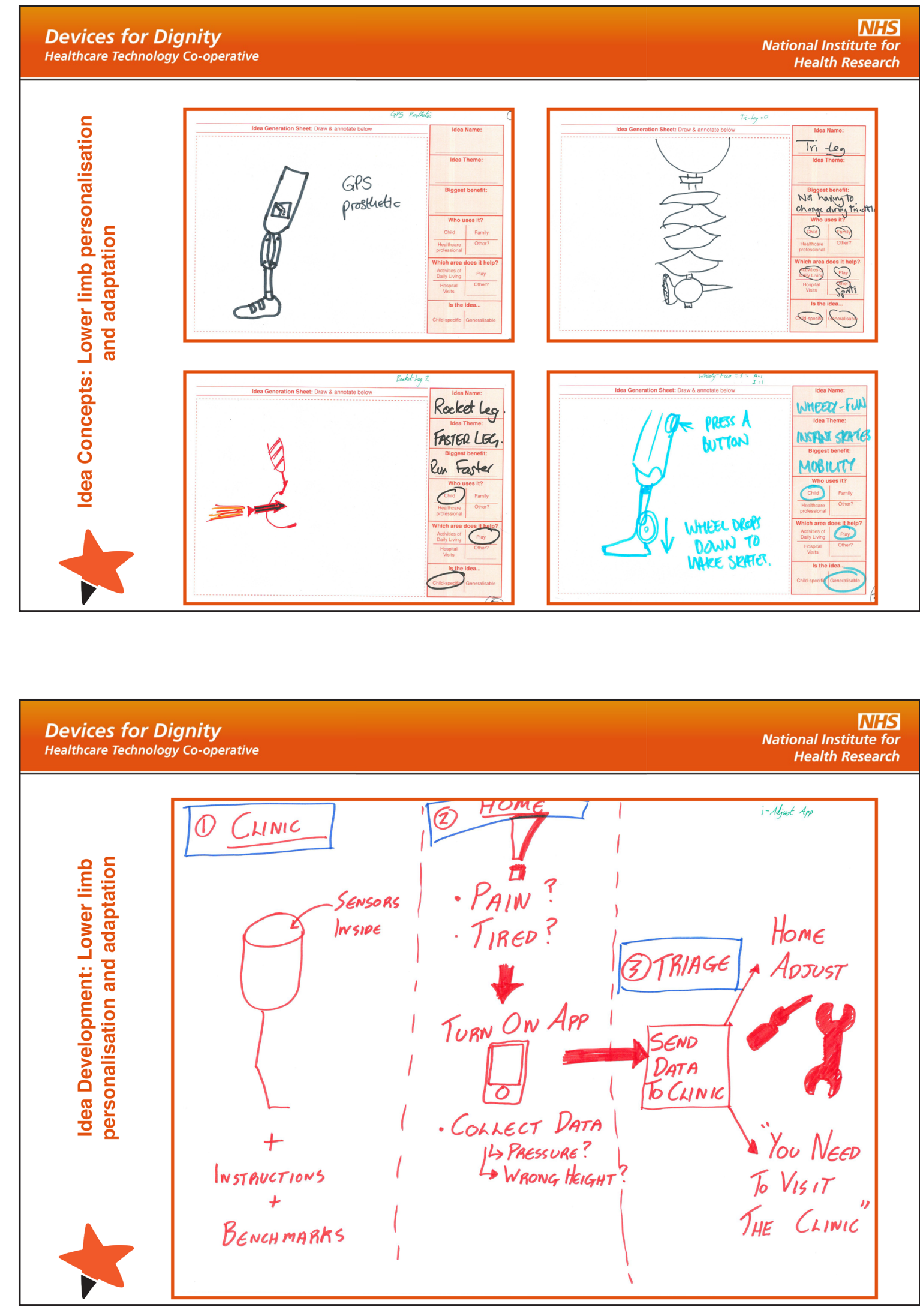

Devices for Dignity
Heastherer Techoloogy co-operative

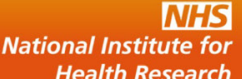
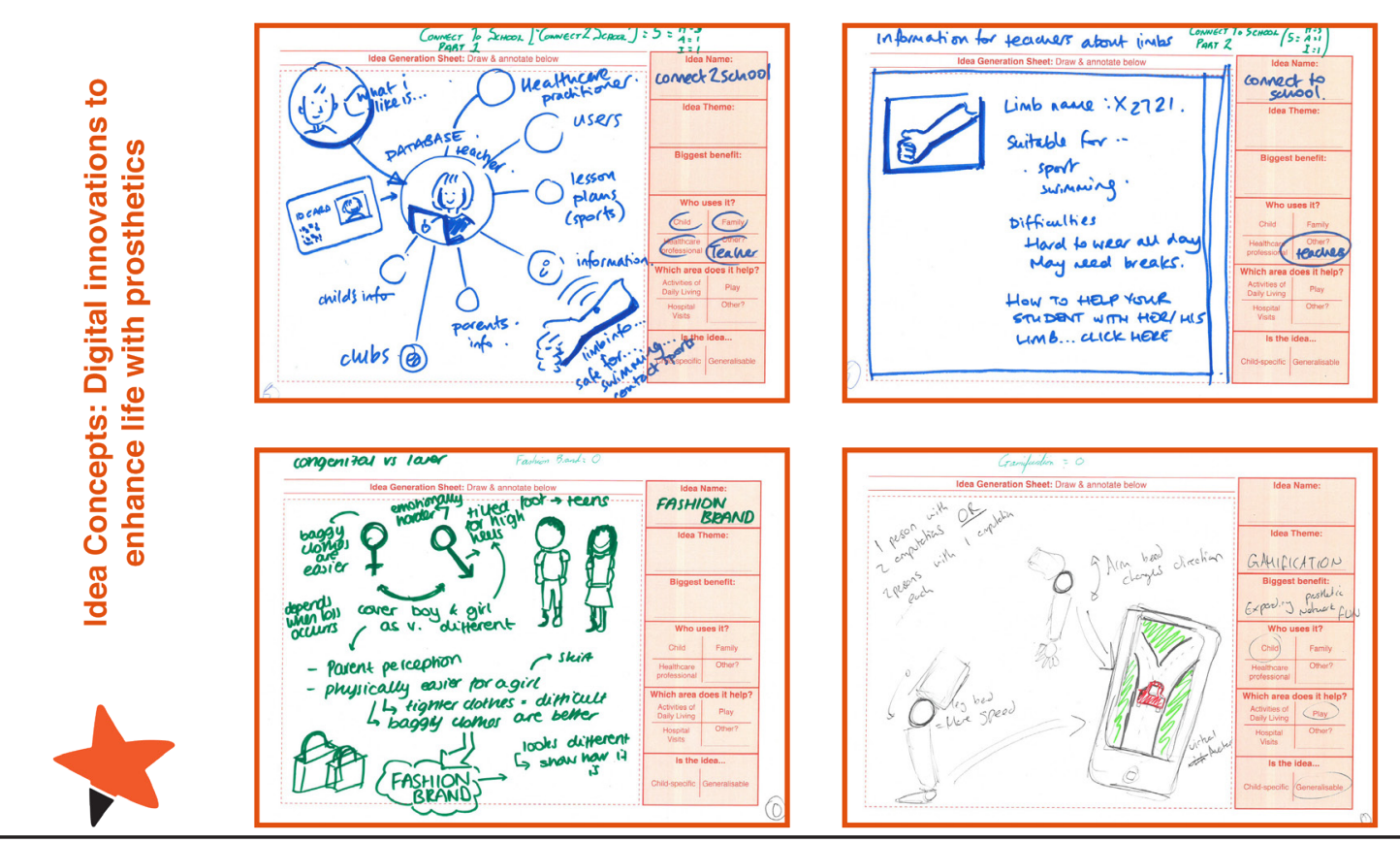

Devices for Dignity
Heartherere Technology co-operative

NHS
National Institute for
Health Research
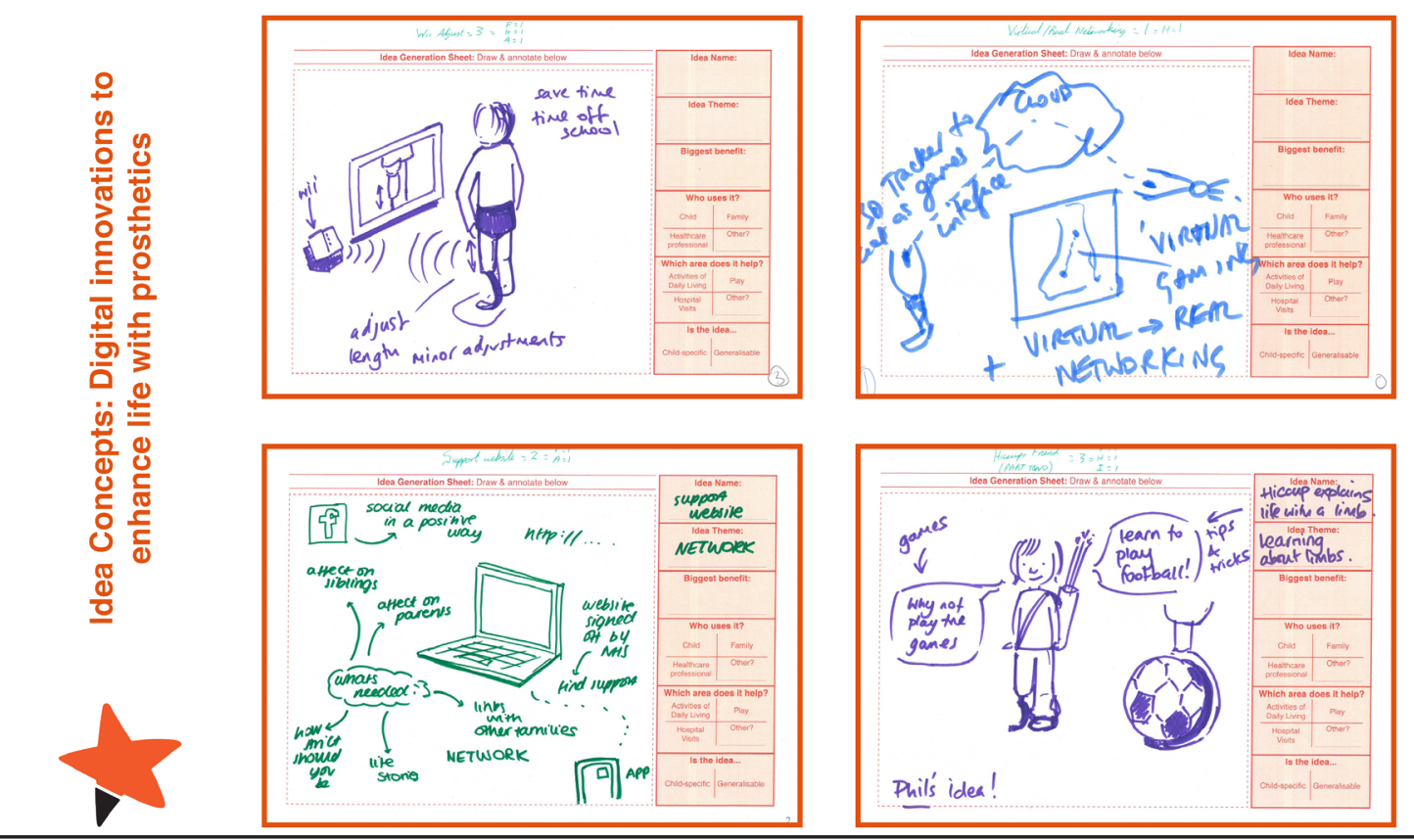

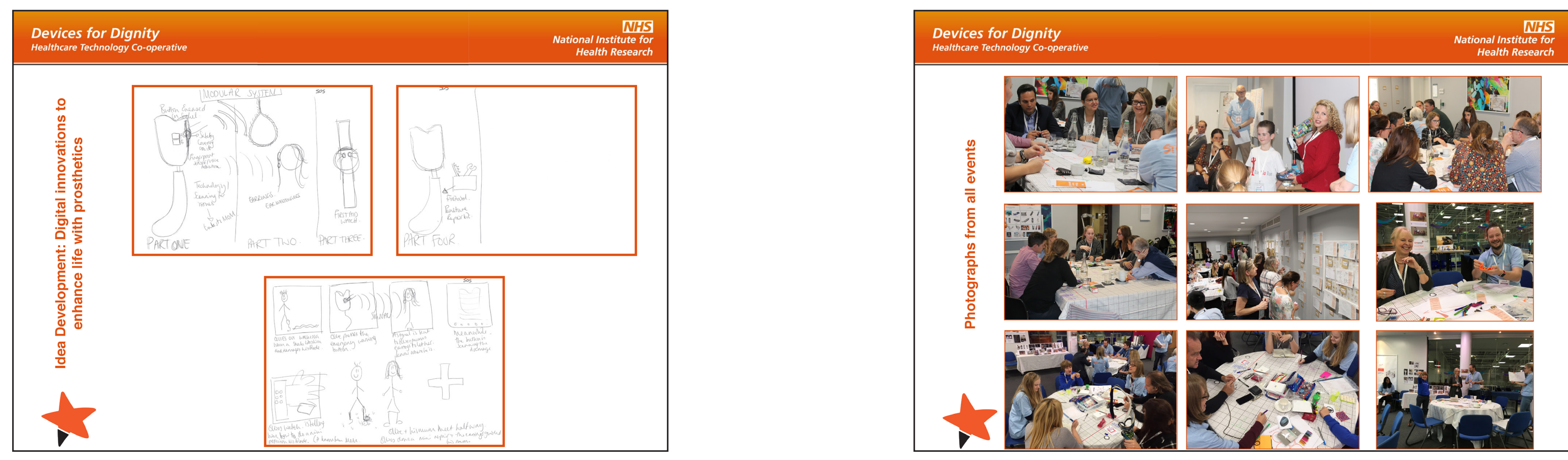

Devices for Dignity
Heathicere Technology co-operative

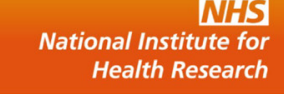

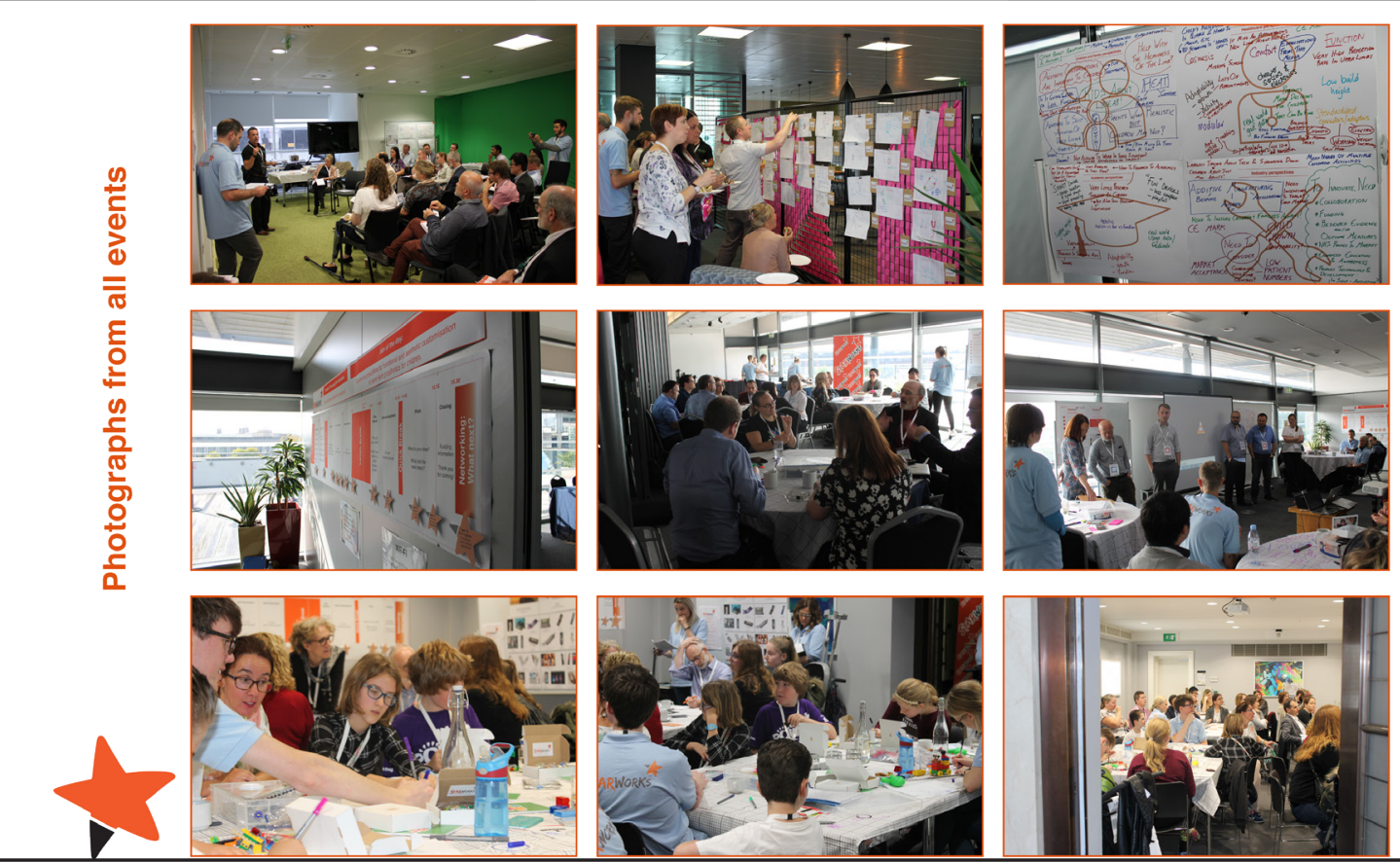




\section{Appendix 7: Detailed breakdowns of the funded 'Proof of Concept' projects}

\section{Starworks Proof of Concept Funding: Summary of the funded projects}

The Starworks Innovation Project is a young people's prosthetics research collaboration, which brings children and their families together with key opinion leaders from the NHS, Industry, Clinical Academia and leading National Research Centres with capabilities in child prosthetics.

Following a multi-stakeholder needs assessment, and a series of creative, collaborative 'sandpit events', The Starworks Project opened a call for applications to 'proof of concept' funding to develop the seeds of ideas germinated through this exciting collaboration.

A total of 23 applications were received, 14 from academia, 7 from industry/SME's and 2 from charities. The approach taken was to ask applicants to consider a co-design cross sector collaboration, with children and families at the centre of this. We believe this is evidenced in the high quality of applications received, most of which fully involve children and families.

A total of $£ 429,323$ was awarded across ten projects through the Starworks funding, which are described in more detail below.

\section{Limbformation - An inclusive website for children and families}

Limbformation will be a website, offering support to children and families living with a limb difference. Designed as an easy to use and one-stop shop, offering information, links and advice. The website will also offer guidance and suggestions to professionals working with these children, including both those who are born with a congenital limb disorder and those who have experienced an amputation.

It has been clear for some time that there needed to be a family-friendly website, with all the information available in one place. Limbformation will offer a child-specific platform offering downloadable information, practical advice to support the child's journey and other useful material. Limbformation will be a practical resource designed to connect all areas of life for a child living with a limb difference and to take a further step in fighting the isolation that many families feel.

The project will be led by LimbPower.

\section{Developing bespoke breathable prosthetic liners with growth tracking \& active cooling}

The interface between a residual limb and a prosthetic requires a liner material that ensures the transmission of forces while ensuring comfort and preventing skin damage. This is a considerable engineering challenge because a prosthetic wearer's body changes size and shape throughout the day. In the case of children there is another complicating factor, growth, which over time changes the fit of the prosthetic and the liner. Skin damage occurs due to a number of factors including temperature, exertion, hydration levels, and shear \& pressure forces due to poorly fitting liners, slippage and misalignment. Our proposed solution is a bespoke silicone liner that is 3D printed. The liner will be printed in one piece containing breathable porous structures throughout the liner, along with active cooling channels. In the last stages of the project we hope to include growth tracking sensors in the liners.

This project will be led by the University College London.

Customisable 3-D printed covers for children's prostheses

Children who are happier with the appearance of their artificial limb may be inclined to wear the device and use it more. The majority of children's prostheses are fixed in shape and hard to the touch. The choice and style of cosmetic finishes are limited. Children and their families may value some interchangeability; allowing them to change their cover according to their mood, situation or changing tastes.

This project will use both scanning and 3-D printing technology to develop low-cost high quality customisable covers. Individually printed covers will seamlessly clip on over the surface of the existing structural shape, and will be easy to remove or change according to the child's choice and activity.

This process will help improve engagement with the prosthetic rehabilitation process. Design processes will be fun and promote positive discussion between the family, friends and the child about the prosthesis and the rehabilitation journey.

This project will be led by the University of Strathclyde.

Ideal material-structure interface for personalised paediatric prosthetic socket

An innovative new prosthetic socket which adapts to growing limbs aims to alleviate discomfort for thousands of child amputees as well make exercise more comfortable. Existing sockets with fixed shape and rigidity are not fit for demanding sports and do not provide regulation for elevated temperature and humidity caused by physical activity. The new 3D printed device has been tailored to minimise skin abrasion caused by wearing the artificial limb and improve hygiene. A team led by Dr Simin Li, from Loughborough University, jointly with Manchester Metropolitan University, University of Leeds, and industrial company, Chas A Blatchford \& Sons, is to use latest 3D printing technology to develop a highly customisable prosthetic socket that can be manufactured on-demand. The artificial structures are breathable and will self-adjust in rigidity and volume to suit 
individual's anatomy and growth. The team hopes the developed technology can help improve wearing comfort, reduce cost and needs for frequent socket adjustment.

This project will be led by Loughborough University.

Play Attachment

The split hook is functional, lightweight, durable, cheap, and easy to operate: Ideal for children. Unfortunately, it is often rejected by parents and children because of the way it looks.

We began to investigate the creation of an attachment that could make the split hook more attractive and child-friendly. Using Lego blocks we built a platform on top of the split hook to make it more playful, less clinical and more acceptable to children and their parents. This device produced positive results.

The next challenge was to make such a device affordable, simple and open-source, so we developed a 3D printed Lego ${ }^{\circledR}$ plate (a 'Play Attachment') that can be easily clipped on to the top of a standard child's split hook. Starworks funding is helping us develop the Play Attachment for wider use, and to run 'Lego Play Date' sessions to help us research and evaluate it in use.

This project will be led by Steeper.

A novel Socket Interface Monitoring System (SIMS) to guide socket fitting for growth in lower limb child amputees

The high growth rate of children means that children who have lower limb loss also require prosthetics that can match their rate of growth. This creates a significant problem as it means that a "new" socket might be needed very often, just like children go through many pairs of school shoes due to growth spurts. Once a prosthetic socket is fitted to a child, it may soon be too small, and if left unaddressed may lead to skeletal development problems. This project aims to develop a system called SIMS (socket interface monitoring system), which will use a system of sensors in the socket and a smartphone app to help identify the correct time for socket adjustments. The aim is to help ensure children always have good fitting and comfortable prosthesis so that they can participate fully in normal lives and most importantly have fun!

This project will be led by the University of Southampton.

Child Upper Limb 3D Printable Prosthetic Development
A multidisciplinary team comprising academics from Manchester Metropolitan University and clinicians from Manchester University NHS Foundation Trust are working together to develop next-generation 3D printable prosthetics for children under the age of 5 years. Current prosthetics are limited in terms of design and functionality. Using the latest 3D printing technology and the use of advanced materials, baby friendly prosthetics will be developed and will be designed to help with each of the infant's developmental milestones, something which current NHS approaches are not able to offer.

This project will be led by Manchester Metropolitan University

\section{Biofeedback Gaming for Child Prosthetics}

Our project will teach children how to control a robotic hand by playing an immersive computer game. Learning novel ways to control forearm muscles will be a core part of the gameplay. The goal is for children to understand how to use a modern robotic hand before they are provided with one.

Modern robotic hands can perform a variety of grips and gestures. However, if a child cannot control these movements, they are often better off using a simple gripping hook. We have chosen to focus on teaching hand control because we believe robotic hands have the potential to enhance children's everyday lives in ways that gripping hooks cannot.

This project will be led by Newcastle University.

\section{Developing child-focused artificial legs to facilitate active play}

Starworks has awarded funding to Cambridge Prosthetics to develop child-focused artificial legs that facilitate active play. Natural legs are very good at absorbing impacts when running, jumping and rapidly changing direction. Current prostheses are rigid, heavy and cumbersome. They are poorly suited to children.

Cambridge Prosthetics is developing a new generation of prosthetic limbs that are more versatile, reliable, affordable and available worldwide. It is a collaboration between a materials scientist and lifelong prosthesis user, a leading rehabilitation consultant and a social impact specialist.

Chief Designer, Dr Philip Blakeley, said: "Starworks funding will enable us to develop a prototype leg designed specifically for children. Using Cambridge Prosthetic's innovative techniques, children worldwide with artificial legs will be able to run, jump, play and participate more equally in activities and games with their peers. As a prosthetics user since childhood, I know the difference this can make." 
This project will be led by Cambridge Prosthetics.

An adjustable electrode housing to accommodate growing residual limbs

Our project is developing a user-friendly, adjustable device that should improve the function of myoelectric (bionic) prosthetic arms for children. Myoelectric arms are controlled by electrodes that are usually fixed within the prosthetic interface, called the 'socket'. These electrodes require close, secure contact against the skin of the child's residual limb to

operate efficiently. However, prosthetic sockets for children are like children's clothes; they often only last a few months, before they become too tight and new ones have to be made. When a new socket is made, with a small amount of growing room, the electrode may be too loose to work the hand effectively. Our design should enable parents to optimise the contact that the electrodes have on the remaining muscles within the residual limb, even when the socket itself is a little looser, thereby providing better levels of prosthesis control for the child.

This project will be led by the University of Salford.

The Starworks Team will continue to support these projects on an individual basis as they develop. 
Appendix 8: Illustration of the Starworks Project

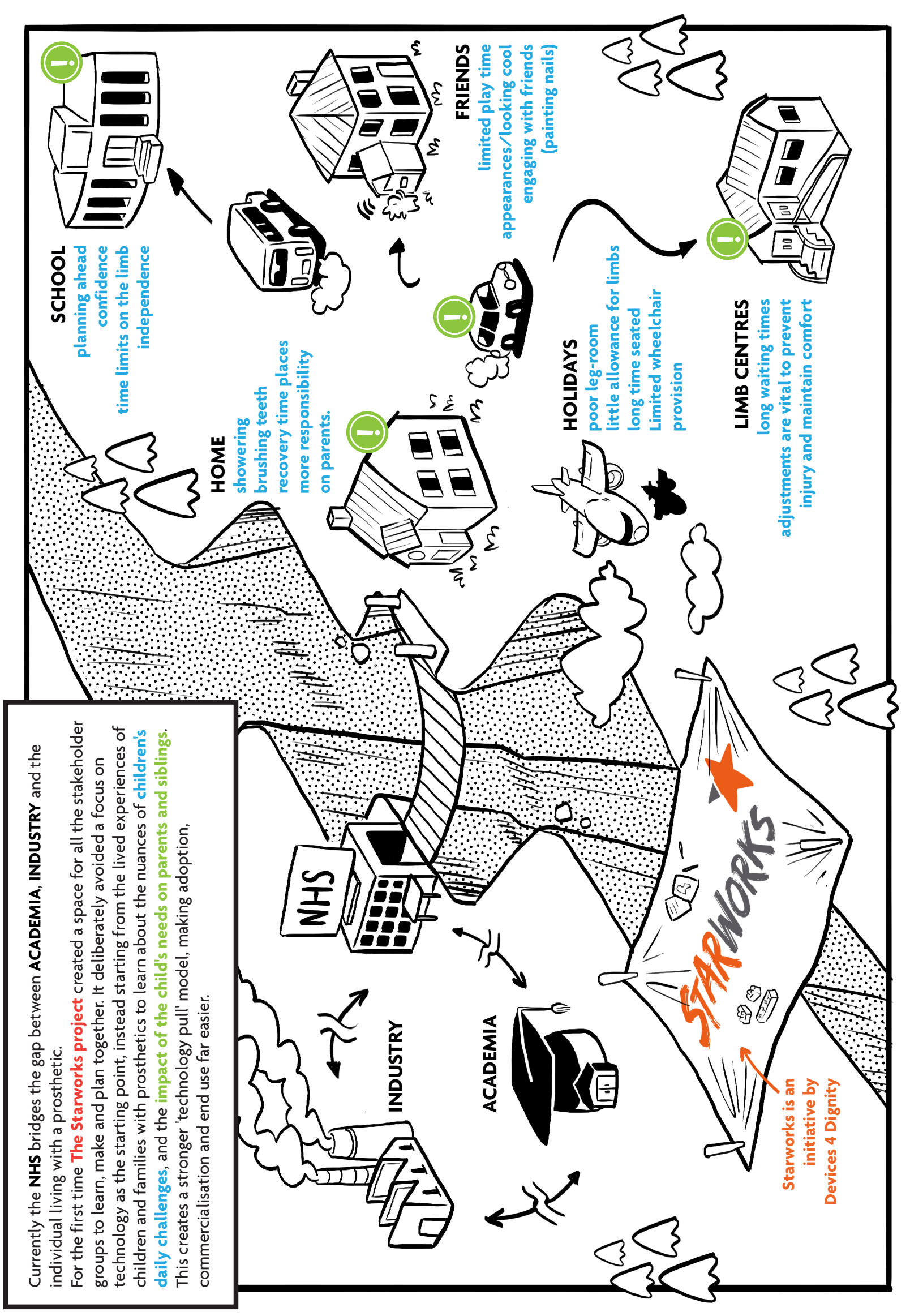

Appendix 9: Illustration of 'a day in the life' of a child who

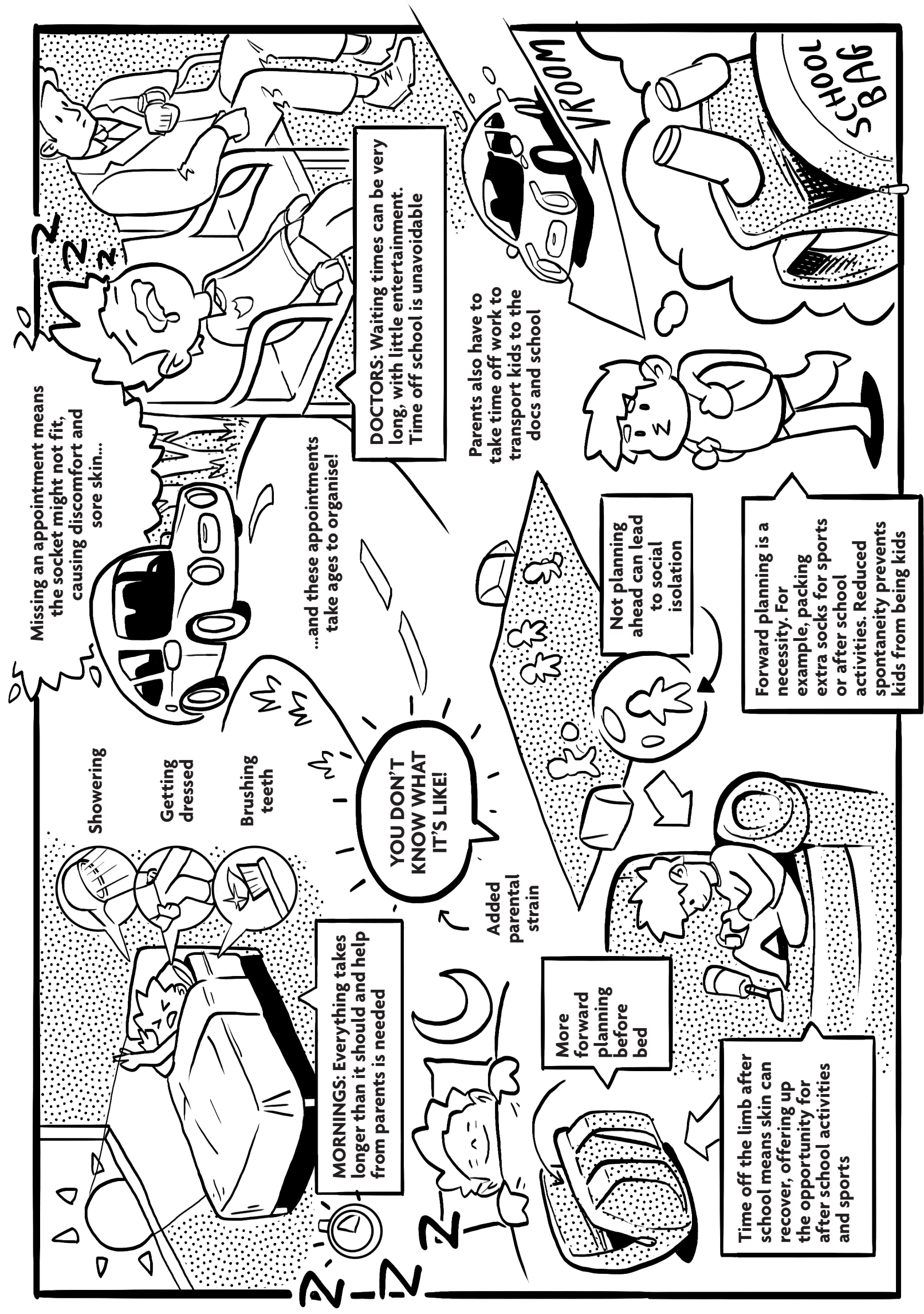





\section{Sheffield Hallam University}

The Starworks Project: Annual Report to National Institute for Health Research 2017-2018 WHEELER, Gemma, MILLS, Nathaniel and LANGLEY, Joe

Available from the Sheffield Hallam University Research Archive (SHURA) at: http://shura.shu.ac.uk/27851/

\section{Copyright and re-use policy}

Please visit http://shura.shu.ac.uk/27851/ and http://shura.shu.ac.uk/information.html for further details about copyright and re-use permissions. 